Evidence from Field Experiments and Panel Dafa Analysis 


\section{Incentives and Financial Institutions in the Development Process}

Evidence from Field Experiments and Panel Data Analysis.

John Sseruyange 


\section{Thesis committee}

\section{Promotor}

Prof. Dr E.H. Bulte

Professor of Development Economics

Wageningen University \& Research

\section{Co-promotor}

\section{Dr J.G Klomp}

Associate professor, Development Economics Group

Wageningen University \& Research

\section{Other members}

Prof. Hilde A.J. Bras, Wageningen University \& Research

Dr. Menale Kassie, International Centre of Insect Physiology and Ecology, Nairobi, Kenya Prof. Daan P. van Soest, Tilburg University, the Netherlands

Prof. Niels L.M. Hermes, University of Groningen, the Netherlands

This research was conducted under the auspices of the Wageningen School of Social Sciences (WASS) 


\title{
Incentives and Financial Institutions in the Development Process \\ Evidence from Field Experiments and Panel Data Analysis.
}

John Sseruyange

\author{
Thesis \\ submitted in fulfilment of the requirements for the degree of doctor \\ at Wageningen University \\ by the authority of the Rector Magnificus, \\ Prof. Dr A.P.J. Mol, \\ in the presence of the \\ Thesis Committee appointed by the Academic Board \\ to be defended in public \\ on Wednesday 16 May, 2018 \\ at 11a.m. in the Aula.
}


John Sseruyange

Incentives and Financial Institutions in the Development Process:

Evidence from Field Experiments and Panel Data Analysis

205 pages.

PhD thesis, Wageningen University, Wageningen, the Netherlands (2018)

With references, with summaries in Dutch and English

ISBN: 978-94-6343-864-3

DOI: https://doi.org/10.18174/446914 


\section{To My Children}

Always endeavour to do beyond my

limits and always remember

that failure is not an

option. 



\section{Contents}

Chapter 1 Introduction 1

Chapter 2 Do Incentives Matter for the Diffusion of Financial Knowledge? 23

$\begin{array}{lll}\text { Chapter } 3 & \text { Wage Differentials and Workers' Effort } & 57\end{array}$

Chapter 4 Mitigating Natural Disaster Effects on Economic Growth: The Role of

Microfinance Institutions $\quad 85$

Chapter 5 Earthquakes and economic outcomes: Does central bank independence matter? 129

$\begin{array}{lll}\text { Chapter } 6 & \text { Synthesis } & 165\end{array}$

$\begin{array}{ll}\text { References } & 176\end{array}$

$\begin{array}{ll}\text { Summary } & 201\end{array}$

$\begin{array}{ll}\text { Acknowledgements } & 204\end{array}$ 

Incentives and Financial Institutions in the Development Process

\section{Chapter 1}

Introduction

\subsection{Background}

\subsubsection{Economic development experiences}

Even though many scholars, policy makers and development practitioners across the globe have come up with various policies and programs to narrow the income gap between countries, their effort still seem not to yield the intended outcomes. Developing countries are still troubled by high rates of poverty, low access to safe water and sanitation, poor health services, malnutrition and child abuse, underdeveloped transport systems and environmental abuse. A lot of effort has been invested in explaining such differences among countries. Starting with the classical growth theory, the differences in the real GDP among countries is attributed to population and resource endowments. According to this theory, if real per capita GDP rose beyond a certain level, it would trigger population expansion causing a downward pressure to real GDP. The classical theory has been criticised on the grounds of ignoring the possibility of technical progress, capital accumulation and institutional setups which can influence the development paths for various countries.

Neoclassical growth models attribute the income gap between countries to variations in production factors (labour, capital and technology). The neoclassical economists maintain that accumulation of capital accompanied by its proper use provides the basis for economic growth. In this growth model, technology is used to enhance labour productivity since it boosts the output capacities of labour. The major weakness of the neoclassical growth theory lies in assuming that the production factors are exogenous giving way to endogenous growth models which observe investment in 
Introduction

human capital, innovation and knowledge to be the contributors of economic growth. Moreover, a large body of literature also attributes the income gap between countries to differences in the design and/or functioning of institutions (Keating, et al., 2003; Knack and Keefer, 1995; Lin and Nugent, 1995; Rodrik, et al., 2004; Wolf, 1955), wars and civil conflicts (Collier, 1999a, 1999b; Fearon, 2008; Montalvo and Reynal-Querol, 2005), draining of productive labour force from some of the current developing countries through slavery (Anderson and Gallman, 1977; Graham, 1981; Nunn, 2008; Parker, 1970), discrimination among workers (Cain, 1986; Drury, 1993; Lundberg and Startz, 1983, Carlsson and Rooth, 2007), the prevailing knowledge and technological differences among countries (Kumar, 2003; Lapan and Bardhan, 1973; Laursen, 2000; Malecki, 1997) and the frequency and severity of natural disasters (Guimaraes, et al., 1993; Kahn, 2005; Smith and McCarty, 1996; Strömberg, 2007a).

Although, endogenous growth models emphasise investments in human capital, innovation and knowledge, it is equally important to note that countries across the globe have a mis-match in terms of their knowledge stock with developing countries lagging behind developed countries. For that reason, developing countries can catch up with developed countries if they can adopt knowledge and skills invented from elsewhere - diffusion. Diffusion of knowledge affects economic outcomes $^{1}$. But, existing literature provides a mix of conclusions. For instance, while studying the diffusion of agricultural innovations in rural Malawi, BenYishay and Mobarak (2016) found diffusion of knowledge to spread easily from communicators to other co-villagers if the communicators are comparable to the recipients. They also found out that, knowledge spreads easily if the communicators are incentivized. Similarly, Berge et al (2014) found the training content to have spread within borrowing groups in Tanzania. On contrary, Sayinzoga et al. (2016)

\footnotetext{
${ }^{1}$ See: for example, BenYishay and Mobarak (2016), Sayinzoga et al. (2016) and Berge et al (2014)
} 
Incentives and Financial Institutions in the Development Process

found no evidence of financial knowledge spillovers beyond the trained village bank representatives in rural Rwanda. Basing on such conflicting conclusions from the existing literature, a more understanding of the mechanisms that underlie knowledge transfer within defined social networks is still required.

Moreover, literature relating workers' discrimination and social comparisons to workers' effort exists (Bellemare and Shearer, 2009; Bracha et al. 2015; Breza et al. 2015; Cain, 1986; Clark et al. 2010; Drury, 1993; Fehr et al. 1993; Gachter and Thöni 2010; Hellerstein, et al., 1999; Karnes 2009; Lundberg and Startz, 1983, Carlsson and Rooth, 2007). For instance, Fehr et al. (1993) analyzed the fair wage-effort hypothesis, postulating that fairness considerations affect the supply of effort by workers if effort is not perfectly contractible. Clark et al. (2010) reveal that workers with high earnings supply more effort and incur a greater effort cost to reduce the gap between their net earnings and those of others. Through the use of a field experiment in an Indian manufacturing firm, Breza et al. (2015) discovered that while absolute wages for groups of workers can be similar, reference values are likely to be manipulated by exogenous variation in wages of the relevant co-workers and by variation in the observability of productivity across tasks. In support of that, Cohn et al. (2014) studied effort supply by pairs of workers in response to wage cuts and revealed that cutting both wages decreases performance (the fair wage-effort hypothesis), but unilaterally cutting of only one wage decreases performance of the affected worker and leaves effort of the other worker unaffected. In spite of the already invested effort in understanding the impact of wage differences on workers' effort, evidence is only available for the paid (contract) work but no evidence exists to explain the response of workers towards voluntary tasks which may be outside their contract specifications. 


\section{Introduction}

More still, studies document a relationship between financial institutions and disaster effect mitigation (Heltberg, et al., 2009; Kunreuther, 1996; McDermott, et al., 2014; Skoufias, 2003). But, more specifically, a recent study by McDermott et al., (2014) concludes that even if disasters cause some destructions, access to credit increases investments in the aftermath whereby compensating for any losses to capital stock and restoring the economy back to its pre-disaster long-term growth plans. Thus, McDermott et al., (2014) provides an understanding on how financial sector development can help to boost economic growth after a disaster but it provides no evidence on how this financial sector development impacts on specific sectors in the aftermath. Additionally, the same study uses private credit to indicate for financial sector development and ignores the role of informal financial services in mitigating the consequences of natural disasters to economic growth.

Lastly, it has been widely documented in the previous literature that catastrophes affect the economic performance of many countries (Skidmore and Toya, 2002; Raddatz, 2009; Noy 2009; Loayza et al., 2012; Lis and Nickel, 2010; Noy and Nualsri, 2011; Gassebner et al., 2010; Oh and Reuveny, 2010). Therefore, it is expected that they can also influence the monetary policy of the affected countries followed by their respective central banks. Although, central banks target low inflation (Cukierman 2008, Meade and Crowe 2007) and may fail to influence the real economic output (Alesina and Summers 1993), evidence pertaining how the degree of central bank independence can impact on economic outcomes in presence of disasters is largely lacking.

The contribution that this thesis makes to existing literature is mainly three-fold. In the first place, this thesis contributes to the literature that explains the mechanism through which incentives affect knowledge diffusion. I use a randomized control trail setting to test whether providing a 
Incentives and Financial Institutions in the Development Process

performance based monetary incentive can influence knowledge sharing within self-selected groups. Second, this thesis also contributes to the economic literature surrounding wage discrimination. I use a lab-in-the-field experiment to test whether wage differences impact on workers' effort commitment on both paid (contract) and voluntary work. Lastly, it contributes to the existing body of literature explaining the behaviours of financial institutions when natural disasters have occurred. For this concern, I use secondary panel data to examine whether microfinance institutions are able to mitigate the effects of natural disasters to economic growth and also to test whether independent central banks can influence the economic performance of countries in the period after a disaster - earthquake.

The remainder of this chapter provides an overview of the relationships between the concepts that make up the individual chapters of this thesis. It later describes the objectives of this research and the questions it tries to answer. Finally, it also provides an overview of the methodologies used and presents an outline of this thesis.

\section{The Knowledge diffusion process}

Growth theories like the traditional classical and neoclassical theories together with the modern endogenous theories recognise labour as one of the fundamental factors that affect economic growth. However, classical economists first observed labour in quantitative terms. The latter theorists put much emphasis on its quality purposely to increase its capacity in the use of capital and technology. Labour exists everywhere across the globe but its quality is scarce in some countries especially in developing countries. Thus, such countries need to catch-up with developed countries through knowledge sharing. 


\section{Introduction}

Knowledge diffusion is the process of sharing or transferring scientific knowledge from one party to another though the transfer process takes different channels. For instance, knowledge can flow horizontally (transferred between parties of equal social power or degree of centrality) or vertically (transferred between parties with different social power or degrees of centrality). Ernst and Kim, (2002) and Van Gils, et al., (2009) observe that knowledge transfer can distinctively flow through two broad mechanisms — formal and informal mechanisms. These two mechanisms are dissimilar basing on contract arrangements involved in the transfer programs. Formal knowledge transfer involves signing of contracts between the collaborating parties and it's governed by secrecy and intellectual property rights which is not the case for the informal type. With the formal knowledge transfer channel, the collaborating firms are allowed to freely share specific knowledge which increases the use of it.

Lucas and Ogilvie, (2006) argue that the success of a knowledge transfer process highly depends on employees' perception of one another (reputations), how they manage their relationships (culture) and the inducement offered to motivate the process (incentives). Precisely, they point out that incentives play two crucial functions in the knowledge transfer process. (1) They act as a reward for successful knowledge transfer or realisation of specific performance improvements as a consequence of knowledge transfer (outcome-based function) and (2) they motivate parties to engage in the knowledge transfer process (behavioural-based function). Lucas and Ogilvie further maintain that it does not matter whether the objective of incentive provision is outcome-based or behavioural-based, knowledge sharing can improve the workers' performance.

Knowledge transfer is affected by a number of barriers. These include the monetary costs involved in its sharing, time and effort invested by both the knowledge suppliers and receivers and the possibility that the transferred knowledge may not fit in another country or region. The implication 
Incentives and Financial Institutions in the Development Process

for such barriers is that the process of knowledge transfer is hardly smooth. Some of the transferrelated problems can be diagnosed easily and resolved routinely by those directly involved in the transfer while other problems may transcend the resourcefulness of the organisational actors who are normally affected by such transfer-related problems (Szulanski, 2000). Szulanski points out that such complex problems in the transfer of knowledge require additional deliberation, recourse to nonstandard skills, allocation of supplemental resources and escalation of transfer-related decisions to higher hierarchical levels for resolution. Szulanski's argument is supported by BenYishay and Mobarak, (2014). While examining the power of social influence in studying the policies that promote the adaptation of new agricultural technologies in Malawi, BenYishay and Mobarak find that even within social networks, communicators (initially-trained peers) require costly effort to communicate and convince their fellow peers to adopt new agricultural technologies.

Viewed from that angle, knowledge cannot flow freely between individuals even if those individuals are connected via social networks. In other words, it may not spread beyond the initially (first) trained since it requires an investment decision by those possessing the knowledge (suppliers) and those seeking to access it (receivers). One important question that comes into quotation is whether providing of monetary incentives can foster knowledge diffusion beyond the initially trained.

The subject of incentives in the process of knowledge and technological transfers has received substantial attention (Belenzon and Schankerman, 2009; Ernst and Kim, 2002; Friedman and Silberman, 2003; Kaindl et al., 2002; Lucas and Ogilvie, 2006; Modi and Mabert, 2007; Saggi, 2002). However, existing literature provides a mix of conclusions. BenYishay and Mobarak, (2014) find the act of providing incentives to communicators to promote the adaptation of new 
Introduction

agricultural technology and transmission of knowledge from one farmer to another. Likewise, Friedman and Silberman, (2003) use a two-stage regression analysis to examine the determinants of technology transfer and find incentives to be a strong enhancing factor in the transfer process. Marinova, (2004) uses longitudinal quasi experiments based on simulation to test the dynamic process that governs the impact of market knowledge diffusion on innovation effort and its subsequent effect on the firm performance. Marinova revealed that total shared market knowledge helps small firms to actualise better returns from their innovation efforts than the big firms. Additionally, Anderson and Feder, (2004) maintains that if effective agricultural extension requires adequate and timely access by farmers, then, there is need for relevant advice and appropriate incentives for adopting the new technology even when it suits their socioeconomic and agro ecological conditions. In this study, incentives (monetary) are seen as a necessary ingredient for the purchase and distribution of inputs. Lucas and Ogilvie, (2006) find culture and reputation to have a significant impact to knowledge transfer but fail to find evidence that supports incentives to be drivers of the knowledge transfer process. It is upon this background that chapter 2 analyses the impact of providing a performance based incentive to the process of knowledge diffusion within the framework of social networks.

\subsection{Wages and workers' productivity}

A good employer-employee relationship is a fundamental attribute for a pleasant work environment (Karnes, 2009) and most literature in this line points to a common belief that each party has to play its defined responsibilities and must also achieve its expectations if a mutual agreement is to prevail. For instance, Copeland, (1993) documents that if employees are treated respectfully, adequately compensated and provided with safe working conditions, they compensate the employer with more output. In line of that, Karnes, (2009) maintains that employers who are 
Incentives and Financial Institutions in the Development Process

willing to provide their employees with what they want are more likely to register success in their organizations.

A wealthy body of empirical literature relates wage to workers' productivity and the general industrial operations (Baum and Ford, 2004; Holmlund and Zetterberg, 1991; Pfeffer and Ross, 1990). They are used to compensate workers for the corresponding opportunity cost of work. However, the amount of wages paid to workers varies greatly within a firm and between firms. Some of the early works among nonunionised workers attributed wage variations to industrial differences which arise from the systematic differences in the workers' ability that is correlated with the industrial status (Dickens and Katz, 1986). Altonji and Blank, (1999); Blinder, (1973), Cotton, (1988), Oaxaca and Ransom, (1994) attribute it to race, sex and differences in production characteristics like education levels, skills and experience. A recent study by Freeman and Katz, (2007) seem to support earlier studies as it points to educational and gender differences to account for these wage variations.

At the industrial level, wage differences can broadly be categorised into two i.e. (1) inter-industry differences (wage differences occur between workers performing the same occupation but in different industries) and (2) intra-industry differences (wage differences occur between workers performing the same occupation but within the same industry). According to Dickens and Katz, (1986), inter-industry wage differences can be explained by differences in the ability to pay for a particular industry and the transitory differences related to shifts in labour demand and supply while intra-industry wage differences can be attributed to differences in workers' ability, the industry's stage of development and its desire to keep its human capital. Although, workers are generally affected by wage differences, the extent of discrimination seem profound under intraindustry differences compared to inter-industry differences. The possible explanations for this is 
Introduction

that within the same industry wage differences could be based on some unmeasurable qualities of individual workers such that the under paid may feel discriminated by the employer.

Putting that aside, wage differences also occur within firms (intra-firm wage dispersion) and have a weighty effect on the performance of firms (see: Battisti and Stoneman, 2005; Ding, et al., 2009; Jirjahn and Kraft, 2007; Lallemand, et al., 2004; Stole and Zwiebel, 1996; Winter-Ebmer and Zweimüller, 1999). For example, while studying the relationship between intra-firm wage dispersion and firm performance among Belgian firms, Lallemand, et al., (2004) find a positive and significant relationship between intra-firm wage dispersion and the performance of those firms. This study also revealed that such a relationship is even stronger for blue-collar workers and within firms that implement a high degree of monitoring. In support of that, Ding, et al., (2009) used a sample of 395 Chinese companies and examined the impact of inter and intra hierarchy wage dispersion to the performance of companies. The study reveals that inter-hierachy wage dispersion between managers and workers cause better company performance but intra-hierarchy wage dispersion within managers and workers weakly improve performance. In line of that, Battisti and Stoneman, (2005) point out that if firms pay different wages to their workers, the level of intra-firm diffusion of new technology is likely to be affected.

Firms/employers have defined objectives to fulfil and as a result they might be willing to offer higher wages compared to other firms as explained by the efficiency wage theories. These efficiency wage theories suggest that firms may be forced to offer higher wages above the market clearing wages so that these wages differ from other industries' wage structures within and across industries purposely to improve the workers' morale for increasing their effort and consequently increase output. The efficiency wage theories emphasise that wage differences for similar workers may reflect industrial characteristics that do not directly affect the utility of workers and may not 
Incentives and Financial Institutions in the Development Process

require compensation to the low paid workers as specified in Dickens and Katz, (1986). Put differently, activities in the industry might be affected especially if low paid workers get information about these wage gaps and happen to treat it as discrimination. Consequently, the under-paid workers may supply less effort and their marginal productivity may reduce even under a contract (work for pay) regime.

Many empirical studies suggest that wage differences affect workers' productivity and the general industrial operations (Baum and Ford, 2004; Bellemare and Shearer, 2009; Holmlund and Zetterberg, 1991; Pfeffer and Ross, 1990) but, Even if, the relationship between wage differences and workers' productivity has received considerable attention, more effort has been paid to understanding the response of workers to wage differences in relation to paid (contract) work but evidence pertaining the workers' response toward such wage differences in relation to voluntary work is largely lacking. Thus, chapter 3 of this thesis studies the response of workers to both paid and voluntary work under conditions of wage differences.

\subsection{Disasters, financial institutions and disaster mitigation}

The increasing frequency and severity of natural disasters across the globe have caused numerous deaths, injuries and lots of economic damages not only in developing countries but also in developed countries. Over the last four decades, more than 10,000 natural disasters have occurred worldwide, affecting more than 7 billion people, and causing an estimated damage that exceeds $\$ 2$ trillion (EM-DAT, 2012). Earthquakes, tsunamis, hurricanes, storms and floods cause immense economic impacts but they are sometimes difficult to quantify since they involve vulnerability of specific individuals and wider communities as well as costs of interrupted livelihood and economic activities. 


\section{Introduction}

It is widely documented that natural disasters affect economic development through various channels (Loayza, et al., 2012; Raddatz, 2009; Rasmussen, 2004; Skidmore and Toya, 2002). For instance, disasters may adversely affect real GDP per capita (Laframboise and Loko, 2012; Raddatz, 2009), trade balance (Strömberg, 2007a), and can trigger civil conflicts especially in developing countries (Nel and Righarts, 2008). The impact of natural disasters may differ across sectors and among countries (Loayza et al., 2012). Precisely, natural disasters have great implications for developing countries. Africa, Asia and Oceania have experienced a large number of disasters in the recent past, with over $80 \%$ of the affected population living in those areas (EMDAT, 2012). This consequence is mainly attributed to over reliance on agriculture and people living in high-risk areas with weak infrastructure (Raddatz, 2009). More worrying is that this situation is likely to worsen in coming decades since natural disasters are often attributed to climate change that directly impacts on agriculture (IPCC, 2007).

To make countries more resilient to adverse disaster effects, appropriate policies must be provided. Among others, the existing literature identifies the degree of financial development within a country. From voluminous literature, a country's level of financial development matters for its economic development (Al-Yousif, 2002; Arestis and Demetriades, 1997; Christopoulos and Tsionas, 2004; De Gregorio and Guidotti, 1995) as well as disaster mitigation (Kahn, 2005; McDermott et al., 2014). Kahn, (2005) concludes that richer governments can provide implicit disaster insurance through effective regulation, planning and providing of quality infrastructure which reduces fatalities caused by natural disasters. He further points out that rich people can also self-protect through demanding for homes in safer places or homes built with strong materials whereby reducing their disaster risk exposure. In support, McDermott et al., (2014) find the medium-term dynamics of growth in the aftermath of a disaster to greatly depend on the level of 
Incentives and Financial Institutions in the Development Process

the country's financial sector development. Specifically, this study concludes that even if disasters cause some destructions, access to credit increases investments in the aftermath whereby compensating for any losses to capital stock and restoring the economy back to its pre-disaster long-term growth paths.

From a general perceptive, countries with developed financial markets tend to have a variety of financial options like formal credit, insurance markets, remittances and microfinance credit, which serve a crucial role in disaster mitigation and economic development, These financial institutions avail compensation and credit schemes which can help people to guard against or address disaster effects like reduced production and income volatility that directly affect welfare.

By and large, financial institutions matter in disaster mitigation as well as aiding economic development. But, more needs to be understood especially concerning the extent to which various financial services - informal financial services can aid disaster mitigation. While studying the role of financial sector development in mitigating disaster effects, McDermott et al., (2014) use private credit to indicate for financial sector development. However, private credit is a formal financial service, yet, it is documented (Alcántara-Ayala, 2002, Noy, 2009; Toya and Skidmore, 2007) that natural disasters have greater implications for developing countries where the financial sector is not well developed. According to Chaia et al., (2013) over $60 \%$ of the adult population in developing countries does not use formal financial services. This low level of formal financial service accessibility in developing countries puts microfinance institutions in a limelight of providing financial services to the majority of the people in such countries. However, evidence relating to the role of these microfinance institutions in mitigating the consequences of natural disasters to economic growth is still lacking. In this context, chapter 4 of this thesis studies the 


\section{Introduction}

relevance of microfinance institutions in mitigating the adverse macroeconomic consequences of natural disasters.

Additionally, a vast literature demonstrates the relationship between central bank independence and economic outcomes (Alesina and Summers, 1993; Cukierman, et al., 1993; De Haan and Kooi, 2000; Eijffinger, et al., 1998; Loungani and Sheets, 1997; Pollard, 1993). Most of these studies carry a general consensus that independent central banks are able to maintain low inflation rates through contractionary monetary policies especially when the productive sectors of their economies are constrained. However, when natural disasters occur, the central banks can be forced to alter their specified monetary policies so as to stimulate economic recovery. Precisely, a real shock causes production shortages in the short run leading to a temporary negative deviation from the long run growth path (Loayza et al., 2012; Klomp, 2016; Fomby et al., 2013). This can cause the central banks to exercise expansionary monetary policies with an interest of stimulating the economy. However, such expansionary policies at a time when domestic output is temporarily reduced by disasters may result into inflation. On the other hand, if they decide to control inflation increments through contractionary monetary policies, output may even be reduced further. This dilemma demonstrates that central banks are not able to stimulate the economy and stabilize prices at the same time after a disaster shock. Although, empirical studies on natural disasters confirm a production shortfall especially in the short run, the fundamental question that has remained unanswered is: Does the degree of central bank independence matter in mitigating the impact of natural disasters on output and inflation rate? Chapter 5 tries to provide answers to this question. Specifically, this chapter explores empirically whether, and if so to what extent, the degree of central bank independence drives the economic outcomes after a natural disaster. 
Incentives and Financial Institutions in the Development Process

\subsection{Objectives and research questions}

The research in this thesis is based on field experiments and panel data analysis, aiming to establish causal relationships between incentives, financial institutions, disasters and economic outcomes. The overarching objectives of this thesis are: (1) to examine how monetary incentives affect economic outcomes, specifically knowledge sharing and workers' effort and (2) to examine whether financial institutions are able to smoothen economic outcomes in the aftermath of a disaster. Precisely, I analyse whether: (1) providing a performance-based monetary incentive affects knowledge diffusion within self-selected groups, (2) monetary incentives affect workers' effort to both paid and voluntary work under conditions of information absence and information availability and (3) financial institutions are able to address the consequences of natural disasters and smooth economic performance in the aftermath. The main research questions that also define each individual chapter of this thesis are the following:

(1) Do monetary incentives matter in the process of knowledge diffusion? (Chapter 2)

(2) Do differences in monetary incentives affect workers' effort? (Chapter 3)

(3) Are microfinance institutions able to mitigate the adverse macroeconomic consequences of disasters to economic growth? (Chapter 4)

(4) Does the degree of central bank independence matter in mitigating the effects of natural disasters on output and inflation rate? (Chapter 5)

Besides the main four questions listed above, I also answer some supplementary questions in each individual chapter. For instance, I answer other questions like:

(i) Is providing of monetary incentives a cost-effective approach for diffusing knowledge?

(Chapter 2) 


\section{Introduction}

(ii) Does providing of monetary incentives increase the learners' effort to master the training content? (Chapter 2)

(iii) Does social-comparison in terms of wage earnings affect workers' effort? (Chapter 3)

(iv) Does the nature of microfinance institutions matter in disaster mitigation? (Chapter 4)

(v) What monetary policy rules influence the response of the central banks to economic performance following a disaster? (Chapter 5)

\subsection{Methodology}

Some of the problems that affect researchers studying issues related to economic growth or economic development are endogeneity and reverse causality. In this thesis, these problems are addressed. Starting with the field experiments (chapters 2 and 3), I used randomization to determine the respondents. This randomization is combined with specific interventions that define each individual chapter. Randomizing allows for the use of the probability theory to express the likelihood of chance as a source for the difference of the final outcome. Precisely, it serves as a natural instrument because it creates variation among respondents which increases the credibility of causal inference. Thus, problems of endogeneity resulting from potential selection bias and reverse causation can be ironed out. In cases where the scare about endogeneity rose in studies that use panel data (chapters 4 and 5), internal instruments were used to address the problem.

As earlier stated, this thesis is based on two broad data types i.e. data from field experiments and surveys and on panel data. In efforts of collecting field data, I used a combination of field experiments and surveys and for panel data, I based on different data sources as described in each individual chapter. Field experiments are increasingly becoming an important tool of data 
Incentives and Financial Institutions in the Development Process

collection (see for example, Beekman, et al., 2014; Beekman, et al., 2015; Bellemare and Shearer, 2009; Cecchi, et al., 2016; Cecchi and Melesse, 2016) possibly because they can help researchers to deal with the problem of causality whereby allowing them to achieve credible casual inferences. Remarkably, experiments rely on randomization which serves as an instrument in itself by creating natural variations among participants. The field experiments presented in this thesis include a labin-the-field experiment and a natural experiment.

A lab-in-the-field experiment is employed in chapter 3 of this thesis. Lab-in-the-field experiments take decontextualized laboratory experiments to the field and randomly assign participants to different treatment arms. Although, these experiments may not represent the real-life situation because of being organised in a tightly controlled environment, in our study, we try to solve for this weakness by capturing extra information especially on the socio-demographics of the participants. Integrating of the socio-demographics into the analysis helps in tracing the behaviours of the participants even with the presence of an intervention. Using a lab-in-the-field experiment, I measure the response of workers to both paid and voluntary work to the difference in monetary incentives ${ }^{2}$ under conditions of information absence and information availability. With the same approach, I also measure the behaviour of workers resulting from work/job experiences.

In chapter 2, I use a natural field experiment. In such experiments, subjects are observed in their natural environment, but are not aware that they are taking part in the experiment. The most commonly used natural experiments are impact evaluations that are normally conducted through randomized control trials (RCTs). RCTs are experimental studies where the effect of an intervention is assessed by comparing data before and after the intervention. The random

\footnotetext{
2 The difference in monetary incentives is framed in terms of differences in piece rate payments.
} 


\section{Introduction}

assignment of the participants into the treatment arm and the control arm means that all factors other than the intervention have been considered equal which increases the credibility of the casual inference. I used a RTC to measure the impact of providing a performance-based monetary incentive to knowledge diffusion within self-selected groups. RCTs are widely used in literature (see for example, Clark et al., 1996; Nissen et al., 2004; Steinhubl et al., 2002) to allow for an explicit examination of the impact of a given intervention.

In chapters 4 and 5, I constructed two panels using data obtained from different secondary sources ${ }^{3}$ to study the role of microfinance institutions in mitigating the adverse macroeconomic consequences of disasters to economic growth (chapter 4) and also to study whether countries with independent central banks are able to maintain low inflation and yet stimulate economic output following a natural disaster (Chapter 5). Specifically in chapter 4, I used a dynamic panel model in which I included over 80 countries for a period between 1995 and 2010. The sample of countries and the period of study were all determined by data availability. One of the important variables in this study is microfinance accessibility. However, microfinance institutions are common in developing countries which cause some middle-income and high-income countries to drop out. Secondly, because of the self-reporting mechanism allowed by Mix market ${ }^{4}$, some microfinance institutions do not report to it. This reduced the sample of countries.

In chapter 5, the issue of causal relationships arises especially between the two dependent variables (inflation and economic growth—output gap). Inflation can affect economic growth (see: Bruno and Easterly, 1998; Jones and Manuelli, 1995; Sarel, 1996). Likewise, inflation can be a result of economic growth (see: Canetti, 1991; Ha, et al., 2003; Khan, et al., 2007). To account for this

\footnotetext{
${ }^{3}$ For data sources, please, refer to individual chapters.

${ }^{4}$ For data on microfinance institutions refer to www.mixmarket.org
} 
Incentives and Financial Institutions in the Development Process

causal relationship and also with the likely endogeneity, a system of equations was estimated simultaneously using the Generalized Method of Moments (GMM) estimator. This system of equations was again re-estimated as seemingly unrelated equations and as structural equations at some point.

Lastly, most of the macroeconomic literature that uses data on microfinance especially from Mix markets, point to the problem of possible selection bias resulting from the self-report mechanism which increases the possibility that only large MFIs may report to it. This, combined with the possibility of reverse causations may cause a fear of endogeneity problems. Since it is generally accepted that finding strong and valid instruments is difficult, in chapters 4 and 5, I use a dynamic panel data estimator of Arellano and Bover (1995)/Blundell and Bond (1998) that uses internal instruments to address this type of problem. The overall validity of such instruments is checked by Hansen tests of over-identifying restrictions and autocorrelation of the differenced error terms is tested by Arellano-Bond test.

\subsection{Outline of the thesis}

The chapters in this thesis are structured as follows. Chapters 2 through 5 form the core part of the thesis. They provide empirical answers to the research questions outlined above. Each chapter presents an individual academic paper, with its own definite contributions to existing literature. In chapter 2, we use a combination of a field experiment and surveys to investigate the impact of providing a performance-based monetary incentive to knowledge diffusion within self-selected groups. The field experiment used a randomised control trail in which a financial literacy training was given to two arms but with one arm promised to be paid a monetary incentive based on the test scores of other group members who were not initially trained. Our findings suggest that 


\section{Introduction}

incentives increase knowledge sharing within self-selected groups, and also that providing of incentives to the initially trained subjects is a cost-effective approach for promoting knowledge diffusion. Moreover, we also find a performance-based incentive to affect knowledge accumulation by learners (initially trained) during the training.

Chapter 3 studies the response of workers to wage differences under conditions of information absence and information availability — social comparisons. I use a lab-in-the-field experiment enriched with a survey on demographic factors. The results reveal that effort choices are not very sensitive to own earnings. In other words, in absense of social comparisons, wage differences cannot be used to explain variations in effort. Moreover, while we only obtain weak support for the hypothesis that positive social comparisons invite extra effort during paid stages of the experiment, the effect of social comparisons is important during voluntary tasks.

In chapters 4 and 5, we combine panel data and dynamic panel models to study the impact of natural disasters to economic outcomes and also investigate how the intervention of financial institutions helps in addressing such effects. Specifically, chapter 4 explores whether microfinance institutions are able to mitigate the adverse macroeconomic consequences of disasters across the different economic sectors present in a country. Our findings suggest that natural disasters mainly have an adverse effect on the performance of the agricultural sector but access to lending facilities from MFIs mitigate these negative effects to some degree. We also find that the extent to which MFIs are able to mitigate these effects largely depends on their organisational structure, profitability, legal status, age and the number of their clients.

Chapter 5 investigates whether countries with independent central banks are able to maintain low inflation and also stimulate economic output following a natural disaster. We find central banks 
Incentives and Financial Institutions in the Development Process

that are less politically constrained put more weight on lowering the inflation pressure after an earthquake than on stimulating short run output. In other words, an increase in the inflation rate after an earthquake is significantly smaller when monetary policy is conducted by a more independent central bank, and that countries with an independent central bank are confronted with a wider output gap following an earthquake. Finally, chapter 6 provides a general discussion of the main findings of the thesis and also discusses the broader implications for policy issues and future research. 
Incentives and Financial Institutions in the Development Process 


\title{
Do Incentives Matter for the Diffusion of Financial Knowledge? Experimental Evidence from Uganda
}

\begin{abstract}
Many development interventions involve training of beneficiaries, based on the assumption that knowledge and skills will spread "automatically" among a wider target population. However, diffusion of knowledge or innovations can be slow and incomplete. We use a randomized field experiment in Uganda to assess the impact of providing incentives for knowledge diffusion, and pay trained individuals a fee if they share knowledge obtained during a financial literacy training. Our main results are that incentives increase knowledge sharing, and that it may be cost-effective to provide such incentives. We also document an absence of assortative matching in the social learning process.
\end{abstract}

Publication status: Sseruyange, J. \& Bulte, E. (2017). Do Incentives Matter for the Diffusion of Financial Knowledge? Experimental Evidence from Uganda. Revised and Resubmitted to the Journal of African Economies. 
Do Incentives Matter for the Diffusion of Financial Knowledge?

\subsection{Introduction}

Knowledge diffusion is a key topic in economics, and a major determinant of economic performance at the macro- as well as the micro level. This insight has motivated extension and training interventions aimed at promoting knowledge transfer. Development practitioners typically assume that diffusion of knowledge and skills will leverage the impact of such interventions knowledge is supposed to flow freely within social networks, eventually reaching a much larger group of agents than the sub-group initially reached by the training. ${ }^{5}$ While training interventions are often costly, they may pass economic cost-benefit tests if transferred knowledge and skills spread to a sufficiently large number of other households or firms in the target population, affecting their poverty status as well as that of the initially-trained sub-group.

It is well-known there are barriers to the diffusion of technology and knowledge. The existence of such barriers to the diffusion of technology across international borders is perhaps not surprising. Technologies may not fit conditions elsewhere, and often there are costs associated with adoption (such as in the case of improved seeds or fertilizer) which may be difficult to overcome if capital markets are imperfect. But even knowledge, which supposedly may spread at relatively low cost, sometimes does not travel easily - not even within organizations, local communities, or tightlyknit social groups. In developing countries, incomplete diffusion has been documented in a range of important domains, including agricultural innovations (Feder et al. 1985), health (Chami et al. 2016), and financial literacy (Sayinzoga et al. 2016). Even if individuals are connected via social networks, the spreading of knowledge beyond initial "seed nodes" typically requires time and effort on both the supply and demand side (see below). Hence, the spreading of knowledge can be

\footnotetext{
5 This is akin to assumptions underlying models of endogenous growth, premised on the idea that knowledge is a public good so that innovations readily spread within and across countries.
} 
Incentives and Financial institutions in the Development process

viewed as an economic process, involving an investment decision by those possessing the knowledge and those seeking to access it. Viewed in this light, it seems natural to ask whether the diffusion of knowledge can be promoted by economic incentives.

The objective of this paper is twofold. First, and most importantly, we test whether incentivizing seed nodes fosters the diffusion of knowledge within social networks. We follow BenYishay and Mobarak (2016), discussed below, who pioneered the use of an experimental approach in this context, but consider diffusion of financial knowledge rather than an agricultural innovation. ${ }^{6}$ Second, we probe the individual characteristics of seed nodes and their peers, and the alignment of these characteristics across them, to gain a better understanding of factors promoting diffusion. Our main results are that (i) incentivizing individuals has a large effect on the diffusion of knowledge, and (ii) that providing small monetary incentives is a cost-effective approach to foster the spread of information (compared to extending the extensive margin via additional trainings). We also find that (iii) social proximity does not foster social learning within the context we study. We study the effect of incentives on diffusion of financial literacy knowledge with a randomized controlled trial (RCT). Our implementing partner is a local nongovernmental organization active in peri-urban Uganda, whose development strategy involves the formation of so-called self-help groups of up to 30 members. These groups receive training and support in various forms (see below). We include 50 of these groups in an RCT with two treatment arms and one control arm. Randomization occurred at two levels: we randomly allocated groups to one of the two treatment arms or the control arm, and next invited a random sub-sample of members from treatment groups to participate in a six-day financial literacy training. Trained individuals were afterwards

\footnotetext{
${ }^{6}$ For non-experimental work pointing at the importance of incentives for diffusion, refer to Sorenson and Fleming, (2004), Lucas and Ogilvie, (2006), and Alavi and Leidner (2001).
} 
Do Incentives Matter for the Diffusion of Financial Knowledge?

encouraged to share newly acquired knowledge with their fellow group members. The difference between the two treatment arms was as follows: group members in one arm received the conventional training program, and group members in the other arm received the training as well as an incentive for diffusion. Specifically, these group members were promised a monetary reward in case sufficient knowledge diffused within their own self-help group. We revisited both treated groups and the control group after a period of 10 months, and measured the extent to which training content had actually spilled over to other members.

The focus on financial literacy is timely and important. Evidence suggests the impact of microfinance (interventions) varies with levels of human capital among recipients, so many microfinance institutions and NGOs have embraced financial literacy trainings as a tool to support development (the so-called "Finance-Plus" strategy). ${ }^{7}$ Financial literacy captures consumers' awareness, skills, and knowledge enabling them to make informed, effective decisions about financial resources. Studies across a range of countries have shown that levels of financial literacy tend to be low (Lusardi and Mitchel 2007, 2008). Focusing on developing countries, a small number of studies have probed how financial literacy affects economic behavior, including insurance adoption (Giné et al. 2013, Cohen and Young 2007), savings (Tustin 2010, Bruhn et al. 2013, Landerretche and Martínez 2013), bank account ownership (Cole et al. 2011), and business practices and outcomes (Sayinzoga et al. 2016).

There is very little evidence on the diffusion of financial knowledge beyond trained individuals, and the little bit of evidence that is available proves to be inconsistent. While Sayinzoga et al.

\footnotetext{
${ }^{7}$ Financial literacy trainings are often-times part of a broader training agenda, aiming to promote modern business practices and entrepreneurship (e.g. Berge et al. 2014, Bjorvatn and Tungodden 2010, Gine and Mansuri 2014, Karlan and Valdivia 2011). The literature on the impact of business and entrepreneurship trainings on business practices and outcomes has produced mixed results, and is summarized by McKenzie and Woodruff (2014).
} 
Incentives and Financial Institutions in the Development Process

(2016) find no evidence of financial knowledge spillovers beyond trained village bank representatives in rural Rwanda, Berge et al (2014) find that training content spread within borrowing groups in Tanzania. A key difference in context between these studies was that, in Tanzania, limited liability within groups implied, the seed node had a direct incentive to train his peers to reduce exposure to bad financial decisions of these peers. This insight suggests diffusion processes may be partly driven by economic considerations.

The paper is organized as follows. In the next section, we provide background to the topic of knowledge adoption and diffusion, summarizing part of the relevant literature. In section 3, we describe the details of our experiment and explain our sampling strategy. In section 4 we introduce our data and outline our simple identification strategy. In Section 5, we present our empirical results and attempt to unravel the factors that influence knowledge diffusion. Discussion and conclusions are presented in section 6 .

\subsection{Adoption and Diffusion}

A large literature studies the diffusion and adoption of technologies in developing countries. Much of this literature focuses on the spreading of agricultural innovations, such as improved seeds and fertilizers, or bundles of agricultural activities (e.g., Feder et al. 1985, Knowler and Bradshaw 2007). This focus seems appropriate in light of the importance of the agricultural sector in developing countries. However, other relevant domains have been studied as well, including health (e.g. bed nets, deworming pills), hygiene (water purifiers, menstrual cups), and fertility (contraceptives). A recent survey of the adoption literature is provided in Foster and Rosenzweig (2010). Yesuf and Köhlin, (2009) also observe that the up-take of technologies that are supposed 
Do Incentives Matter for the Diffusion of Financial Knowledge?

to improve farm production is affected by market imperfects including access to credit, risk consideration and the rates of time preferences.

Diffusion of innovations fits in the broader literature on peer effects. This literature distinguishes between three different types of effects; pure imitation, social learning, and (behavioral) complementarities or external effects. The learning literature is perhaps largest, in spite of wellknown challenges to proper identification based on observational data. Manski (1993) coined the term "reflection problem" to describe the difficulty of disentangling peer effects from contextual effects in social interaction models. Peers influence each other, and peer groups do not form randomly but are likely to be a result of homophilous peer selection. The presence of strategic considerations further complicates matters (e.g., Foster and Rosenzweig 1995, Bandiera and Rasul 2006, Breza 2015). Think of learning spillovers, inviting free-riding on peers' experimental efforts, or considerations in the context of competition for scarce resources, rival goods, or contested markets.

Notwithstanding these challenges, the social learning literature has advanced considerably. The evidence suggests Bayesian learning through social networks can be effective and rapid when innovations have large payoffs for large swaths of the population, are easily observed, and can be applied homogenously across space. In early stages of the green revolution, for example, the adoption of new technology spread very quickly across large parts of India. Similarly, there is evidence of rapid social learning and diffusion in the domain of advantageous health and sanitary innovations benefiting large groups of people more or less alike (e.g., Dupas 2014, Oster and Thornton 2012). 
Incentives and Financial Institutions in the Development Process

However, these conditions for Bayesian learning are not always met, and the evidence of widespread social learning is therefore "decidedly mixed" (Breza 2015). Diffusion of knowledge varies with the structure of social networks and the position of innovators within that network (e.g. Banerjee et al. 2013, Cai et al. 2015, Beaman et al. 2015). Moreover, interventions may have heterogeneous payoffs varying with individual attributes (e.g. Suri 2011), so information acquired by one farmer may be uninformative for his neighbor (Munshi 2004). In this context, individuals should carefully target whose behavior and outcomes to observe, paying special attention to people doing unexpectedly well or that are comparable to oneself (Conley and Udry 2010, BinYishay and Mobarak 2016). Finally, social learning will be incomplete and diffusion will be slow if individuals cannot easily observe the experiences of their peers. In this case, information does not automatically flow from one person to another. Instead, this will only occur if both parties invest sufficient time and effort into the knowledge-sharing process. In many cases, however, the innovator stands to gain little from spreading knowledge. Since actively engaging in the sharing of knowledge typically entails a cost, investing a lot of effort into this process is unlikely to be privately optimal. Can innovators or early adopters be incentivized to share information with their peers - internalizing learning externalities?

This important issue is first analyzed in the field by BenYishay and Mobarak (2016), who study the diffusion of agricultural innovations in rural Malawi: pit-planting and composting. They select different types of "communicators" (seed nodes) and expose them to the new technology. A random subsample of these communicators receives a performance-based incentive (a bag of seeds), where performance is based on co-villagers' knowledge about (and adoption of) the new technologies. The main lessons from the study are that co-villagers are more likely to learn from communicators comparable to themselves (see above); communicators invest more time and effort 
Do Incentives Matter for the Diffusion of Financial Knowledge?

in learning about the new technology when they are incentivized to share knowledge later; and, most importantly, providing incentives to communicators increases the flow of information and fosters knowledge levels and adoption by co-villagers. Transmission of information is not automatic, and can be manipulated via economic incentives.

The issue of incentivizing individuals to share knowledge speaks to a broader literature on intrinsic and extrinsic motives to engage in pro-social actions. The thrust of this literature is that the effect of incentives on prosocial behavior may be complex. Bénabou and Tirole (2006) develop a behavioral theory that combines altruism with concerns for social reputation and self-respect. Since material or image-related incentives create doubt about the underlying motives for which good deeds are done, they may partially or fully "crowd out" prosocial behavior. This is referred to as the "over-justification effect." If respondents receive a reward for engaging in information sharing - an act of prosocial behavior - co-villagers are unsure about the motives for sharing: was the respondent driven by altruism or desire for the reward? The former may give an impetus to somebody's status or reputation in the village, the latter presumably would not. ${ }^{8}$ Self-image concerns suggest that similar logic applies in the absence of reputational concerns (Bénabou and Tirole 2011). If respondents value conformity between actions and values or identity, then the selfimage value of engaging in prosocial deeds is undermined by incentives. See, for example, Fehr and Falk (2002) or Bowles and Polonia-Reyes (2012) for extensive discussions of these issues, and related ones.

On theoretical grounds, the effect of incentivizing individuals to engage in prosocial activities such as information sharing is therefore ambiguous. Ultimately it is an empirical and presumably

\footnotetext{
${ }^{8}$ In a lab experiment, Ariely et al. (2009) find that monetary incentives reduce the image value of pro-social behavior and the effort committed to such behavior by respondents.
} 
Incentives and Financial Institutions in the Development Process

context-specific matter whether extrinsic motives promote or discourage diffusion of knowledge. We now turn to our experiment.

\subsection{Experimental Description}

To test whether monetary incentives have a positive impact on knowledge diffusion, we organized an RCT in Uganda. We seek to explore the diffusion of information (social learning), and do not consider whether the training content was applied by our subjects in practice. ${ }^{9}$ The experiment was conducted in conjunction with CBS PEWOSA; a social responsibility section of Central Broadcasting Services (CBS) radio, affiliated with the Buganda kingdom. CBS-PEWOSA aims to encourage and facilitate the formation of homogeneous self-help groups of 15-30 members in communities in the Kingdom, and then to empower these groups with skills transfer programs, income-generating activities, food security projects, and savings programs. Groups evolve endogenously, and villagers may self-select into a group if they wish (provided they are accepted by other group members). Multiple groups may form in one village. CBS-PEWOSA has proven able to engage effectively with a large number of communities. Their modus operandi, via selfformed groups, creates a useful context for our study as it provides a natural reference group of peers to study the diffusion of knowledge.

Our RCT involved two survey waves. Baseline data were collected in October 2014, when we randomly selected 50 groups to enroll in the experiment (out of a sample frame of 153 communities groups partnering with CBS-PEWOSA). All groups in the sample are from different villages. We randomly assigned 20 groups to the incentive treatment (outlined below), and another 20 groups to the treatment arm with the conventional training. From each group we randomly selected several

\footnotetext{
${ }^{9}$ We also do not know how useful the shared information is for subjects in their daily lives.
} 
Do Incentives Matter for the Diffusion of Financial Knowledge?

members to participate in a financial literacy training. Following CBS-PEWOSA practice, we used a training ratio of $4: 1$ (rounding them to the nearest integer) so that we would train 6 members out of a group of 22 members. In total, we trained 266 respondents, of which 132 belonged to the incentive treatment arm. Respondents were informed about their treatment status before the training began, so we leave open the possibility that treated beneficiaries will work harder during the training to become more effective knowledge communicators after the training. To incentivize diffusion, we promised participants in the treatment arm they would receive a payment of UGS 35,000 (approximately USD 10) in case they managed to share some of the training content with their (untrained) CBS-PEWOSA group members. Specifically, a participant qualified for the payment in case a randomly selected group member (i) passed a financial literacy test, and (ii) identified that particular participant as her primary source of information (i.e., as the communicator). We did not inform training participants about the number of CBS-PEWOSA group members that would be tested, nor about the content of the test or the relevant knowledge threshold. ${ }^{10}$ Henceforth we will refer to group members who did not participate in the training themselves as "other group members" or untrained members.

The financial literacy training was conducted in January 2015 by CBS-PEWOSA field officers using the CBS-PEWOSA financial literacy manual. The training consisted of six sessions, lasting from 9:00 am to 3:00 pm (with a one-hour lunch break). The training covered basic topics such as keeping financial records, budgeting, savings, and loan management. An outline of the contents of

\footnotetext{
${ }^{10}$ Because the content of the test was unknown to the training participants they could not collude with their peers and "teach to the test" in order to qualify for the performance fee. We assume there is no difference in the incentives to exert effort in answering the test questions (or that untrained individuals did not exert extra effort because they made side deals with trained individuals on splitting any reward).
} 
Incentives and Financial Institutions in the Development Process

the training sessions is provided in Appendix 1. After the training, participants in both experimental arms took a financial literacy test to gauge knowledge levels (the test was based on Sayinzoga et al. (2016) and Lusardi and Mitchell (2007), and is included in Appendix 2). We constructed a knowledge index score by awarding 1 point to correct answers, $1 / 2$ point to partially correct answers, and 0 points to wrong answers. ${ }^{11}$ All participants were encouraged to share the learned knowledge with other members of their CBS-PEWOSA group, and were informed that we would revisit the CBS-PEWOSA group after 10 months to measure the extent to which knowledge-sharing had actually occurred.

Some 10 months after the training, in October 2015, we revisited the 40 CBS-PEWOSA groups, and organized a follow-up survey among a random subsample of untrained members. All groups still existed, so there was no attrition. We randomly selected 10 members per group, and in total, 394 untrained members participated in the second wave of the study for a cross-section analysis we did not contact these households at the baseline. Of these other group members, 200 were from groups with incentivized peers and 194 from groups with non-incentivized peers (as logistical reasons prevented us from engaging 6 members from two of the CBS-PEWOSA groups of the control arm).

During this survey wave we collected data on demographics as well as the level of financial literacy. To measure knowledge levels we used the same test as we used before to measure knowledge levels of the trained individuals. We also asked untrained group members to identify the person who shared training content with them. If the untrained member passed the test, the payment was provided to the trained peer identified as the individual engaged in knowledge

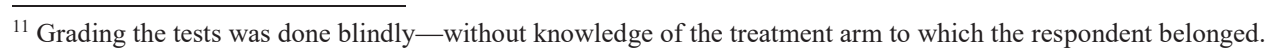


Do Incentives Matter for the Diffusion of Financial Knowledge?

diffusion. We did not receive complaints from trained group members at the payment stage, suggesting that untrained group members correctly identified the individuals engaged in sharing information with them. If certain trained group members were identified more than once we would still pay them the fee only once. We paid the performance fee to $47 \%$ of the incentivized group members.

Finally, at the endline we also collected financial knowledge data among members of other groups that did not participate in either of the treatment arms. Specifically, we visited the remaining 10 groups that did not participate in the training intervention, and surveyed 10 random members per self-help group to assess their financial knowledge. Data from this control group provides the benchmark knowledge level against which knowledge gains and the cost-effectiveness of the training and incentive interventions will be assessed.

\subsection{Data and Identification Strategy}

In Table la we summarize basic demographic information of trained group members, distinguishing between respondents from incentivized and non-incentivized training groups. There are no statistically significant differences between the groups ( $\mathrm{p}$-values from simple t-tests are reported). On average, respondents are less than 40 years old, and the majority of them are married, employed in the private sector, and have completed lower secondary school. ${ }^{12}$ Table $1 \mathrm{~b}$ does the same for the samples of untrained group members, and includes the group of respondents from the control arm. Again, there are no significant differences across the treatment arms. We include controls in some specifications to increase the precision of our regression estimates.

\footnotetext{
${ }^{12}$ In additional balancing tests, available on request, we demonstrate that respondents of the control group have the same characteristics as members of the treatment arms.
} 
Incentives and Financial Institutions in the Development Process

Table 1a: Summary of the data for the trained group members

\begin{tabular}{|c|c|c|c|c|c|c|}
\hline Variables & $\begin{array}{l}\text { Incentivized } \\
\text { group }\end{array}$ & $\mathrm{N}$ & $\begin{array}{l}\text { Non- } \\
\text { Incentivized } \\
\text { group }\end{array}$ & $\mathrm{N}$ & Differences & P-values \\
\hline Age & 37.515 & 132 & 37.649 & 134 & 0.134 & 0.763 \\
\hline Gender (male) & 0.205 & 132 & 0.209 & 134 & 0.004 & 0.930 \\
\hline Married/Engaged & 0.621 & 132 & 0.619 & 134 & -0.002 & 0.976 \\
\hline Education & 3.258 & 132 & 3.269 & 134 & 0.011 & 0.897 \\
\hline Tribe (Muganda) & 0.818 & 132 & 0.858 & 134 & 0.040 & 0.377 \\
\hline
\end{tabular}

Table 1b: Summary of data for the untrained group members

\begin{tabular}{lcccccc}
\hline & $\begin{array}{c}\text { Incentivized } \\
\text { group }\end{array}$ & Non-Incentivized & Control & P-values & P-values & P-values \\
& $\mathrm{N}=200$ & $\mathrm{~N}=194$ & $\mathrm{~N}=100$ & & & \\
Variables & 37.000 & 38.165 & 37.660 & 0.372 & 0.666 & 0.734 \\
\hline Age & 0.235 & 0.237 & 0.220 & 0.961 & 0.772 & 0.743 \\
Gender (male) & 0.615 & 0.686 & 0.710 & 0.143 & 0.105 & 0.668 \\
Married/Engaged & 3.295 & 3.046 & 3.200 & 0.126 & 0.624 & 0.437 \\
Education & 0.810 & 0.825 & 0.850 & 0.706 & 0.394 & 0.584 \\
Tribe (Muganda) & & & & & & \\
\hline
\end{tabular}

Turning to analysis, we first test whether the provision of incentives affects the effort that respondents invest in the training, and compare the financial literacy test scores of (trained) respondents across the two treatment groups. Specifically, we first regress the index score of 
Do Incentives Matter for the Diffusion of Financial Knowledge?

trained respondent $\mathrm{i}(\mathrm{i}=1, \ldots, 7)$ in group $\mathrm{j}(\mathrm{j}=1, \ldots, 40)$ on the incentive dummy $\mathrm{D}_{\mathrm{j}}$ and vectors of individual controls and group variables; $\mathbf{X}_{\mathrm{ij}}$ and $\mathbf{Z}_{\mathrm{j}}$ respectively:

$$
\text { Score }_{i j}=\alpha+\beta D_{j}+\delta \mathbf{X}_{i j}+\gamma \mathbf{Z}_{j}+\varepsilon_{i j}
$$

If respondents engage more intensively with the training content when they are incentivized to share knowledge, then we will find $\beta>0$. Following BenYishay and Mobarak (2016), we hypothesize that incentivized respondents work harder because they view the training as an investment opportunity. We use OLS to estimate model (1) and cluster standard errors at the group level. ${ }^{13}$ To account for the censored nature of our dependent variable we also estimate Tobit models, and to account for the ordinal nature of our dependent variable (index scores taking values $0, \ldots, 7)$ we also estimate ordered Probit models.

Next, we turn to our main research questions and use the endline data to test whether incentives affect knowledge diffusion. For this analysis we include the individuals from the control group. We regress the index score of untrained group member $\mathrm{k}(\mathrm{k}=1, \ldots, 10)$ in group $\mathrm{z}(\mathrm{z}=1, \ldots, 50)$ on the same variables as above:

$$
\text { Score }_{\mathrm{kz}}=\alpha+\beta_{1} \mathrm{D}_{1 \mathrm{z}}+\beta_{2} \mathrm{D}_{2 \mathrm{z}}+\delta \mathrm{X}_{\mathrm{kz}}+\gamma \mathrm{Z}_{\mathrm{z}}+\varepsilon_{\mathrm{kz}}
$$

where $\mathrm{D}_{1}$ is a dummy taking value one for members of any treatment group, and $\mathrm{D}_{2}$ is a dummy taking the value one for members of the incentive group (so $\mathrm{D}_{2}$ identifies a subgroup of $\mathrm{D}_{1}$ ). Members of the control group are the omitted category. Estimated coefficient $\beta_{1}$ captures the effect

\footnotetext{
${ }^{13}$ Note that the number of clusters is rather small (40). It is well-known that standard asymptotic tests can over-reject with few clusters, and Cameron et al. (2008) refer to "few" as five to thirty. While our number of clusters exceeds the minimum value implied by this interpretation, all of our results are robust (in a qualitative sense) to using the cluster bootstrap-t procedure. The remaining regression analysis are based on 50 clusters, which we assume to be sufficiently large for standard asymptotic tests to be valid.
} 
Incentives and Financial Institutions in the Development Process

of the conventional training intervention on untrained members, and coefficient $\beta_{2}$ captures the additional effect of incentivizing group members to share knowledge (so that the total sharing effect for the incentivized group amounts to $\beta_{1}+\beta_{2}$ ). As robustness tests we again estimate Tobit and ordered Probit models. Note that our experimental design allows us to pick up the total effect of performance fees on diffusion, which may take place via two channels: (i) additional effort of the trained group members during the training (as discussed above and captured in (1)), and (ii) additional effort of the trained group members after the training (time spent teaching their peers). ${ }^{14}$

Finally, we try to probe the knowledge diffusion process in a bit more depth. Group members are free to approach each other and invest time in either teaching the other, or learning from the other. What sort of "matching" occurs in the setting we study? We are especially interested in establishing whether social proximity fosters diffusion, and therefore ask whether assortative matching occurs in the experiment. We assess the extent to which peer-teaching occurs along certain demographic lines, and ask whether incentivizing trained respondents affects their propensity to teach peers with whom they share fewer characteristics. The characteristics we consider are age (young versus old), gender, education level, and tribal affiliation.

\subsection{Empirical Results}

\subsubsection{Incentives and accumulation of knowledge: effort during the training}

We first ask whether the promise of performance-based fees affects the effort of respondents during the training. This would be consistent with the finding of BenYishay and Mobarak, who documented that incentivized farmers are more likely to adopt the innovation themselves. To

\footnotetext{
${ }^{14}$ To identify the magnitude of these effects separately one could include an additional treatment arm where trained individuals receive an incentive to diffuse knowledge, but where this incentive is announced after the training has been completed (so that effort during the training session is unaffected by the incentive)
} 
Do Incentives Matter for the Diffusion of Financial Knowledge?

explore whether performance-based incentives affect effort during the training, we compare knowledge scores of trained respondents in the incentive treatment and conventional training arm. These data were collected shortly after finalizing the training so should only reflect the effect of the incentive on accumulation of knowledge. Regression results of model (1) are reported in Table 2. 


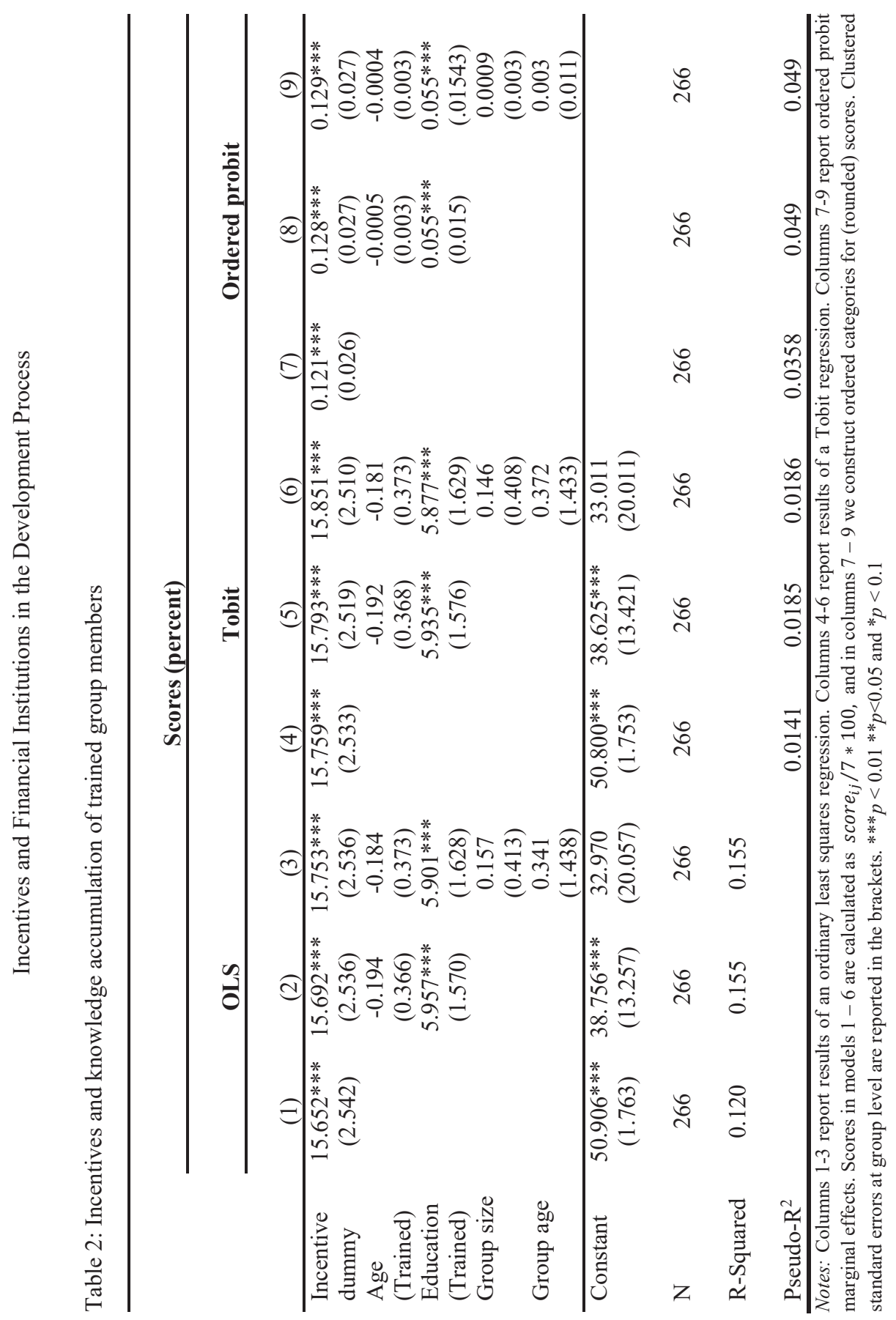


Do Incentives Matter for the Diffusion of Financial Knowledge?

In columns (1-3) we present the results of OLS models, in columns (4-6) we present results based on the Tobit estimator, and in columns (7-9) we use the ordered Probit estimator. Across all models we first consider a parsimonious specification, and then estimate models including vectors of controls (respondent and group variables, respectively).

Across all nine models we find positive coefficients associated with the incentive dummy, and in all models these coefficients are significantly different from zero at the $1 \%$ level. The estimated coefficient is stable across specifications, which is of course what we would expect (given that, by design, treatment status is uncorrelated with individual or group characteristics). These models reveal that the promise of a performance-based incentive increases the effort (attention) of training participants to grasp the training content. The impact of the fee on effort is also economically meaningful: OLS and Tobit estimates of the parsimonious models suggest that incentives increase post-training test scores by about $30 \%$. Not surprisingly, perhaps, we also find that better-educated respondents achieve higher knowledge scores.

\subsubsection{Incentives and diffusion of knowledge}

We next analyze how incentives affect the diffusion of knowledge by comparing financial knowledge levels of "other group members" across the experimental arms and the control arm. The reduced form models we estimate capture the joint impact of incentives on effort of trained respondents during the training (discussed above) as well as additional effort after the training sharing the content of the training with other group members. Before presenting our results in a regression framework we first demonstrate histograms displaying the number of other group members that achieve a certain test score, split out between untrained group members from incentivized and non-incentivized groups. 


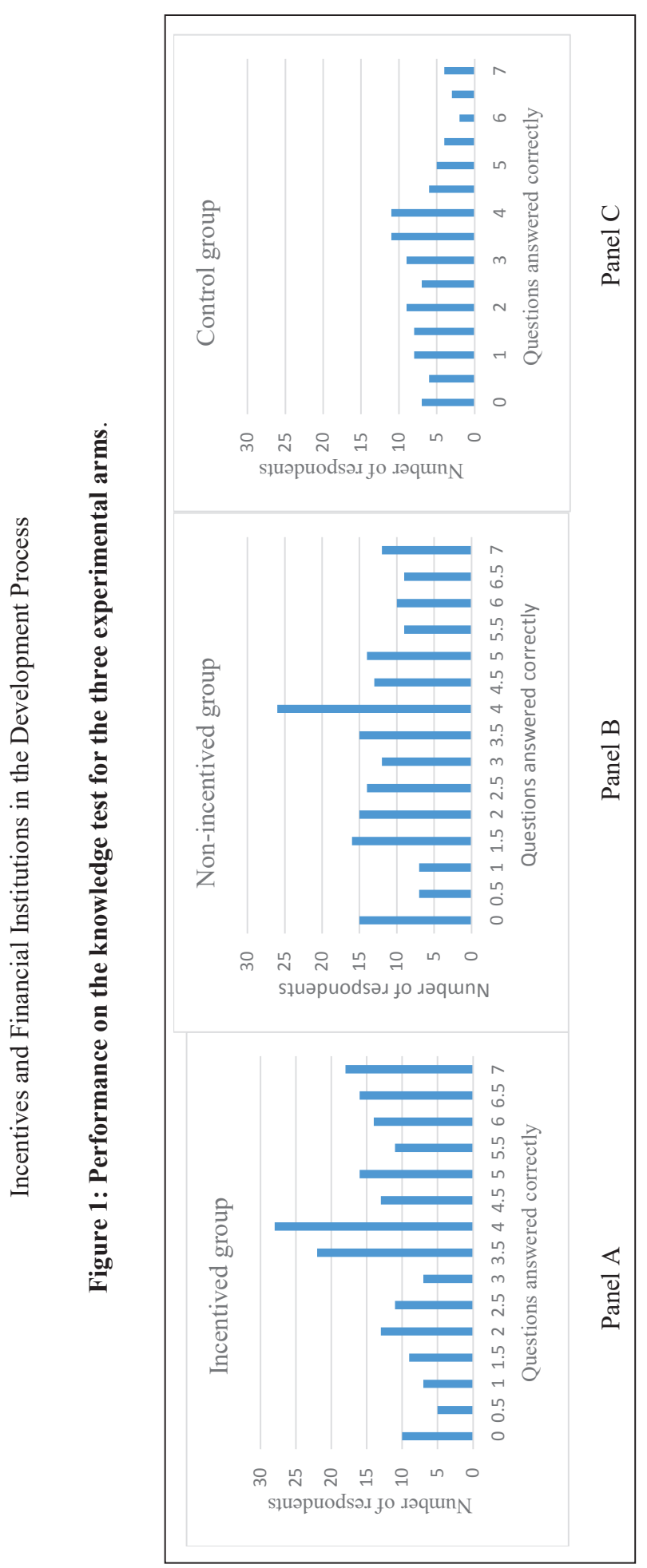


Do Incentives Matter for the Diffusion of Financial Knowledge?

The figure suggests that members of the control group performed worse than members of the treatment groups, and moreover that other members from groups with incentivized respondents (Panel A) tend to answer more questions correctly than group members from the conventional training arm. For example, the number of other group members scoring 6.5/7 (or 7/7) equals 16 (18) from the incentivized group, and only 9 (12) from the non-incentivized group. The number of other group members scoring $2 / 7$ or worse equals 39 for the incentivized group, and 60 for the non-incentivized group. These patterns in the data are also evident from the regression analysis. Estimating model (2) provides the following results: 


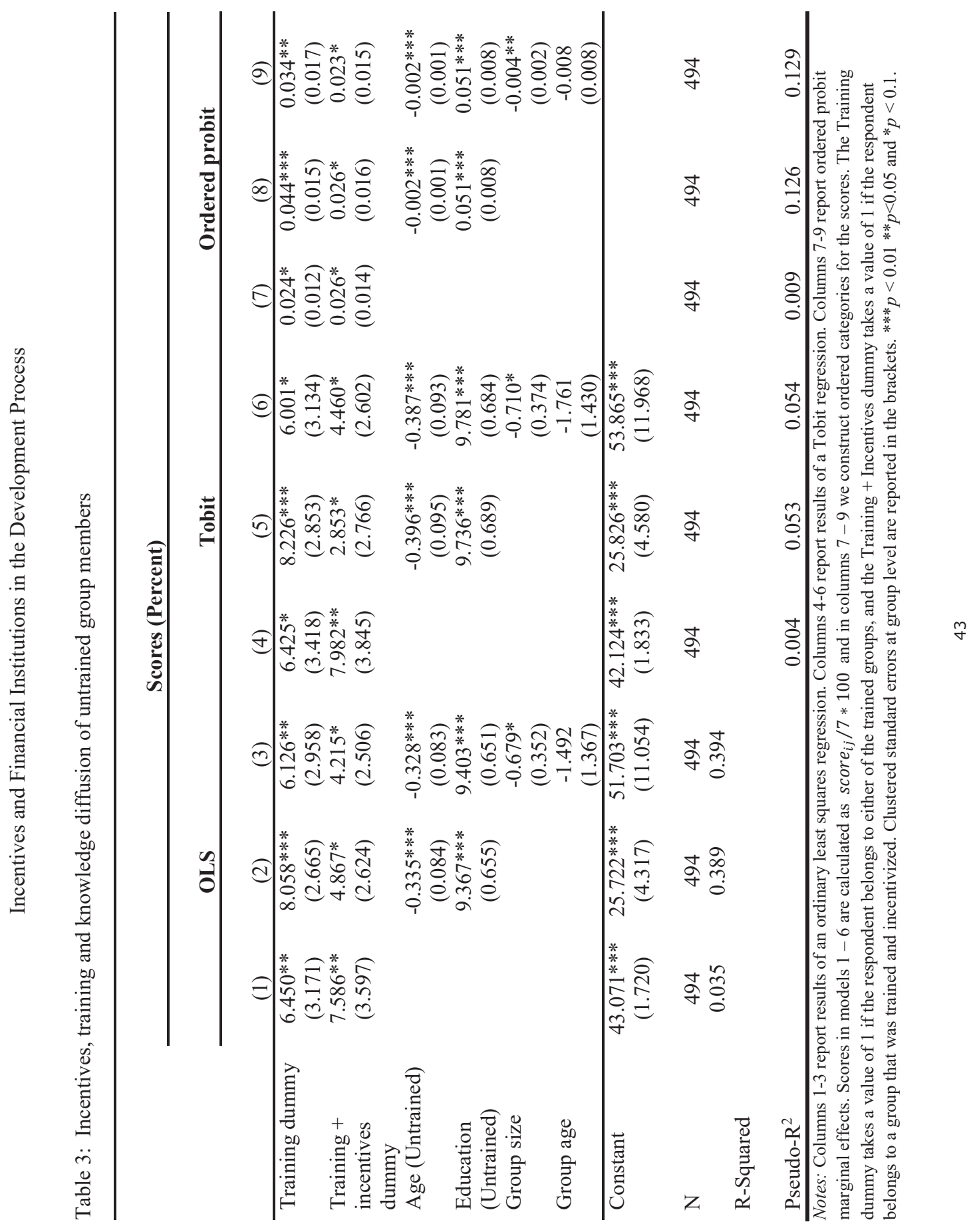


Do Incentives Matter for the Diffusion of Financial Knowledge?

Across all three sets of outcomes (OLS, Tobit, ordered Probit), we again consider a parsimonious specification, and then estimate more "complete models" including vectors of controls, $\mathrm{X}_{\mathrm{ij}}$ and $\mathrm{Z}_{\mathrm{j}}$. The first thing to observe is that the training dummy $\mathrm{D}_{1}$, associated with the two treatment arms, is consistently positive and significant across all specifications. We document significant sharing of knowledge within self-help groups, and according to the parsimonious OLS and Tobit specifications it is the case that group members achieve knowledge scores that are some $15 \%$ higher than those of their peers in control groups. Indeed, it appears as if the sharing of knowledge within self-help groups is almost complete. According to the parsimonious OLS model, untrained members from the conventional training arm achieve knowledge scores of $(43.071+6.450=)$ 49.521, which is statistically identical to the knowledge level of trained group members $(50.906$, or the constant in Table 2).

The second thing to observe is that, across all nine models, we find positive coefficients associated with the incentive dummy $\mathrm{D}_{2}$. Moreover, these coefficients are significantly different from zero, albeit only at the $10 \%$ level in most specifications. This, we believe, is our main result: untrained members in groups with incentivized respondents accumulate more financial knowledge than untrained members from the conventional training group (and, of course, much more than members from the control group). This difference in learning across experimental arms is relatively large. When comparing the incentive effect to the knowledge level of the conventional training group, our parsimonious OLS and Tobit estimates reveal that incentives increase knowledge sharing by some $15 \% .{ }^{15}$ As before, we find that knowledge sharing within the subsample of incentivized group members is fairly complete: the knowledge scores obtained by 15 The Wald test on the coefficients in columns 1-3, and columns 4-6 indicate that the explanatory variables have
different effects on the dependent variables. This is evident from the F-statistics which are significant. 
Incentives and Financial Institutions in the Development Process

other (untrained) group members only lag slightly behind the scores of the trained group members. Specifically, from Table 3 we learn that the average untrained group member has a knowledge score of $57.1(43.071+7.586+6.450)$, which should be compared to the average score by trained group members $(50.906+15.652=66,558$, from column 1 in Table 2$)$. In other words, untrained group members achieves scores that, on average, are no less than $85 \%$ of the scores of trained individuals. We conjecture that slight differences in the extent to which sharing occurs across the two treatment arms are due to increasing marginal costs (or diminishing marginal returns) to teaching and learning within self-help groups.

Next, turn to the other covariates. Not surprisingly, we again find that more educated group members tend to perform better on the knowledge test. We also find that the age of the respondent matters - young respondents appear to score better, but this effect is not very large. Interestingly, group size does not matter. This presumably reflects that we have selected a fixed number of other group members for the endline survey, which implies that the probability of picking any specific untrained group member goes down as the group gets larger. From the perspective of trained group members, this reduces the expected payoff of investing time and effort in training specific individuals. $^{16}$

\subsubsection{Who learns from whom?}

We asked untrained group members to identify the individual who shared training content with them - if anybody. Obviously matching occurs endogenously, and is not based on experimental variation. We ask whether assortative matching occurs in the self-help groups, or whether individuals are more likely to learn from group members with similar demographic characteristics.

\footnotetext{
${ }^{16}$ Observe that group ties within larger groups may be weaker, so that (on average) the altruistic incentive to train fellow group members may also be lower. This will be the case in both treatment arms.
} 
Do Incentives Matter for the Diffusion of Financial Knowledge?

We then compare outcomes across the treatment arms to explore whether matching processes are affected by incentives.

Table 4 reports the extent to which matching on such variables occurs. For each untrained individual we create four dummy variables capturing whether the group member that "trained" her shared the same age, gender, education level, and tribal affiliation. We then average the value of these binary variables across respondents to obtain a (treatment arm specific) measure of assortative matching intensity. We compare this actual intensity level to the predicted level of matching that would occur if untrained and trained group members matched randomly within the self-help group. 


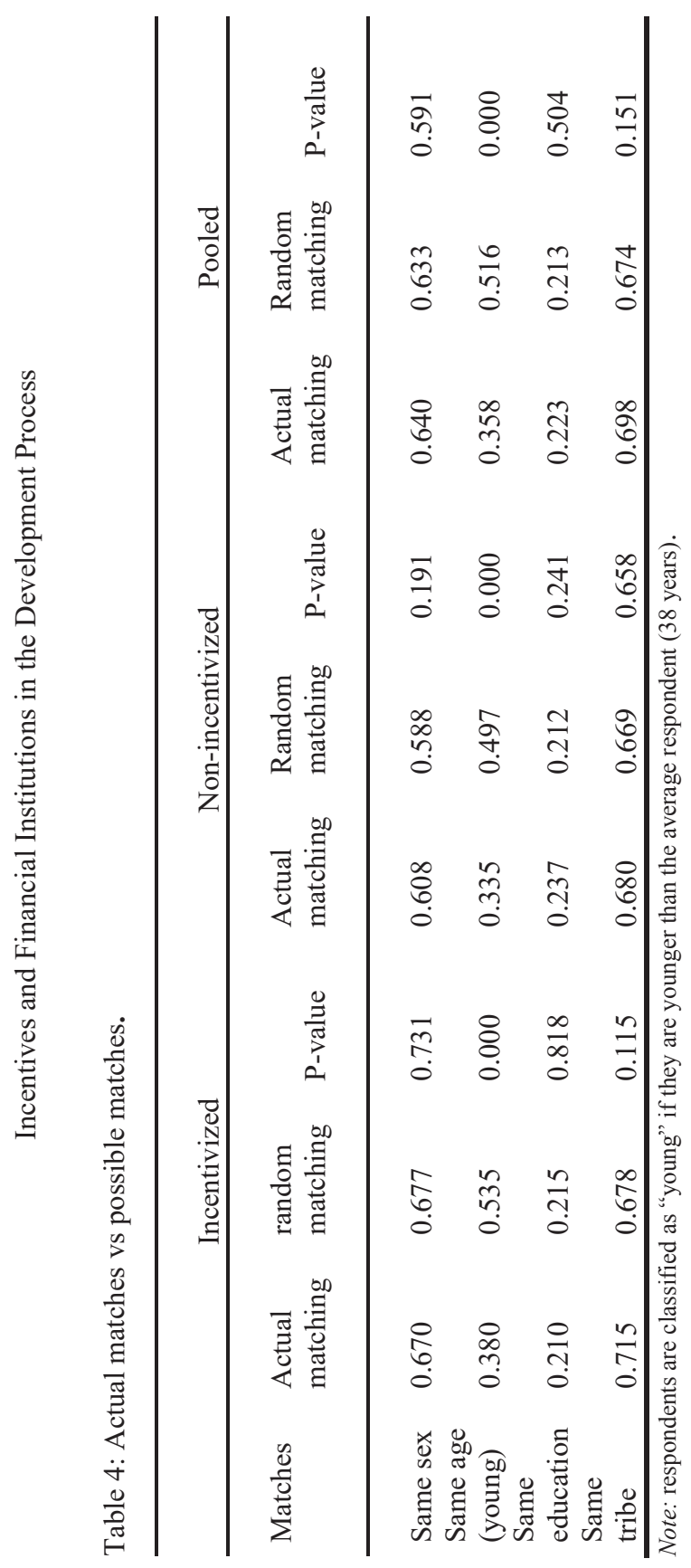


Do Incentives Matter for the Diffusion of Financial Knowledge?

Most of the social learning occurs for pairs with the same gender - this is the case for $67 \%$ of the matches. However, this degree of assortative matching is not statistically different from the degree of matching that would occur if group members are randomly matched. Similarly, there is no evidence of assortative matching based on education level or tribal affiliation. The single demographic variable for which actual and random matching intensity is different is age, and there the opposite of assortative matching appears to occur. Closer inspection of the data revealed that the old members learned from the young, who on average performed better on the knowledge tests. Interestingly, the same patterns emerge in the data for the incentivized and the non-incentivized treatment arm. We do not observe that incentivizing causes trained individuals to single out fellow group members who are more like themselves (i.e., more assortative matching), nor that they become less "picky" about whom to spend time with (less assortative matching). If we regress the measured assortative matching intensity on an incentive dummy we consistently find there is no significant correlation between matching intensity and the treatment dummy (results not shown, but available on request). To some extent this is an artefact of the social context within which we study social learning. Self-help groups are not composed of randomly selected villagers, but consist of individuals who have self-selected into the group. Social capital levels within the group are likely to be high, and we expect considerable willingness to help fellow group members. This also implies the extent of social learning in these groups may not be representative of the intensity of knowledge sharing occurring in settings where individuals cannot choose their peers, such as in natural villages. 
Incentives and Financial Institutions in the Development Process

\subsubsection{Cost effectiveness of incentivizing diffusion}

Does it make economic sense to incentivize trained individuals to share knowledge with their peers? A full-blown cost-benefit analysis is beyond the scope of the current paper, and requires a comparison of the costs of the training and incentives to economic gains for beneficiaries - data that are currently unavailable. However, it is possible to compare the cost of raising knowledge scores across treatment arms. That is, we can use our survey data to compute the cost effectiveness of the conventional training approach and the alternative modality that includes incentives for knowledge sharing.

Consider an "average" self-help group in our sample, consisting of 24 group members. Of this self-help group, 6 members are invited to participate in the training, and the remaining 18 members remain untrained (by CBS-PEWOSA). If this group is allocated to a conventional training program, the estimated implementation cost of the training amount to UGS 1.1 million (according to CBS-PEWOSA data). If, instead, the group is assigned to an incentive program, the total training costs (now including performance fees) amount to UGS 1.2 million. ${ }^{17}$ We ask whether the additional expenditure of UGS 100,000 increases or decreases the per-unit cost of knowledge transfer.

The conventional training arm achieves the following gains in terms of knowledge scores: 6 trained members gain an additional 7.835 points per member (compare the constant terms in column 1 of Table 2 and Table 3), and sharing effects imply that 18 untrained members gain 6.450 knowledge points. The total gain in knowledge, according to our estimates, equals 163.1 index points (or (6× $7.835)+(18 \times 6.450))$, so the average cost per unit of knowledge gain amount to UGS 6,744 .

\footnotetext{
${ }^{17}$ Recall that in the incentive group, $47 \%$ of the trained individuals receive a payment of UGS 35,000 .
} 
Do Incentives Matter for the Diffusion of Financial Knowledge?

We can do the same exercise for the training modality that includes incentives. We find the same training now produces a total increase in knowledge equal to 393.5 index points, with an associated average per-unit cost of only UGS 3,049. In other words, providing incentives for diffusion approximately cuts the average costs of knowledge transfer in half. It therefore appears like an attractive opportunity for NGOs or governments with binding budget constraints - promoting diffusion is less expensive than up scaling teaching interventions. Observe that our performance fee of UGS 35,000 was chosen in a rather arbitrary fashion, so additional efficiency gains may be possible by optimizing the amount of the reward.

\subsection{Discussion and Conclusions}

Diffusion of knowledge and innovations often seem to occur at rates that are "too low." As a result, advantageous behaviors and production techniques may remain limited to pockets of the overall population, with adverse effects for (economic) outcomes. Limited social learning also undermines the cost effectiveness of development interventions, possibly eroding the economic rationale for such interventions. It is important to improve our understanding of how knowledge spreads in target populations to enhance the efficiency and effectiveness of trainings and projects.

In this paper we examine whether the diffusion of knowledge can be promoted by the provision of (monetary) incentives. We study social learning in the context of NGO-founded self-help groups in which individuals can self-select. Endogenous membership presumably implies these groups have high levels of social cohesion and social capital, or provide a setting where social learning is given the best chance to succeed. Care must be taken when extending the main insights of this study to other contexts, such as villages, where membership is (more) exogenous and inter-person ties are presumably looser. 
Incentives and Financial Institutions in the Development Process

Our first result is evidence of knowledge diffusion even in the absence of incentives. Indeed, we find that nearly all the knowledge gained by (randomly selected) group members spills over to peers. Our second result is that incentivizing individuals to share knowledge with their group members encourages these individuals to study harder and accumulate more knowledge during the trainings. The increase in knowledge due to the trainings for members of the incentivized group is about one-third of the gain for un-incentivized individuals. Our third and main result is that incentivizing individuals has a large effect on social learning. Indeed, we demonstrate that the magnitude of the sharing implies that the provision of incentives is a cost-effective approach to promoting knowledge diffusion.

The result that people respond to incentives is perhaps not surprising to most economists. Nevertheless, we believe it is important to confirm and emphasize this insight in specific development settings, such as the one studied here. Too often decision-makers assume that knowledge will spread automatically, or that poor villagers are keen to provide public goods for free. This may simply not be realistic. Examples include many extension initiatives in the domain of agriculture (e.g. farmer field schools), but also programs in the public health sector. For example, it is estimated that this sector suffers from a shortage of 7 million professional health workers (WHO 2013). To address this problem, so-called community health workers or community medicine distributors have been recruited in many developing countries. Such individuals typically receive a short training but no compensation for their time or effort. It should be no surprise that this lack of incentives translates into disappointing outcomes (Chami et al. 2016). We speculate the introduction of incentives - monetary or otherwise - may help to improve the performance of development interventions across a swath of relevant domains. 
Do Incentives Matter for the Diffusion of Financial Knowledge?

While it is comforting to observe that social learning can leverage the effectiveness of training interventions, and that the extent of social learning can be manipulated by incentives, it is evident that major challenges remain for practitioners seeking to put the lessons from this analysis to practice. Specifically, there are many cases and contexts where knowledge diffusion should not stop after a single round of social learning. Individuals benefitting from the knowledge imparted on them by their peers should, in turn, share this knowledge with other villagers - and so on, until the entire target population has been reached. Affecting the behavior of "downstream" beneficiaries via individual incentives may be far from straightforward. Exploring efficient and effective designs that promote diffusion downstream of initially trained beneficiaries is left for future research. 


\section{Appendix 1: Financial Literacy Training Manual for CBS-PEWOSA}

CBS-PEWOSA financial literacy training manual is comprised of the topics

(1) Understanding financial literacy.

(2) Taking financial records.

(3) Budgeting.

(4) Saving as a culture.

(5) Loan management.

Topic 1 entitled "Understanding financial literacy" focuses on imparting knowledge and skills on members concerning the use of financial resources productively. That is, it encourages members to use money wisely and calls on members to have discipline in spending such that money becomes "a friend" than an "enemy". Further, it covers aspects of inflation and its associated effects plus the need of valuing money regardless of which face value-illustrations including examples are used to explain why money should be valued.

Topic 2 entitled "Taking financial records" emphasizes the need to take records on daily earnings, daily expenditures and daily savings. It also teaches members to aggregate their daily records at week level and month level. Members are taught to compare their earnings, expenses and savings at all levels (daily, weekly and monthly) to track for the differences/changes. Then, members are encouraged to find reasons for such differences. Thereafter, finds solutions if the records are not moving the intended way.

Topic 3 which is entitled "Budgeting" focuses on understanding the meaning and the need for budgeting, when and how to make a simple budget, categorizing of the household needs (starting from the most pressing needs) and how to stay within your budget.

Topic 4, "Saving as a culture" takes participants through the need for saving and explains how saving should be a culture to everyone. It also covers the different ways of saving which range from non-cash savings like assets to cash savings. It further compares the advantages and disadvantages the informal saving schemes like keeping money in the house to semi-formal savings like keeping money in self-help groups and then to formal savings like keeping money in banking institutions. This topics also covers some aspects of investment like why invest, how to identify a better investment option, how to manage your investment venture, how to help it grow, customer care, customer attraction and customer retention as major tools of expanding any investment venture.

Topic 5, "Loan management" starts with explaining the various terms used in borrowing. These terms include loan size, interest rate (members are trained on how to compute simple interest rate and how to compute interest on decreasing balances), fees, grace period, repayment schedule etc. 
Do Incentives Matter for the Diffusion of Financial Knowledge?

\section{Appendix 2: Test Questions for Knowledge Diffusion.}

(1) Suppose you made a stock of some goods today at a cost of shs. 405000 and with a transport charge of shs. 35000. You pay people who help you to load the goods a free of shs. 15000. If you sale those goods at a price of shs. 515000, what is your profit? Answer: 60000.

(2) What do you understand by preparing a daily budget in a home. Answer: Preparing a document/instrument that shows daily earnings and expenditure within the home.

(3) Suppose you receive a loan worth $1,000,000 /=$ at an interest rate of $5 \%$ per month. If its repayment period is six months, what would be your monthly interest payment? Answer: 50000/=

(4) From (3) above, what could be the total repayment amount (principle+interest) at maturity? Answer: $1,300,000 /=$

(5) Suppose you have $1,00,000 /=$ in your savings account and the interest rate paid on your savings is $10 \%$ per month and you never make any withdraw. After six months, how much would you have in your account? Answer: 160,000/=

(6) Assume that interest rate on your savings account is 5\% per year and inflation is $10 \%$ per year. After one year, how much would you be able to buy with the money on your account? Answer: Less than today

(7) Assuming you are interested in borrowing 1000,000 Uganda shillings today for investment and you get information that inflation stands at $10 \%$ but it is projected to be at $17 \%$ in the next four months. When would you take the loan? Answer: Today. 
Incentives and Financial Institutions in the Development Process

\section{Appendix 3 - Detailed Variables Definition}

Age: defines the age of female respondents in complete years.

Gender (Male): dummy variable taking value " 1 " if participant is male

Married/Engaged: respondent's marital status with married or engaged $=1$, zero otherwise.

Education: highest grade/class completed by the male respondent.

Religion (Christian): respondents whose religious affiliation is Christian.

Tribe (Muganda): respondents who are Baganda by tribe. 
Incentives and Financial Institutions in the Development Process 
Chapter 3

\title{
Wage Differentials and Workers' Effort:
}

\author{
Experimental Evidence from Uganda.
}

\begin{abstract}
We organize a real-effort field experiment with varying piece rates to assess the impact of wages and social comparisons on productivity. In addition to analyzing how piece rates affect productivity during the "paid stage" of the experiment, we also consider how social comparisons affect effort supply during a voluntary and unpaid follow-up task. Our main results are that effort supply is relatively unresponsive to variation in own earnings, but responds strongly to pay inequality. While we only obtain weak support for the hypothesis that positive social comparisons invite extra effort during paid stages of the experiment, the effect of social comparisons is important during voluntary tasks. Specifically, positive social comparisons positively affect productivity during unpaid tasks, and negative comparisons have the opposite impact.
\end{abstract}

Publication status: Sseruyange, J. \& Bulte, E. (2018). Wage Differentials and Workers' Effort: Experimental Evidence from Uganda. Revise and Resubmit at the Oxford Bulletin of Economics and Statistics. 


\section{Wage Differentials and Workers' Effort}

\subsection{Introduction}

While conventional economic models assume that people only care about their own income and consumption level, a rich literature suggests most people also care both about how their income and consumption levels compare to those of others (e.g., Leibenstein, 1950, Duessenberry, 1952, Frank, 1985). The implications of concern about one's relative position have been studied for a range of issues, including happiness and well-being. A related literature considers the behavioral effects of social comparisons, including studies of job choice and effort provision. Social comparisons among workers may occur within firms as well as in the wider labor market, affecting job satisfaction (Card et al., 2012) so that relative pay can act as a compensating differential. Concerns about relative wages may also help explain wage compression (Charness and Kuhn 2007), secrecy rules regarding earnings, or the sorting of heterogeneous workers across firms. Since within-firm workers make for a more salient reference group than outside workers (e.g. Clark and Senik 2010), relative pay concerns also affect whether specific tasks are contracted out or organized within firm boundaries (Nickerson and Zenger 2008). ${ }^{18}$

In this paper we consider the interface of social comparisons and efficiency wages, or giftexchange between employer and worker. We focus on effort supply in a context where workers interact and are able to compare their earnings. Social comparisons may shape reference values, and help individuals to decide whether they have been treated "fairly." The literature on the fair wage-effort hypothesis suggests effort supply is governed by a desire for reciprocity - workers respond to higher wages by working harder. The presence of such reciprocal workers affects how

\footnotetext{
${ }^{18}$ Wage differences may of course create dynamic incentives, as workers may seek to acquire experience and invest in their human capital to increase their productivity and qualify for high wages in the future.
} 
Incentives and Financial Institutions in the Development Process

labor markets work, and could result in non-competitive wages and involuntary unemployment (e.g., Akerlof 1982, Akerlof and Yellen 1990). Reciprocity in the workplace may be rationalized by reference-dependent preferences, but alternative rationalizations also exist. Social comparisons are an important mechanism helping workers to form reference values.

If social comparisons shift reference values they may also affect effort supply - especially in a context of imperfect contractibility. A small literature, summarized below, analyses this issue. We contribute to this literature by examining whether absolute and relative earning levels affect effort supply in a real-effort field experiment in Africa. Our study is distinct for three reasons. First, in addition to focusing on effort supplied during the (paid) experimental task, we also elicit willingness to supply effort to a voluntary unpaid task after the experiment. This allows us to probe reciprocity beyond the quid-pro-quo relationship defined by the contract. Second, we use an experimental design based on exogenous variation in piece rates, rather than in the hourly wage as in most other studies. Bracha et al. (2015) also analyse the implications of varying piece rates, but focus on labor supply (time spent on a task), rather than productivity, or output per unit of time. Third, we use a non-conventional sample of African respondents - mainly smallholders and casual workers - that is quite distinct from the ones used in existing work. This allows us to verify the robustness of insights obtained earlier, in a different cultural context.

An important reason for studying piece rates in our experiment is the simple fact that piece rates represent the main payment regime in the context of informal or semi-informal labor markets in developing countries. It also avoids confusion about whether or not higher earnings are justified by greater productivity. Of course a drawback of using piece rate treatments is that the identification of reciprocity is not straightforward, as extrinsic motives for effort supply vary with the level of the piece rate. As mentioned by Bellemare and Shearer (2009), gift exchange occurs 


\section{Wage Differentials and Workers' Effort}

in a piece rate setting as long as the employer's valuation of the produced output is sufficiently high (exceeding the marginal cost due to the piece rate). To cleanly identify the effect on reciprocity we therefore analyse effort supply during a voluntary (unpaid) task. We also include two control groups (where social comparisons are eliminated by design) with high and low piece rates to study productivity.

We find that effort choices are not very sensitive to own earnings: piece rate levels do not explain variation in effort in the absence of social comparisons. However, relative wages have an impact on effort supply, but not always. Unlike earlier work we do not find that, relative to a control group, low wages reduce effort during the paid stage of the experiment. We document some evidence that positive comparisons make people more productive. Importantly, social comparisons significantly affect productivity during unpaid stages of the experiment. Low-piece rate workers supply less effort during the unpaid task when shirking is "cheap" and workers do not have to sacrifice their own income if they choose to be unproductive. This finding supports earlier studies based on fixed wages, where withholding effort is also privately cheap. Reciprocity carries over to settings beyond the contract, which is arguably an important result as many organizations depend on voluntary or badly monitored contributions of their co-workers for (economic) success.

The paper is organized as follows. In the next section we briefly summarize the existing literature on social comparisons and effort supply, focusing on recent experimental studies. In section 3 we introduce our experiment, summarize our data, and outline our identification strategy. Section 4 contains our empirical results, focusing both on effort supply for the paid and voluntary tasks. The conclusions and discussion ensue. 
Incentives and Financial Institutions in the Development Process

\subsection{Social comparisons and effort supply}

Starting with seminal work of Fehr et al. (1993), many papers have analysed the fair wage-effort hypothesis, postulating that fairness considerations affect the supply of effort by workers if effort is not perfectly contractible. To decide about what constitutes a "fair" level of earnings, a worker can refer back to earlier payments (Cohn et al. 2014, Clark et al. 2010, Bracha et al. 2015) or consider how the surplus is (vertically) distributed between herself and the employer (HennigSchmidt et al. 2010). Importantly, the evaluation of "what is fair" may also be based on horizontal comparisons among peers engaged in the same activity. Social comparisons help workers to form reference values, and own earnings are likely to be evaluated as "fair" when exceeding the reference level. Conversely, wages below the reference value may be seen as "unfair" and invite feelings of disappointment or even anger.

The literature contains several explanations for why fairness evaluations may affect effort supply in the context of fixed wages. Clark et al. (2010) framed their results in terms of a concern for status, but observe that inequality aversion would yield similar results. Workers with high earnings supply more effort and incur a greater effort cost to reduce the gap between their "net earnings" and those of others. Relatedly, Hennig-Schmidt et al. (2010) introduce tensions due to cognitive dissonance. To alleviate tensions between an offered and reference wage, workers may provide extra effort (for wages exceeding the reference value) or shirk (in case the reverse is true). An alternative explanation would be a model based on a reciprocity norm prescribing how much effort to provide in response to a certain wage level - where higher wages imply workers should work harder. The salience of such a norm could vary with perceived fairness of the wage level, so workers feel free to ignore the norm when feeling badly treated (see, for example, the theory of “motivated reasoning” discussed by Benabou and Tirole, (2016). The empirical evidence for social 
comparisons as a determinant of effort is strong, but not overwhelming. ${ }^{19}$ Several studies document that workers' effort does not always respond to co-workers' wages in a simple fashion (e.g. Charness and Kuhn 2007, Hennig-Schmidt et al. 2010, Bartling and von Siemens 2011). This may be due to the fact that assessing the appropriate reference value is not always straightforward. For example, fixed wage differentials may be justified when workers are not equally productive. When workers are paid a fixed wage, then, paying higher wages to more productive workers appears reasonable. In the context of heterogeneous workers, wages paid to high-productivity individuals should not map automatically on reference values of low-productivity workers. ${ }^{20}$

Nevertheless, the majority of the empirical work supports the hypothesis that social comparisons affect effort supply. This has been established in studies based on observational data (Karnes 2009, Clark et al. 2010), and in lab games (Clark et al. 2010, Gachter and Thöni 2010, Bracha et al. 2015). ${ }^{21}$ Breza et al. (2015) organize a field experiment in an Indian manufacturing firm, offering different daily wages with or without a clear justification for wage differences (based on baseline productivity differences). While absolute wages of groups of workers are similar, reference values are manipulated by exogenous variation in wages of the relevant co-workers and by variation in the observability of productivity across tasks. The empirical evidence suggests negative comparisons - being paid less for the same task than your peer, without a clear rationale or

\footnotetext{
${ }^{19}$ The persistence of reciprocity and gift exchange between employer and worker over time has also been debated (e.g., Gneezy and List 2006; Kube et al. 2012, Bellemare and Shearer 2009).

${ }^{20}$ Gachter and Thöni (2010) also demonstrate that "intentions matter more than consequences," or that workers more readily accept wage differentials that appear random than the result of discrimination by the employer. For earlier work on intention-based reciprocity, refer to Dufwenberg and Kirchsteiner (2004).

${ }^{21}$ The design of Bracha et al. (2015) is a bit different from the other studies. They do not study how much effort is allocated to a task (per unit of time), but ask how many minutes students want to work on a specific task when receiving a high or low piece rate.
} 
Incentives and Financial Institutions in the Development Process

justification - reduce effort supply. In contrast, positive comparisons do not increase effort on average.

This is consistent with experimental evidence by Cohn et al. (2014), who study effort supply by pairs of workers in response to wage cuts. Cutting both wages decreases performance (the fair wage-effort hypothesis), but unilaterally cutting only one wage decreases performance of the affected worker more than twice as much (and leaves effort of the other worker unaffected). Cohn et al. (2015) also report that the "removal of perceived unfairness," rather than positive reciprocity, determines performance. Workers who perceive to be underpaid at the base wage increase their performance after their wage is increased, but those who feel fairly paid do not change their performance after a wage increase.

\subsection{Experimental Design and data ${ }^{22}$}

We designed and implemented a real-effort field experiment in Kamuli district, Uganda, in November and December of 2015, and collected data in 9 villages. We arrived in the villages one day before the experiment and asked the chief to provide us with a census of the households. After randomly selecting households to participate in the experiment, we invited selected households to send one (adult) representative. More than $95 \%$ of the households complied, and declining households were replaced by others randomly drawn from the same population. We clearly announced the experiments were for (university) research purposes, and not part of any electoral campaign starting up in preparation of the 2016 elections in Uganda. Participants were informed there would be an opportunity to earn money. To avoid within-village information spill-overs we ran several sessions simultaneously, overseen by multiple enumerators, and not consecutively. To

${ }^{22}$ Refer to appendices 2 and 3 for the summary experimental protocols 
avoid between-village spill-overs the selected villages were geographically spread out and we never announced in which villages we would collect data next.

In total, we recruited 600 respondents from a peri-urban environment to engage in the experiment: 400 subjects were randomly assigned to our two treatment arms, A and B (or 200 subjects per arm), and 200 enrolled in two control arms (100 per control arm). Within experimental arms we allocated respondents to groups of 10 villagers, participating in the experiment together. Subjects were aware that assignment to experimental arms was random. All participants received a showup fee of UG shillings 5,000 ( 1 USD $\approx 3,300$ UGS), or about half of the average daily wage in the townships where we collected our data (UGS 8,000). This context is a setting that is intermediate between the conventional "lab" (without interaction between subjects, other than via the game) and the "field" (where subjects are unaware they participate in an experiment). Many subjects in our study spent time together before (and presumably after) the experiment, which enhances the saliency of social comparisons.

The experiment consisted of 2 stages (stages 1 and 2), or 4 sub-stages (1a, $1 \mathrm{~b}, 2 \mathrm{a}$, and $2 \mathrm{~b}$ ). In stages 1a and $2 \mathrm{a}$ we asked the subjects to sort beans for 30 minutes, in exchange for payment. ${ }^{23}$ They were handed 12 kilograms of mixed dried beans in one large container: 3 kilograms from each of four different types, known by their local names as: nambale short, nambale long, NAADs, and Masavu. During stages 1a and 2a we paid participants a fixed piece rate per gram sorted (based on type). Subjects from treatment arm A were paid a relatively low piece rate of UGS 5 per gram sorted, and subjects from treatment arm B received a high piece rate of UGS 9 per gram. Subjects

\footnotetext{
${ }^{23}$ Hence, our subjects were not free to choose the time spent sorting beans. For example, Fehr and Goette (2007) study whether agents work harder when wages go up, allowing workers to choose the number of hours spent working as well as effort per hour. In their study, the number of hours increased, and effort per hour decreased. Our subjects have fewer degrees of freedom, so our predictions with respect to effort per unit of time are unambiguous. Fehr and Goette (2007) do not study social comparisons, but do document evidence in favour of reference-dependent utility.
} 
Incentives and Financial Institutions in the Development Process

from the two treatment arms worked in nearby but different rooms, and during the sorting there was no contact between them. Subjects from the control groups also received a high (100 respondents) or low piece rate (100 respondents). At the end of stage 1a sorted output was measured, and individual earnings were computed and announced to individual subjects.

Immediately after stage $1 \mathrm{a}$ we implemented stage $1 \mathrm{~b}$, in which we invited subjects to engage in a voluntary task for which they would earn no money. We emphasized that people were free to leave for the break, but that it would be appreciated if they wanted to help by sorting some more beans. Those willing to engage in additional, unpaid bean sorting were invited to sort another type of beans (from another container) for an additional five-minute interval. Subjects picked different types of beans from the mix for the paid and unpaid stages of the experiment. Specifically, they picked the nambale long type during the paid stage, and the masavu type during the unpaid task. Since sorting the latter type is much easier (unlike nambale long, it is quite distinct from the other three types of beans in the mix), productivity in the unpaid task is higher, all else equal, so we cannot compare productivity levels across paid and unpaid stages of the experiment. After stage $1 \mathrm{~b}$, and out of sight of the subjects, we mixed all sorted beans for the next experimental session. The beans included in the experiment were local varieties, well-known to the great majority of the respondents.

The difference between stages 1 and 2 of the experiment is in the information that participants have about their relative earnings. During stages $1 \mathrm{a}$ and $1 \mathrm{~b}$ participants knew only their own piece rate (or the piece rate of others in their group). Social comparisons entered in stages $2 \mathrm{a}$ and $2 \mathrm{~b}$, after players (presumably) learned about the piece rates earned by their co-workers from other groups. This was accomplished as follows. During sessions, two groups of subjects were always sorting simultaneously in two adjacent rooms. After stage $1 \mathrm{~b}$ we gave participants a 20 minutes 
break and provided them with snacks and refreshments. During this break, participants from the two groups were brought to a common room where they mingled and discussed. We assume information about earnings spread naturally across the participants during this break (which was invariably the case, according to the exit interviews).

Participants from the two treatment arms were always matched with individuals from the other treatment arm - bringing together high and low piece rate workers. In contrast, workers from control groups were matched with other control group workers earning the same rate. Hence, social comparisons are only salient for subjects from treatment arms A and B. Specifically, after discussing their piece rates and earnings with subjects in arm B, subjects in arm A learn they have been treated relatively badly even if absolute earnings were considerable—-see below. In contrast, subjects from arm B presumably feel privileged. We did not provide any explanation for the gap in piece rates, and explored whether social comparisons affect productivity in the follow-up tasks.

After the break, participants returned to their working environment, and engaged in a second round of 30 minutes of bean sorting (stage 2a) and afterwards were again invited to contribute to an unpaid task (2b). During stage 2a all subjects worked for the same piece rate as before, and sorted the same beans as before. After this second stage, we paid subjects their earnings. Subjects participated in only one session. Mean earnings in the low (high) piece rate treatment equalled about UGS 1,600 (3,000) during the first stage, and UGS 2,000 $(4,100)$ during the second stage. Mean earnings for the full experiment, including the show-up fee, range from UGS 8,400 for the respondents receiving the low piece rate to UGS 12,100 for subjects receiving the high rate. The former amount is roughly a full day of wages for unskilled labor in our study region, so even subjects in our low piece rate regime were paid rather well given that the experiment took less than half a day. 
Incentives and Financial Institutions in the Development Process

The analysis rests on a comparison of productivity across groups with and without social comparisons, both for the paid and unpaid task. To identify the effect of own wage and co-worker's wages on effort we do not rely on before-after comparisons but include control groups in a difference-in-differences analysis. The reason is that (i) workers may learn by doing, so their productivity could improve across rounds, and (ii) workers might have difficulty grasping the implications of a specific piece rate for potential earnings (that is: they may find it difficult to predict how many grams they can sort in half an hour, or how much they can potentially earn). The dynamics of effort across rounds for the control groups capture experience and updated information about productivity, enabling proper identification of the additional impact due to social comparisons.

We also analyse the data in a regression framework. First, to analyse whether own wage affects effort, we use the first stage data $(\mathrm{N}=600)$ and estimate the following model:

$$
y_{i}=\beta_{0}+\beta_{1} \operatorname{High}_{i}+\beta_{2} X_{i}+\epsilon_{i}
$$

where $y_{\mathrm{i}}$ captures the quantity of beans sorted by respondent $i$ (in grams), High $h_{\mathrm{i}}$ is a dummy variable taking the value of " 1 " if the subject received a high piece rate, $X_{\mathrm{i}}$ is a vector of controls, and $\epsilon_{\mathrm{i}}$ is an error term. We always cluster standard errors at the experimental group level. If higher piece rates invite additional effort, then we find $\beta_{1}>0$.

We use data from the second stage to estimate the following model:

$$
y_{i}=\beta_{0}+\beta_{1} H_{i g h}+\beta_{2} S C+\beta_{3} S C \times H i g h_{i}+\beta_{4} X_{i}+\epsilon_{i}
$$

where $S C_{\mathrm{i}}$ is a dummy variable indicating whether the respondent was in one of the experimental arms (i.e. spent the break with subjects earning a different piece rate). This variable take the value 
of " 1 " if subjects were matched with subjects earning a different piece rate, and takes a value of " 0 " for subjects from the control arms. The estimate coefficient $\beta_{1}$ again picks up the effect of own wage on effort, $\beta_{2}$ picks up the effect of unequal payment, and $\beta_{3}$ picks up any additional effect of unequal payment for high piece rate earners. Average quantities sorted for the various experimental groups during the $2^{\text {nd }}$ stage of the experiment are therefore as follows:

Low piece rate, control group: $\beta_{0}$

High piece rate, control group: $\beta_{0}+\beta_{1}$

Low piece rate, treatment arm A: $\beta_{0}+\beta_{2}$

High piece rate, treatment arm B: $\beta_{0}+\beta_{1}+\beta_{2}+\beta_{3}$

Table 1 summarizes the observables of our participants, across the three experimental arms. The great majority of our subjects are (married) Christian women of the Musoga tribe, with little education. The average subject has approximately 4 children and has access to 1.7 acres for farming. Observe that participants are statistically identical for most observables, but that Christians and members of the Musoga tribe are slightly underrepresented in the control group. Religion and ethnic affiliation are not correlated with productivity in bean sorting. Overall, random assignment to arms resulted in rather balanced experimental groups, but we will control for observables in our regression models to increase the precision of our estimates. 
Incentives and Financial Institutions in the Development Process

Table 1: Descriptive Statistics and Balance Test

\begin{tabular}{|c|c|c|c|c|c|c|}
\hline Variables & $\begin{array}{l}\text { Treatmen } \\
\mathrm{t} \operatorname{arm}(\mathrm{A}) \\
\mathrm{N}=200\end{array}$ & $\begin{array}{l}\text { Treatment } \\
\operatorname{arm}(B) \\
\mathrm{N}=200\end{array}$ & $\begin{array}{c}\text { Control (C) } \\
\qquad \begin{array}{c}\mathrm{N}=200\end{array}\end{array}$ & $\begin{array}{l}p \text {-values } \\
\mathrm{A}=\mathrm{B}\end{array}$ & $\begin{array}{l}p \text {-values } \\
\mathrm{A}=\mathrm{C}\end{array}$ & $\begin{array}{l}p \text {-values } \\
\mathrm{B}=\mathrm{C}\end{array}$ \\
\hline Male & 0.270 & 0.295 & 0.285 & 0.580 & 0.640 & 0.755 \\
\hline Married/Engaged & 0.630 & 0.645 & 0.640 & 0.756 & 0.769 & 0.883 \\
\hline Number of children & 4.075 & 3.840 & 3.605 & 0.495 & 0.041 & 0.304 \\
\hline Education & 2.300 & 2.350 & 2.390 & 0.649 & 0.246 & 0.605 \\
\hline Religion (Christians) & 0.805 & 0.820 & 0.720 & 0.702 & 0.008 & 0.002 \\
\hline Tribe (Musoga) & 0.930 & 0.900 & 0.880 & 0.283 & 0.031 & 0.386 \\
\hline Land size & 1.760 & 1.720 & 1.580 & 0.898 & 0.111 & 0.214 \\
\hline
\end{tabular}

\subsection{Empirical results}

We first report the outcomes of a series of pairwise comparisons starting with the paid stages of the experiment. Consider stage 1a of the experiment, when all workers were uninformed about how their piece rate compared to that of others. Sorted quantities for the various experimental arms are provided in the first row of Table 2. Not surprisingly, subjects in treatment arms A and B sort the same quantity of beans as their counterparts in the control groups. That is, in the absence of social comparisons, subjects earning a low piece rate in treatment arm A sort the same quantity of beans as subjects in the control group receiving the same piece rate (columns $1-2 ; p$-values of $\mathrm{t}$ test of equality of sample means is reported in column 3). Similarly, subjects in the high piece rate treatment B sort as much as subjects in their control group earning a high piece rate (columns 4-5; $p$-values from t-test reported in column 6). 
Wage Differentials and Workers' Effort

Table 2: Piece Rates, Social Comparisons and Contractual Effort I

\begin{tabular}{|c|c|c|c|c|c|c|}
\hline & \multicolumn{3}{|c|}{ Low piece rate } & \multicolumn{3}{|c|}{ High piece rates } \\
\hline & $\begin{array}{c}\text { Treatment } \\
\text { A }\end{array}$ & Control & $\begin{array}{c}p \text {-value } \\
\text { (t-test) }\end{array}$ & $\begin{array}{c}\text { Treatment } \\
\text { B }\end{array}$ & Control & $\begin{array}{l}p \text {-value } \\
\text { (t-test) }\end{array}$ \\
\hline Output & 324,5 & 320,0 & 0.71 & 338,6 & 340,1 & 0.92 \\
\hline \multirow[t]{3}{*}{ (Stage 1A) } & $(6,067)$ & $(10,676)$ & & $(8,371)$ & $(11,087)$ & \\
\hline & $\mathrm{N}=200$ & $\mathrm{~N}=100$ & & $\mathrm{~N}=200$ & $\mathrm{~N}=100$ & \\
\hline & $\begin{array}{l}\text { Break with } \\
\text { information } \\
\text { update }\end{array}$ & $\begin{array}{l}\text { Break without } \\
\text { information } \\
\text { update }\end{array}$ & & $\begin{array}{l}\text { Break with } \\
\text { information } \\
\text { update }\end{array}$ & $\begin{array}{l}\text { Break without } \\
\text { information } \\
\text { update }\end{array}$ & \\
\hline Output & 412,9 & 425,2 & 0.41 & 461,5 & 433,4 & 0.05 \\
\hline \multirow[t]{2}{*}{ (Stage 2A) } & (8.116) & $(13.245)$ & & $(8.616)$ & (11.245) & \\
\hline & $\mathrm{N}=200$ & $\mathrm{~N}=100$ & & $\mathrm{~N}=200$ & $\mathrm{~N}=100$ & \\
\hline \multirow{2}{*}{$\begin{array}{l}\text { Stage } 2 \text { - Stage } 1 \\
\text { (t-test) }\end{array}$} & 88.3 & 105.2 & & 122.9 & 93.3 & \\
\hline & $p=0.00$ & $p=0.00$ & & $p=0.00$ & $p=0.00$ & \\
\hline
\end{tabular}

Notes: Grams of beans sorted for different experimental groups, standard errors of the means reported in parentheses. $p$-values refer to outcomes of a simple t-test.

More surprisingly, perhaps, is the finding that there does not appear to be a significant difference between subjects earning a low or high piece rate. While subjects in the latter group sort 338.6 grams, or some 14 grams more on average than their counterparts from the low piece rate group, this difference is not statistically significant at conventional levels $(p=0.19) .{ }^{24}$ Effort does not respond strongly to "own wages." We obtain the same result when we analyse the data in a regression framework; columns 1 and 2 of Table 3. While pooling data from treatment and control

\footnotetext{
${ }^{24}$ The difference in output for high and low piece rate workers in the control group is also not statistically significantly different from zero $(\Delta=4,5$ gram, $p=0.19)$
} 
Incentives and Financial Institutions in the Development Process

arms increases statistical power (as does controlling for observables), clustering standard errors at the group level reduces statistical power, and the net effect is that we find no significant difference in productivity between treatment arms. This could simply reflect that the low piece rate was also relatively high, compared to potential earnings outside the experiment.

Table 3: Piece Rates, Social Comparisons and Contractual Effort II

Beans sorted for payment: Beans sorted for payment:

\begin{tabular}{lcccc} 
Variables & \multicolumn{2}{c}{ first stage } & \multicolumn{2}{c}{ second stage } \\
\hline High & 16.100 & 15.569 & 8.170 & 10.051 \\
& $(12.81)$ & $(12.91)$ & $(18.49)$ & $(18.25)$ \\
$S C$ & & & -12.310 & -6.959 \\
& & & $(16.33)$ & $(16.33)$ \\
$S C * H I G H$ & & & 40.430 & 36.719 \\
& & & $(25.40)^{+}$ & $(25.37)^{+}$ \\
\hline Controls & No & Yes & No & Yes \\
Constant & 323.026 & 299.170 & 425.200 & 423.496 \\
& $(7.08)^{* * *}$ & $(16.86)^{* * *}$ & $(1.248)^{* * *}$ & $(16.509)^{* * *}$ \\
R-squared & 0.006 & 0.041 & 0.028 & 0.117 \\
Observation & 600 & 600 & 600 & 600
\end{tabular}

Notes: Robust standard errors, clustered at the group level, reported in parentheses. Included controls are the variables included in Table 1. ***Coefficient significant at $1 \%$, **Coefficient significant at $5 \%$, ${ }^{*}$ Coefficient significant at $10 \%$, + coefficient significant at $12 \%$.

Next, we consider productivity in stage 2a, or after subjects in treatment arms A and B have been able to compare their earnings to those of others. Quantities sorted for payment are provided in the second main row of Table 2. The first thing to observe is that all subjects have increased their productivity across rounds. This applies to workers in both experimental arms as well as in the 
Wage Differentials and Workers' Effort

control groups. Workers have learned to sort more efficiently, or have obtained a better understanding of the monetary stakes during the experiment (after learning about their stage 1a productivity and earnings).

The simple comparison of group means suggests that productivity levels vary across groups after the break. First, observe that productivity of low piece rate workers does not suffer from negative comparisons. Specifically, output of subjects in arm A increases by $27 \%$, which matches the increment in productivity of their control group $(p=0.41)$. However, outcomes appear different for subjects in treatment arm B, who on average increased their output level by no less than $36 \%$. This increase in output exceeds the increase in output of high piece rate workers in their control group $(p=0.05)$, as well as that of workers in treatment group A $(p=0.00)$. In other words, while negative social comparisons do not significantly reduce productivity in our piece rate experiment, positive comparisons seem to invite an increase in productivity. However, these results are only marginally significant in the regression analysis, reported in columns 3 and 4 of Table 3 . While coefficients $\beta_{2}$ and $\beta_{3}$ have the expected signs (i.e., $\beta_{2}<0$ or a negative productivity effect of negative social comparisons, and $\beta_{3}>0$ or positive productivity effect of positive comparisons), they are imprecisely estimated. Specifically, $\beta_{3}$ is only significant at $p=0.11$ in both models.

The finding that negative social comparisons leave effort of the two experimental groups unaffected contrasts with findings of, for example, Gachter and Thöni (2010), Cohn et al. (2014, 2015) and Breza et al. (2015). These studies document an asymmetric impact of social comparisons on effort, finding that low-wage workers provide less effort and that productivity of high-wage workers is unaffected. For example, Breza et al. (2015) find that, on average, output 
Incentives and Financial Institutions in the Development Process

declines by $22 \%$ for a given wage when a worker earns less than his co-workers, ${ }^{25}$ and document little support for the hypothesis that performance increases when people earn more than their peers. See also Cohn et al. (2015) on differential effort responses to wage increases for underpaid and adequately paid workers, and Card et al. (2012) on the asymmetric effect of wage inequality on job dissatisfaction.

We believe a major reason for the divergence in findings is due to the fact that our subjects are paid on a piece rate basis - a payment regime where shirking is privately costly, especially given the rather high piece rates that we offered (even in the low piece rate treatment). Extrinsic motives appear sufficiently strong to dominate other concerns.

Next, to further probe whether social comparisons are neutralized by extrinsic incentives we analyse how social comparisons affect voluntary work. Recall that in stages $1 \mathrm{~b}$ and $2 \mathrm{~b}$ of the experiment we asked subjects to sort additional bags of beans without payment. First consider productivity prior to social comparisons, in the pre-information stage. The first row of Table 4 documents there is no variation in effort across the experimental arms during stage $1 \mathrm{~b}$ - statistically these four measures of output are identical. Higher piece rates do not improve productivity for an unpaid voluntary follow-up task. We find the same result in the regression analysis (columns 1 and 2 of Table 5). Consistent with productivity during the paid stage of the experiment, this finding could reflect that both low- and high-piece rate workers believe they have been well-paid during the first stage.

\footnotetext{
${ }^{25}$ Workers with low relative pay also more frequently miss work days, and give up nearly $10 \%$ of their income to avoid a workplace where they earn less than their colleagues.
} 
Wage Differentials and Workers' Effort

Table 4: Piece Rates, Social Comparisons and Voluntary Effort I

\begin{tabular}{|c|c|c|c|c|c|c|}
\hline & \multicolumn{3}{|c|}{ Low piece rate } & \multicolumn{3}{|c|}{ High piece rate } \\
\hline & Treatment A & Control & $\begin{array}{l}p \text {-value } \\
\text { (t-test) }\end{array}$ & Treatment B & Control & $\begin{array}{l}p \text {-value } \\
\text { (t-test) }\end{array}$ \\
\hline Output & 114.0 & 116.1 & 0.692 & 118.6 & 119.4 & 0.885 \\
\hline \multirow[t]{3}{*}{ (stage 1B) } & $(3.257)$ & $(3.857)$ & & $(3.442)$ & $(4.385)$ & \\
\hline & $\mathrm{N}=200$ & $\mathrm{~N}=100$ & & $\mathrm{~N}=200$ & $\mathrm{~N}=100$ & \\
\hline & $\begin{array}{l}\text { Break with } \\
\text { information } \\
\text { update }\end{array}$ & $\begin{array}{l}\text { Break without } \\
\text { information } \\
\text { update }\end{array}$ & & $\begin{array}{l}\text { Break with } \\
\text { information } \\
\text { update }\end{array}$ & $\begin{array}{l}\text { Break without } \\
\text { information } \\
\text { update }\end{array}$ & \\
\hline Output & 123.4 & 136.0 & 0.068 & 153.3 & 127.0 & 0.000 \\
\hline \multirow[t]{2}{*}{ (stage 2B) } & (4.282) & $(4.501)$ & & (3.193) & (4.366) & \\
\hline & $\mathrm{N}=200$ & $\mathrm{~N}=100$ & & $\mathrm{~N}=200$ & $\mathrm{~N}=100$ & \\
\hline \multirow{2}{*}{$\begin{array}{l}\text { Stage } 2 \text { - Stage } \\
1 \text { (t-test) }\end{array}$} & 9.4 & 19.9 & & 34.7 & 7.6 & \\
\hline & $p=0.03$ & $p=0.00$ & & $p=0.00$ & $p=0.13$ & \\
\hline
\end{tabular}

Notes: Grams of beans sorted for different experimental groups, standard errors of the means reported in parentheses. $p$-values refer to outcomes of a simple t-test. 
Incentives and Financial Institutions in the Development Process

Table 5: Piece Rates, Social Comparisons and Voluntary Effort II

\begin{tabular}{|c|c|c|c|c|}
\hline \multirow[b]{2}{*}{ High } & \multicolumn{2}{|c|}{$\begin{array}{c}\text { Beans sorted voluntarily: } \\
\text { first stage }\end{array}$} & \multicolumn{2}{|c|}{$\begin{array}{c}\text { Beans sorted voluntarily: } \\
\text { second stage }\end{array}$} \\
\hline & 4.190 & 4.271 & -8.970 & -10.195 \\
\hline & (6.39) & $(6.24)$ & $(7.21)$ & $(6.91)$ \\
\hline \multirow[t]{2}{*}{$S C$} & & & -12.560 & -13.480 \\
\hline & & & $(7.39)^{*}$ & $(7.47)^{*}$ \\
\hline \multirow[t]{2}{*}{$S C * H i g h$} & & & 38.830 & 40.349 \\
\hline & & & $(10.56)^{* * *}$ & $(10.47)^{* * *}$ \\
\hline Controls & No & Yes & No & Yes \\
\hline \multirow[t]{2}{*}{ Constant } & 114.693 & 96.028 & 135.970 & 120.768 \\
\hline & $(4.22)^{* * *}$ & $(7.99)^{* * *}$ & $(5.06)^{* * *}$ & $(8.82)^{* * *}$ \\
\hline R-squared & 0.002 & 0.023 & 0.061 & 0.087 \\
\hline Observation & 600 & 600 & 600 & 600 \\
\hline
\end{tabular}

Notes: Robust standard errors, clustered at the group level, reported in parentheses. Included controls are the variables included in Table $1 . * * *$ Coefficient significant at $1 \%, * *$ Coefficient significant at $5 \%$ and $*$ Coefficient significant at $10 \%$.

How does productivity during the voluntary task evolve after information about relative earnings had been shared? Observe there are two different dimensions to reduced reciprocity. First, subjects may refuse to participate in the task altogether. However such rejections were extremely rare and refusal rates hover around $1-2 \%$ across all experimental arms. We therefore refrain from an econometric analysis of this type of reduced reciprocity.

Second, subjects may participate in the task but supply little effort. This is analysed in the second row of Table 4. For this analysis we have included the non-compliers and gave them an output level of zero grams, so the results are akin to an intention to treat analysis. Similar results are obtained when focusing on the subsample of compliers (details available on request). Productivity 
of low piece rate workers is now negatively affected by the social comparison. This result is significant $(p=0.067)$. For voluntary tasks we find that, compared to the low piece rate members of their control group, workers in treatment arm A sort almost $11 \%$ less beans. This is akin to findings in the literature based on variation in fixed wages: subjects supply less effort hence shirking is cheap. This finding seems to emerge across cultural contexts. The same result emerges in the regression analysis summarized in columns 3 and 4 of Table 5. Negative social comparisons lower voluntary output by 12-13 grams.

By comparison, positive comparisons in the high piece rate treatment B extend beyond the "work for payment stages" of the experiment, because they sort some $20 \%$ more beans than high piece rate workers from their control group $(p=0.00)$. This immediately implies that, for the unpaid task, productivity in treatment arm $\mathrm{B}$ is much higher than in arm $\mathrm{A}(p=0.00)$. This result both emerges in the series of t-tests (Table 4) and the regression analysis (Table 5). Considering everything, it appears as if extrinsic motives dominate effort supply decisions during the paid stages of the experiment, and social comparisons have only a small role to play. However, subjects are aware of whether or not they have been treated "fairly." Both positive and negative comparisons affect effort supply during other stages of the work relation - beyond the contracted task - when shirking does not diminish own income.

\subsection{Discussion and conclusions}

Efficiency wage theory proposes that employers are willing to pay wages above the marketclearing wage, because in return workers are willing to supply extra effort. When effort is unobservable and non-contractible, such gift-exchange may be sustained as an equilibrium outcome if workers are altruistic (kind), inequality-averse, or wish to respect a reciprocal norm - 
Incentives and Financial Institutions in the Development Process

motives that presumably vary across cultural contexts. In this paper we analyse productivity in the context of a task where African workers are paid a piece rate, and where we vary piece rates across subjects to invite positive and negative social comparisons. An innovation of the paper is that we allow information about piece rate differentials to "spread naturally" among our sample of workers, rather than artificially priming its salience during the instruction stage.

While behavioural responses to variation in own piece rates are modest in our experiment, we conclude that social comparisons are an important determinant of productivity during voluntary follow-up tasks. Our results support the hypothesis of gift exchange between workers and employers, and point to social comparisons as an important mediating factor. In the absence of social comparisons, productivity differences between high and low piece rate workers are rather small. Introducing social comparisons does not fundamentally alter this finding, and outcomes appear to be dominated by extrinsic motives. We obtain weak support for the hypothesis that positive social comparisons invite extra effort during paid stages of the experiment, but this finding is only marginally significant.

Social comparisons enter much more prominently when extrinsic motives are eliminated, during the unpaid stages of the experiment. Our subjects supply less effort in a voluntary task after discovering their earlier piece rate was relatively low. In contrast, high piece rate workers become more productive following a positive comparison. This suggests the consequences of social comparisons extend beyond "contractible tasks" for which subjects receive payment, and that both positive and negative comparisons may matter for productivity.

Some of our findings deviate from earlier work. While perhaps part of this difference may be attributed to cultural differences across sample populations, we believe the nature of the payment 
regime helps to explain the divergence. Gift-exchange has been tested mainly in experiments based on hourly wages (and imperfect contracts), where working harder is readily interpreted as an act of altruism or reciprocal behaviour. However, since differences in hourly wages may be justified by underlying productivity differences, fixed wages may send an ambiguous signal about whether payments are fair or not. Instead, we base our study on exogenous variation in piece rates, where under-supplying effort is privately costly. Our findings are consistent with a scenario where extrinsic motives for effort dominate intrinsic ones. Writing about their results based on variation in fixed wages, Cohn et al. $(2014$, p.897) write “... we cannot translate our findings to a piece rate environment. With such a schedule, workers would still have an incentive to produce output." This is exactly what we find: any attenuating impact of negative comparisons appears to be dominated by extrinsic motives. But we also find that social comparisons may re-enter elsewhere in the labour relationship.

The effect of social comparisons on productivity can be formalized in various ways, or there are multiple candidate mechanisms linking comparisons to the supply of effort. Candidate mechanisms discussed in the literature include inequality aversion, status concerns, kindness, a desire for reciprocity or fairness, or context-specific respect for behavioural norms. Further research is necessary to distinguish between alternative theories.

It is important to mention a few caveats to our experimental design. First, while subjects mingled during the break, they "worked" in separate rooms. So subjects may believe that the difficulty of the task varied with the piece rate, which would attenuate incentives for social comparisons. However, the types of beans sorted during the experiment were well-known to the respondents (they are an important part of their daily diet), so during the break they could establish that the tasks were actually identical by discussing the details of their sorting experience. Second, the 
show-up fee was generous and so were the piece rates we offered even in the low piece rate treatment. While this does not eliminate the scope for social comparisons, we believe even low piece rate workers may have been rather satisfied with their earnings, possibly diminishing adverse impacts of negative comparisons. This could be the case, for example, if respondents not only compare their earnings to those of subjects in the other treatment arm, but also to those outside the experiment. Third, the experiments took less than half a day, which is of course a limited time span. It is an open question to what extent experimental findings such as ours extend beyond their specific setting. ${ }^{26}$

Notwithstanding these issues, we hope our experimental findings speak to the design of earning structures within organizations. Earlier work suggests pay inequality may reduce overall satisfaction and willingness to cooperate (see Pfeffer and Langton 1993, but also Bartling and von Siemens 2011 for evidence to the contrary). Our results imply that "low earners" will undersupply effort for voluntary tasks. Insofar as accurate and timely execution of such voluntary tasks by all workers is important to economic success, lowering the morale of part of the workforce implies an organizational risk. If favourable social comparisons invite reciprocal behaviour, it seems better to create a reference group outside the organization. If workers collectively compare themselves to workers from other organizations, and feel privileged or well-treated, this should arouse reciprocal behaviour. Interestingly, this implies a cross-organizational externality: one organization's earning structure will affect the morale and productivity of workers in other

\footnotetext{
${ }^{26}$ Another potential concern is that good news (positive comparisons) may spread more easily among the treatment group than bad news to avoid bad feelings among peers. In this case, treatment $\mathrm{A}$ is less intensively treated than treatment B. This potential concern follows directly from our choice to let knowledge about relative earnings diffuse "naturally" rather than via announcements of the experimenter.
} 
Wage Differentials and Workers' Effort

organizations. Understanding the strategic considerations implied by such outcomes is left for future research. 
Incentives and Financial Institutions in the Development Process

\section{Appendix 1: Detailed Variables Definition}

Male: dummy variable taking value " 1 " if participant is male.

Married/Engaged: dummy variable taking value " 1 " is participant is married or engaged.

Number of children: integer indicating number of children in the household.

Education: highest grade completed by the respondent.

Religion (Christians): dummy variable taking value "1" if participant religious affiliation is Christianity.

Tribe (Musoga): dummy variable taking value " 1 " if participant belongs to Basoga tribe.

Land size: land owned by the participant in acres.

High: dummy that takes a value of "1" for participants with high piece rate.

$S C$ : dummy that takes a value of "1" if participants were matched with other participants earning a different piece rate. 
Wage Differentials and Workers' Effort

Appendix 2: Experimental Design when information sharing is permitted.

\begin{tabular}{|c|c|}
\hline Treatment A & Treatment B \\
\hline \multicolumn{2}{|c|}{ Stage 1, sorting beans } \\
\hline $\begin{array}{c}\text { Low wage } \\
\mathrm{N}=200\end{array}$ & $\begin{array}{l}\text { Higher wage } \\
\qquad N=200\end{array}$ \\
\hline 30 min beans sorting-type $1\left(Q_{j}\right)$ & 30 min beans sorting-type $1\left(Q_{j}\right)$ \\
\hline $\begin{array}{c}\text { Receives a reward } \\
R_{j}=5^{*} Q_{j}\end{array}$ & $\begin{array}{c}\text { Receives a reward } \\
R_{j}=9^{*} Q_{j}\end{array}$ \\
\hline 5 min beans sorting--type 2 & 5 min beans sorting--type 2 \\
\hline Receives no reward & Receives no reward \\
\hline \multicolumn{2}{|c|}{ Participants converge in a common place for a drink and a snack for 20 mina } \\
\hline \multicolumn{2}{|c|}{ Stage 2, sorting beans } \\
\hline Low wage & Higher wage \\
\hline $\mathrm{N}=200$ & $\mathrm{~N}=200$ \\
\hline 30 min beans sorting-type $1\left(Q_{j}\right)$ & 30 min beans sorting-type $1\left(Q_{j}\right)$ \\
\hline $\begin{array}{c}\text { Receives a reward } \\
R_{j}=5^{*} Q_{j}\end{array}$ & $\begin{array}{c}\text { Receives a reward } \\
R_{j}=9^{*} Q_{j}\end{array}$ \\
\hline 5 min beans sorting--type 2 & 5 min beans sorting--type 2 \\
\hline Receives no reward & Receives no reward \\
\hline
\end{tabular}

Where $Q_{j}$ is quantity for type 1 for individual $j$ at stages 1 or 2 and $R_{j}$ is reward for individual $j$.

${ }^{a}$ This is done to allow for information sharing among the participants about the wage differences. 
Incentives and Financial Institutions in the Development Process

\begin{tabular}{|c|c|}
\hline Treatment A & Treatment B \\
\hline \multicolumn{2}{|c|}{ Stage 1, sorting beans } \\
\hline $\begin{array}{l}\text { Low wage } \\
\mathrm{N}=100\end{array}$ & $\begin{array}{l}\text { Higher wage } \\
\qquad N=100\end{array}$ \\
\hline 30 min beans sorting-type $1\left(Q_{j}\right)$ & 30 min beans sorting-type $1\left(Q_{j}\right)$ \\
\hline $\begin{array}{c}\text { Receives a reward } \\
R_{j}=5^{*} Q_{j}\end{array}$ & $\begin{array}{c}\text { Receives a reward } \\
R_{j}=9^{*} Q_{j}\end{array}$ \\
\hline $\begin{array}{l}5 \text { min beans sorting--type } 2 \\
\text { Receives no reward }\end{array}$ & $\begin{array}{c}5 \text { min beans sorting--type } 2 \\
\text { Receives no reward }\end{array}$ \\
\hline \multicolumn{2}{|c|}{$\begin{array}{l}\text { Participants converge in a common place for a drink and a snack for } 20 \text { min but } \\
\text { information sharing is controlled by letting each group meet separately. }\end{array}$} \\
\hline \multicolumn{2}{|c|}{ Stage 2, sorting beans } \\
\hline Low wage & Higher wage \\
\hline $\mathrm{N}=100$ & $\mathrm{~N}=100$ \\
\hline 30 min beans sorting-type $1\left(Q_{j}\right)$ & 30 min beans sorting-type $1\left(Q_{j}\right)$ \\
\hline $\begin{array}{l}\text { Receives a reward } \\
\qquad R_{j}=5^{*} Q_{j}\end{array}$ & $\begin{array}{l}\text { Receives a reward } \\
\qquad R_{j}=9^{*} Q_{j}\end{array}$ \\
\hline 5 min beans sorting--type 2 & 5 min beans sorting--type 2 \\
\hline Receives no reward & Receives no reward \\
\hline
\end{tabular}

Where $Q_{j}$ is quantity for type 1 for individual $j$ at stages 1 or 2 and $R_{j}$ is reward for individual $j$. 
Wage Differentials and Workers' Effort 


\title{
Mitigating Natural Disaster Effects on Economic Growth.
}

\author{
The Role of Microfinance Institutions.
}

\begin{abstract}
In this study we explore whether microfinance institutions (MFIs) are able to mitigate the adverse macroeconomic consequences of disasters on: (1) economic growth and (2) economic sector specific growth. For this purpose we use a panel model including over 80 countries for the period between 1995 and 2010. Our main findings suggest first that natural disasters only have an adverse effect on the performance of the agricultural sector. However, access to lending facilities from MFIs mitigates about $35 \%$ of this negative effect. The extent to which MFIs are able to mitigate these effects depends to a large degree on their nature i.e. their organisational structure, profitability, legal status, age and the number of the clients they serve.
\end{abstract}

Publication status: Sseruyange, J. and Klomp, J. (2018). Mitigating Natural Disaster Effects on Economic Growth. The Role of Microfinance Institutions. Working paper. 


\section{Mitigating Natural Disaster Effects on Economic Growth}

\subsection{Introduction}

Since the 1970s the frequency and severity of natural disasters have risen dramatically. For example, a devastating earthquake hit Haiti in 2010 causing over 250.000 deaths. In November 2013, typhoon Haiyan ravished parts of Taiwan, China, Vietnam and Philippines causing several landfalls and mudslides that resulted into 6.300 deaths, nearly 17 million people being affected and an estimated damage exceeding US\$9.7 billion. These are only two recent examples of extreme events caused by forces of nature that have occurred in the last decade. More worrying is that the situation may even worsen in the coming decades since natural disasters are often linked to the ongoing process of climate change (IPCC, 2007).

Even if, a lot of mitigation effort has been undertaken by many governments and international organizations around the globe, the problem has remained prevalent especially in developing countries. More than 80 percent of the vulnerable population identified lives in Africa, Asia or Oceania (EM-DAT, 2015). This prevalent problem in these countries is explained by a combination of three features that are most present in developing countries: a higher physical exposure in many areas (e.g. proximity to temperature thresholds), a higher economic vulnerability to climate events (e.g. heavier reliance on agriculture) and a lower adaptive capacity (i.e. a lower ability to deal with climate stress) (Raddatz, 2009; Loayza et al., 2012; Fomby et al., 2009; Noy, 2009) .

There is a general consensus in the empirical literature that natural disasters cause a shortfall in the output produced, at least in the short run, leading to a negative deviation of the balanced growth path (Skidmore and Toya, 2002; Raddatz, 2009; Loayza et al., 2012; Cavallo et al., 2013; Mechler, 2003; Narayan, 2003; Rasmussen, 2004; Strömberg, 2007a). The production of a country is mainly 
Incentives and Financial Institutions in the Development Process

under a downward pressure due to the large-scale destruction of the productive capital stock. Thus, one of the key mitigation strategies is to stimulate the immediate provision of capital in the aftermath of a disaster. The promptly provision of aid, FDI or loans following a disaster to the affected areas makes it possible to reinvest by firms and smooth consumption by households. Besides new capital often embeds a more advanced technology than the destroyed capital creating a better long run perspective of a country (Loayza et al., 2012; Klomp and Valckx, 2014). So a successful recovery after a natural disaster starts with the possibility to reinvest which in turn is indisputably related with the access to credit. This view is empirically confirmed by Melecky and Raddatz (2015), Von Peter et al. (2012) and McDermott et al. (2014) who find the degree of financial development to be an important factor in addressing the macroeconomic consequences of a disaster. This is done through lifting of the financial constraint faced by the private sector in the aftermath. Already in the pre-disaster period developed financial markets serve a crucial role by creating opportunities for investing in precautionary measures or infrastructure that can withstand disaster effects. However, there are still two major gaps remaining in the literature that this paper tries to fill.

First, in developing countries the majority of households and private firms have only limited access to formal credit markets (Chaia et al., 2013). When credit markets are missing or incomplete, as in many rural areas in developing countries, households are forced to dispose their productive assets after a natural disaster to finance consumption. This will jeopardize future growth prospects of households or even worse trap them into poverty. Yet, it is exactly these particular countries that are the most exposed to large-scale natural disasters. According to figures reported by EMDAT, at least a quarter of the least developed nations have been hit by between two to eight major disasters per year in the last two decades (EM-DAT, 2015). 


\section{Mitigating Natural Disaster Effects on Economic Growth}

One alternative to formal finance is microfinance. Microfinance has become one of the most important intermediaries in the financial sector in developing countries and is regarded as one of the most successful poverty reduction policies. Many of their borrowers are socially excluded and lack access to conventional credit systems. Microfinance helps poor households in the sense that once they obtain credit from a microfinance institution, they will be able not only to enhance their income and consumption levels, but also to improve their tolerance against idiosyncratic income shocks through the improved access to credit (Armendariz and Morduch, 2005; Collier et al., 2013).

It is already documented in a number of case studies that microfinance enhances economic recovery after a natural disaster. For instance, Shoji, (2010) finds MFIs in Bangladesh to have used a contingent repayment system (rescheduling of weekly saving and instalments) to reduce the repayment pressure on the victims of the 1998 floods. The reduced repayment pressure on the victims played a significant role in the recovery process since it worked as a kind of safety net. The study also revealed that because of this contingent repayment system, the probability for people skipping meals during the shock reduced by 5.1 percent. More so, Berg and Schrader, (2012) combined information from a Ecuadorian microfinance institution together with geophysical data on natural disasters to study the effects of unpredictable shocks on loan demand and access to credit. Their findings showed that microcredit helped the victims of Tungurahua volcanic eruption to recover especially through loan provisions. Similarly, Anand Kumar and Newport, (2005) argue that microfinance should be recognised as one of the key disaster risk management strategies designed to help disaster victims especially the poor households. According to Kumar and Newport, MFIs provide a range of financial services (informal and flexible financial instruments) to the poor for disaster mitigation not only at the community-level but also within the informal economy. This is 
Incentives and Financial Institutions in the Development Process

supported by Pantoja, (2002) who maintains that poor households mainly rely on informal though market based social and financial services. Pantoja observes that after a disaster, affected areas tend to experience a significant reduction in housing, health and education provisions, an increase in unemployment, a temporary shortage of food plus interruptions in agricultural, industrial and service provisions for which the social and financial services provided by MFIs try to mitigate. However, he further points out that the achievements of an MFI can be erased by a single disaster or undermined by repeated disasters whereby causing them to become vulnerable. Consequently, the operational and financial sustainability of such MFIs can be compromised especially if the frequency of the disasters is high.

The second gap we try to fill is related to the non-uniform relation between natural disasters and sector-specific economic development and the potential effectiveness of MFIs on this outcome. As already demonstrated by Loayza et al. (2012), the economic effects of natural disasters cannot be framed within one-sector growth models using an aggregate production function. For example, there is no reason to assume that natural disasters would affect the various economic sectors present within a country to the same extent or even in the same direction. Droughts, for example, exhaust the availability of water as an input to agriculture, while earthquakes are especially a threat to the capital-intensive industrial sector. Hence aggregate growth analyses mask and conflate such differences, which could lead to the puzzling conclusion of nil or ambiguous effects of natural disasters on overall economic development (Altay and Ramirez, 2010; Loayza et al., 2012). Based on this latter observation, the response of MFIs to disaster effects might also differ between economic sectors that are being affected. For example, MFIs may be reluctant in responding to agriculturalists' demands following a disaster due to the high expected default rate associated with farmers in the aftermath. Contrariwise, if industries and services have taken appropriate 


\section{Mitigating Natural Disaster Effects on Economic Growth}

precautionary measures that lower their vulnerability or the extent of damages, their chance of defaulting is reduced (Brown et al., 2008; Ofori, 2002).

Our main contribution to existing literature is twofold. First, we examine whether the relationship between sector-specific economic development and natural disasters relies on the access to the lending facilities provided by MFIs. Second, we try to relate the observed differences across sectors to the nature of particular MFIs being active in a country. Some MFIs operate as regulated banks and are serving a large number of poor households, while others operate more as a nonprofit organizations benefiting only a small number of clients (Miamidian et al., 2005).

For this purpose, we use a panel model including data on natural disasters extracted from the GAME dataset provided by CESifo for a period between 1995 and 2010. We include over 80 low and middle-income countries. The dataset contains detailed information about the exogenous exposure of a specific country to a natural hazard. Moreover, the data used on access to MFI is based on the number of borrowers provided by Mix Market. This dataset includes detailed balance sheet information for more than 1,200 MFIs in over 100 countries. Finally, data on sector-specific economic performance (i.e., agriculture, industry and service sector) are taken from the World Development Indicators (World Bank, 2015).

Our main findings suggest first that natural disasters put a downward pressure on the performance of the agricultural sector only. However, part of the disaster shock caused by natural disasters can be mitigated through an improved access to the lending facilities provided by MFIs. To be more specific, access to MFIs mitigates about $35 \%$ of the initial negative effect. The extent to which MFIs are able to mitigate these effects differs between institutions and depends to a large degree 
Incentives and Financial Institutions in the Development Process

on their nature i.e. their organisational structure, profitability, legal status, age and the number of clients they serve.

The remainder of the paper is structured as follows. Section 2 describes the data and methodology used. Section 3 shows our results which indicate that microfinance institutions are able of mitigating the macroeconomic consequences of disasters especially to agriculture than for industry and service sectors, while the final section offers the conclusions.

\subsection{Data and Methodology}

\subsubsection{Data}

Our aim is to estimate the impact of natural disasters on economic growth and to see to what extent this effect relies on the access to MFIs' lending facilities in a particular country. One of the main challenges in the literature about the macroeconomic impacts of natural disasters is the identification strategy of these events as they are the product of hazard, exposure and vulnerability (Felbermayr and Gröschl, 2014). Most scholars agree that a large part of the hazard to a natural event is beyond government control or can be affected by the behaviour of a single person (exogenous). In contrast, the exposure and vulnerability part of a disaster event, in terms of the number of people affected or physical damage created, depend to some extent on the socioeconomic situation or government choices made (Neumayer et al., 2014). For instance, the total damage created by a disaster is often positively related to the level of income, while the number of people affected is negatively affected by the level of income.

To estimate the impact of natural disasters, it is therefore important to separate the exposure and vulnerability element from the natural disaster impact and focus exclusively on the hazard part. Hence, we should use detailed information about the physical strength of natural disasters - 


\section{Mitigating Natural Disaster Effects on Economic Growth}

earthquakes, storms, floods, droughts. The data on the physical magnitude of natural disasters and their impact are documented in the GAME dataset collected by CESifo.

First, a flood is recognized in a particular month when precipitation is more than five times the monthly long-average or when in a specific month rainfall is more than half of the long run yearly average rainfall. Second, a drought is recorded in a country-year when at least three subsequent months have rainfall below fifty percent of the long-run average monthly mean, or if at least five months within a year have rainfall below fifty percent of the long-run monthly mean. Third, an earthquake is considered when the magnitude of the seismic event is above 4 on the Richter scale. Below this threshold it is almost not felt by people and does not cause any damage. Finally, a storm should at least be at the score one on the Saffir-Simpson Hurricane Wind Scale index which is equivalent to a wind speed of about $119 \mathrm{~km} / \mathrm{h}$. In total there are more than 2,000 natural disasters recognized in our period of analysis. Floods are the most common type of natural disasters. More than half of the natural disasters are recognized in this category. In turn, less than 5 percent of the natural disasters is classified as droughts.

To determine the impact of natural disasters on economic development, we construct for each country-year a disaster count variable that takes the timing of a disaster in the course of a year into account. This allows catastrophes happening at the beginning of the year to have a different impact than those that happen near the end of the year.

$$
\text { disaster }_{i t}= \begin{cases}\frac{\sum\left(\left(12-M_{k t}\right) / 12\right)+\sum\left(M_{n t-1} / 12\right)}{\rho_{i}} & \text { (post)disaster year } \\ 0 & \text { otherwise }\end{cases}
$$


Incentives and Financial Institutions in the Development Process

Since the contemporaneous impact of a disaster within one year is considered, our annual disaster measure is calculated as the weighted sum of disasters $k$ that happened in the current year $t$ and the disasters $\mathrm{n}$ that occurred in the previous year $t-1$. We weighted this sum by the month $M$ when the respective disaster happened. That is, we assign the value $(12-M) / 12$ to a disaster year and $M / 12$ to the post-disaster year. In all other years its value is set to zero. Using a count measure puts equal weight to the disaster events. This has the advantage of reducing the influence of outlier events at the upper end of the disaster distribution. Besides, a country that is hit more than once by a major disaster in the same year will suffer a sharper increase in the external default risk than a country which suffers only a single incident. We normalize the number of disaster events by the land area of a country $i$ in $1,000 \mathrm{~km}^{2}$, represented by $\rho_{i}$. Obviously, larger countries have a higher probability of experiencing a natural event. When, for instance, Argentina is hit by a hurricane the consequences for the economy as a whole is likely to be smaller than when Haiti is hit by the same hurricane. Especially small island states are extremely vulnerable because of the higher frequency of natural disasters that have a disproportionately large impact on their economy (Skidmore and Toya, 2002; Gassebner et al., 2010; Pelling et al., 2002; Freeman et al., 2003; Rasmussen, 2004) .

The data on MFIs is taken from MIX market, a global web-based microfinance information platform $^{27}$. The MIX Market dataset includes information from more than 1,200 MFIs, controlling a total asset of over 100 billion US dollar and serve more than 60 million borrowers. The financial data includes balance sheets, income statements and detailed portfolio report information. MIX market reviews the data against audits and ratings and uses trend data and industry benchmarks for accuracy. The data is further reviewed against more than 150 business rules to identify potential reporting errors. This database has been widely used in the microfinance literature (Cull et al.,

\footnotetext{
${ }^{27}$ www.mixmarket.org
} 


\section{Mitigating Natural Disaster Effects on Economic Growth}

2009; Gonzalez. 2007; Krauss and Walter, 2009; Mersland and Strøm, 2009, 2010; Hermes et al., 2011; Galema et al., 2011) ${ }^{28}$. We base our indicator of access to MFIs on the number of active borrowers in a particular country as a share of total population. This indicator is widely used in a number of studies to measure the access to or outreach of MFI activities (Gutiérrez-Nieto et al., 2009; Tchakoute-Tchuigoua, 2010; Hartarska, 2005). Finally, sector-specific output per capita data and data on real GDP growth are taken from the World Development Indicators (2015).

\subsubsection{Empirical model}

In this section we develop our empirical model. We estimate the following model using an unbalanced panel that includes over 80 low and middle-income countries between 1995 to 2010 .

$$
\begin{aligned}
\Delta \ln y_{i, t}= & \propto_{i}+\beta_{0} \ln y_{i, t-1}+\beta_{1} \text { disaster }_{i, t}+\beta_{2} m f i_{i, t}+\beta_{3}\left(\text { disaster }_{i, t} * m f i_{i, t}\right)+X_{i, t-1}^{k} \\
& +\delta_{t}+\varepsilon_{i t}
\end{aligned}
$$

Where $\Delta \ln y_{i t}$ represents the annual growth rate of each sector-specific value added per capita output (agriculture, service, industry) in constant terms or real GDP growth in country $i$ at year $t$. We include the output in the previous year (in logarithms) to control for auto-regressive tendencies; $X^{k}$ is a vector of (lagged) control variables containing $k$ elements ${ }^{29}$, while disaster $_{i, t}$ is our constructed disaster variable outlined above capturing the exogenous hazard exposure in a particular country-year. Moreover, $m f i_{i, t}$ is our variable that contains our microfinance

\footnotetext{
${ }^{28}$ Reporting to MIX market by MFIs is done on a voluntary basis, which may, at least potentially, have consequences for the reliability of the data. For instance, according to Beisland and Mersland (2012) the self-reporting nature of MIX market may cause a reporting bias since the data is not collected and verified by a third party. As a result there is potentially an over-representation of large MFIs in this dataset. However, this size bias is only minor. Mersland et al. (2011) compare the median loan portfolio reported in the Mix Market with information taken from credit rating reports provided by the Rating Fund II and find no big difference in the results.

${ }^{29}$ Refer to appendix 2 for the variable description.
} 
Incentives and Financial Institutions in the Development Process

accessibility indicator based on the number of active borrowers. Additionally, we include an interaction term disaster $_{i, t} * m f i_{i, t}$ in our specification to test for our hypothesis that access to lending facilities provided by MFIs mitigate part of the negative effect of disasters on economic growth. Logically, if our hypothesis holds, then we should observe a statistically significant positive coefficient $\left(\beta_{3}>0\right)$ on the interaction term. The parameter $\alpha_{i}$ is a country-specific intercept to control for time-invariant characteristics such as geographical factors. By using country-specific intercepts, we place the emphasis of our analysis on the identification of the within country variation over time. This approach reduces the influence of any potential selection bias that might arise, for example, if poorer countries were over-represented in the disaster data due to the likelihood that disasters have a higher hazard risk to such countries (McDermott et al., 2014). Furthermore, the time-fixed effects $\left(\delta_{t}\right)$ controls for shocks that affect all countries simultaneously. The final term $\varepsilon_{i t}$ is the error term.

We base our vector of control variables on the existing studies on the macroeconomic impact of natural disasters (Loayza et al., 2012; Albala-Bertrand, 1993; Kahn, 2005; Klomp, 2014). These control variables help us to capture the omitted variables bias and are related to the macroeconomic environment and financial sector policies. To be specific, we consider the following variables as our controls: inflation (growth rate in CPI), financial depth (private credit as a share of GDP), terms of trade (net barter terms of trade index), trade openness (exports plus imports as a share of GDP), government burden (government final consumption as a share of GDP) and education attainment (gross secondary school enrolment rate) (see, appendix 2 for the data description of the considered control variables).

The ability of MFIs to mitigate disaster effects might depend on their organisational structure. For instance, Some MFIs operate as banks while others operate as non-bank financial institutions 


\section{Mitigating Natural Disaster Effects on Economic Growth}

(Miamidian et al., 2005). Under non-bank financial institutions arrangement, MFIs can be categorised as non-governmental organisations (NGOs) and credit unions. This distinction between banks and non-bank MFIs can be attributed to the differences in lending terms such as interest rates charged on loans, types of loan products (with NGOs and credit unions having a possibility of providing grants or soft loans which is unlikely with banks) and the terms of loan replacement. Such differences in the lending terms can have great implications on the extent to which disaster victims can rehabilitate. Thus, the flexibility of MFIs in altering their lending rates especially during times of hardships can act as a fundamental policy action in ensuring that the pre-disaster living conditions for the victims are realised.

Besides the organisational structure, the response of MFIs in mitigating disaster effects can also depend on whether the institution is formally or informally operating. Many institutions which offer development programs in developing countries are typically informal including many MFIs. Such MFIs provide informal and flexible financial instruments for disaster mitigation at the community-level and within the informal economy (Anand Kumar and Newport, 2005). This is supported by Shoji, (2006) who maintains that during the 1998 flood in Bangladesh people accessed loans for rehabilitation from informal money lenders.

Additionally, the profitability status of MFIs also matters in disaster mitigation. MFIs raise their profits through loaning out of the clients' savings, donations and/or funds borrowed from external sources. However, during a disaster and soon after it, MFIs are faced with heavy withdraws, no fresh savings, non-repayment of existing loans (poorly performing loans) which can increase the portfolio-level problems of the MFI and even affect its solvency (Collier and Skees, 2012). Moreover, the MFIs' external borrowing can also be affected because of the reduced loan 
Incentives and Financial Institutions in the Development Process

repayment to their external lenders and thus, only MFIs with sufficient amounts of internally raised funds may remain supportive to their clients during a shock.

Finally, it is documented that the size of the MFIs' clientele influences their capacity to help disaster victims (Anand Kumar and Newport, 2007; Barnett and Mahul, 2007). During a disaster and soon after a disaster, many clients need capital to rehabilitate (Anand Kumar and Newport, 2007). However, some MFIs are found at a point of liquidity crisis given that individual savings and loan repayments reduce with a disaster. To make matters worse for the MFI, savings withdraws also increase. Thus, if many clients are severely affected by a disaster, the MFIs are more likely to fail to meet their financial demands. Moreover, the age of the MFIs also matters in defining their degree of efficiency, and consequently their capacity to deal with disaster effects. Hermes et al., (2011) reports that through the use of knowledge accumulated by old MFIs, new MFIs tend to be more efficient than old MFIs and this can play a great role in determining the extent to which a given MFI can help its clients when disasters occur.

\subsection{Empirical results ${ }^{30}$}

In this section we present our results. In columns (1)-(4) we report the results of a restrictive specification including only the initial level of output, the indicator for MFI access, the number of natural disasters (per square kilometre) and the interaction between the two latter variables. Even though, our main aim is to explore the sector specific impact of the mitigation process of MFIs for disaster effects, we also present the results of the growth rate of the aggregated real GDP ${ }^{31}$. Surprisingly, the results on the rate of change in the real GDP indicate that disasters have a significant positive effect on development, while the involvement of MFIs in the recovery process

\footnotetext{
${ }^{30}$ For summary statistics, please, see appendix 1.

${ }^{31}$ All coefficients are standardized by the average land size of our sample (764587.6 sq km).
} 


\section{Mitigating Natural Disaster Effects on Economic Growth}

staggers economic development. One rational explanation for this finding is that adding all economic sectors together causes these surprising results. As already explained above, disasters have a non-uniform impact across economic sectors (Loayza et al., 2012). Therefore we split in columns (2)-(4) aggregate GDP into three economic sectors: agriculture, industry and service. The results indicate that natural disasters stagger agricultural development, but benefit the service sector. The former result can be explained by the high vulnerability of the agricultural sector, while the latter result is explained by the resource inflows in terms of medical and housing facilities, food and other forms of relief in the aftermath. On the interaction term, we find that MFI accessibility reduces the impact of disasters in the agricultural sector. To be precise, the accessibility to MFIs reduces the impact of disasters by 35 percent $^{32}$. In turn, we find no mitigation effect in the industry and service sectors. One explanation for this is that MFIs tend to support for small loans which may not significantly help the overall growth or even growth in the industry and service sectors that require sufficiently large amounts of capital that sometimes MFIs cannot provide.

\footnotetext{
${ }^{32}$ Considering the median value of the MFI indicator in our sample, $\{(0.013 * 0.004) /(0.013 * 0.004)-0.0002\} * 100$.
} 


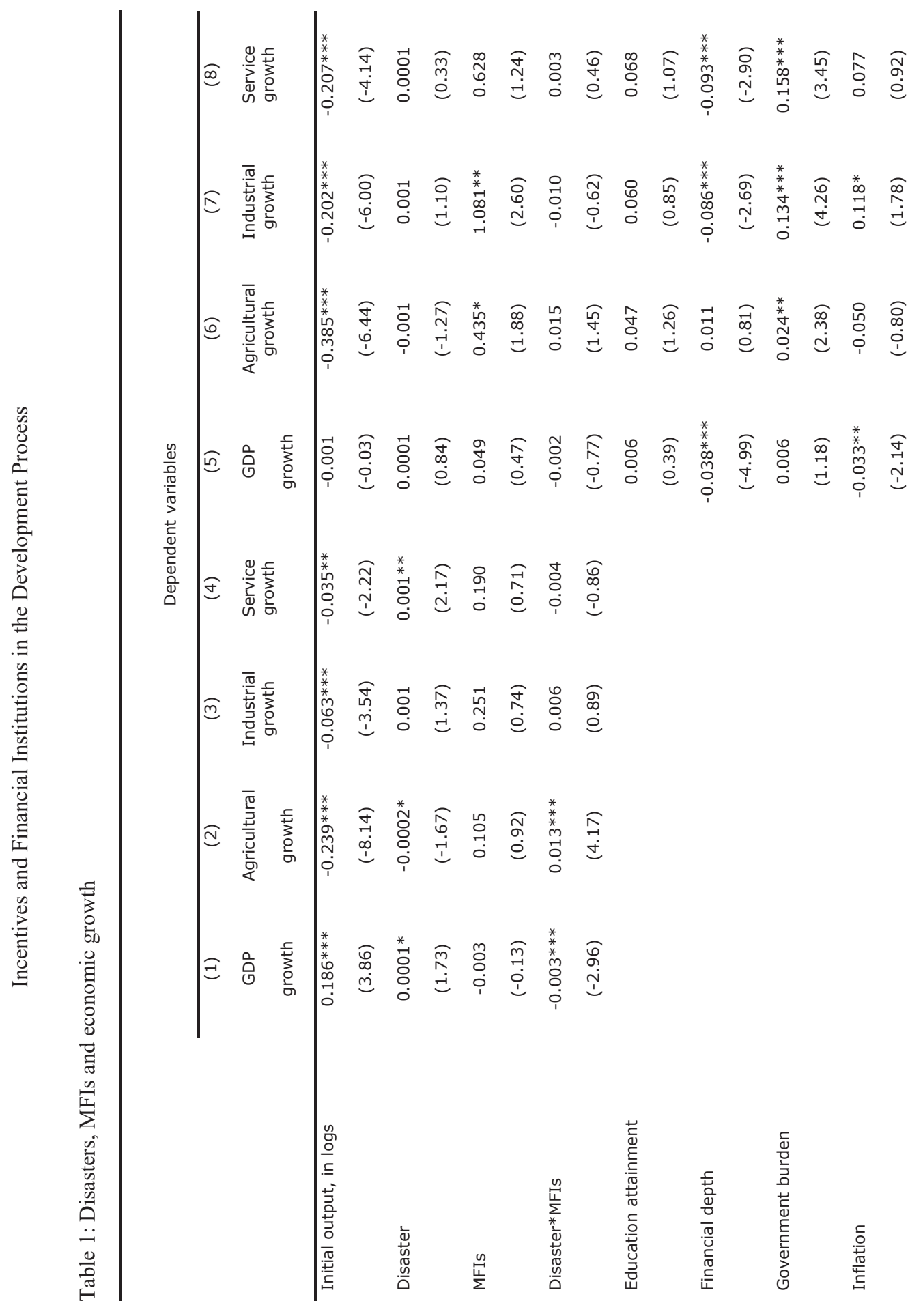




$$
\text { 涪 }
$$


Incentives and Financial Institutions in the Development Process

However, the results presented so far might be driven by the lack of control variables. Thus, suffering from omitted variables bias. In columns (5)-(8) we re-estimate the same models as before, yet, also including the control variables outlined in the previous section. Our findings indicate that we do not have any significant evidence of mitigating effect of MFIs in any of the models. However, adding additional controls to our models creates another concern as some of the data on the covariates are not available for all country-year making the panel data rather unbalanced. Including the suggested controls in one specification reduces our number of observations by about one-third. This in turn increases the potential of a sample selection bias due to the exclusion of many developing countries, while the majority of the damage caused by natural disasters occurs in these particular countries (Freeman et al., 2003). An alternative explanation for the insignificant results is that the set of MFIs included is rather heterogeneous. For instance, while some MFIs might effectively mitigate the disaster impact by providing liquidity, others may harm recovery by having hash repayment schedules or they might restrict lending which is normally related to their organisational structure. Thus, in table 2 below, we try to answer a question whether the nature of MFIs really matters in disaster mitigation. We consider our MFI indicator basing on MFI types (banks, NGOs and credit unions). These are also interacted with the disaster measure.

For the results in table 2 we can draw a number of conclusions. First, in any of the specifications reported disasters have a general or sector-specific effect. Second, in disregard of any disaster events, MFIs that operate as banks have a positive impact on the growth of the industrial and service sectors. In turn, cooperatives or credit unions have a negative effect on the service sector growth. More so, the results demonstrate that NGOs can stimulate the agricultural sector in case of a natural event while credit unions can do better for the service sector. One rational explanation for this finding is that cooperatives are normally owned and managed by self-selected group 


\section{Mitigating Natural Disaster Effects on Economic Growth}

members which makes it easier to decide and allocate resources to service provisions like health facilities, water and sanitation etc. while NGOs may be managed by people from outside the group who might dictate and allocate resources to agriculture so as to increase on food production because food shortage is easily observable. 


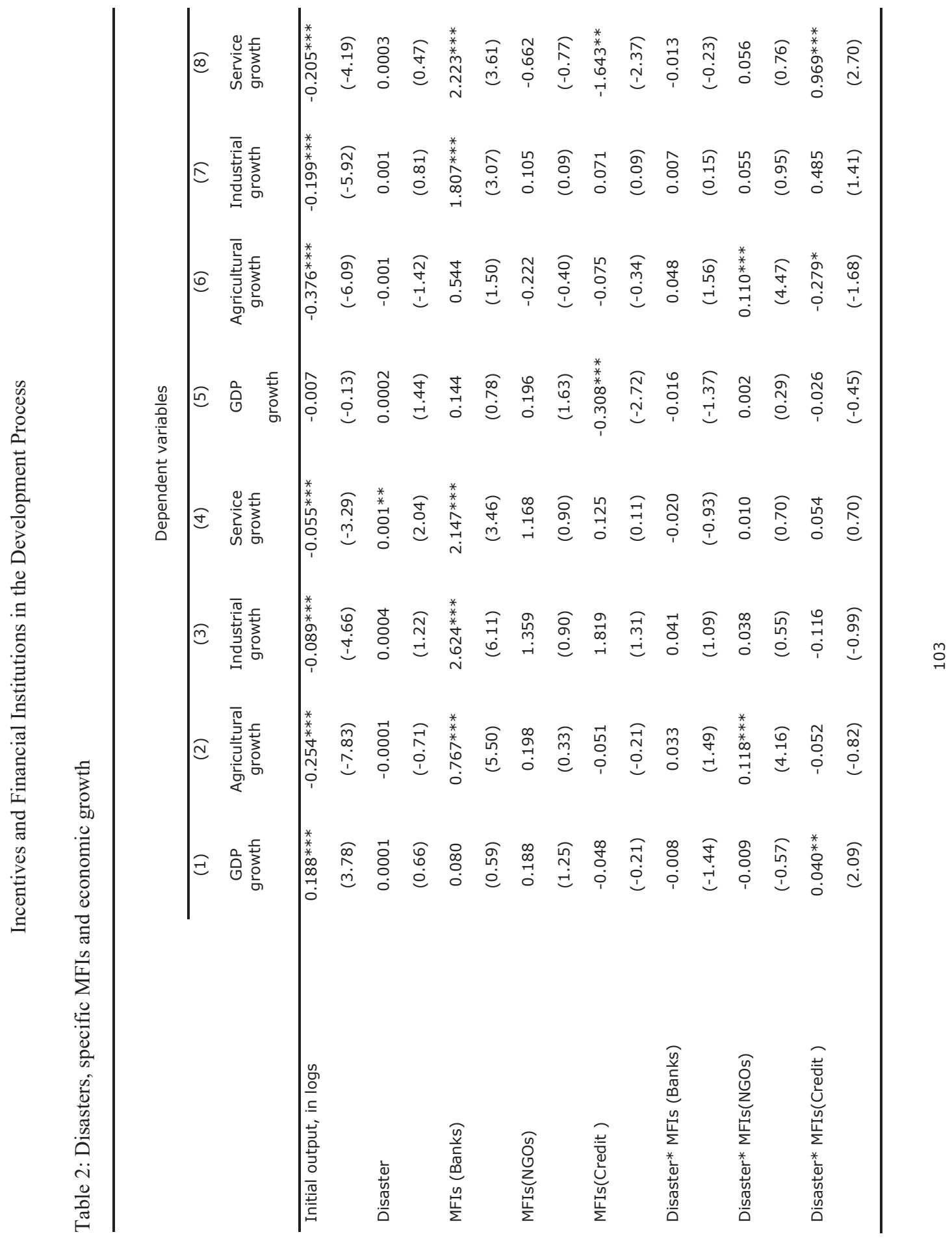




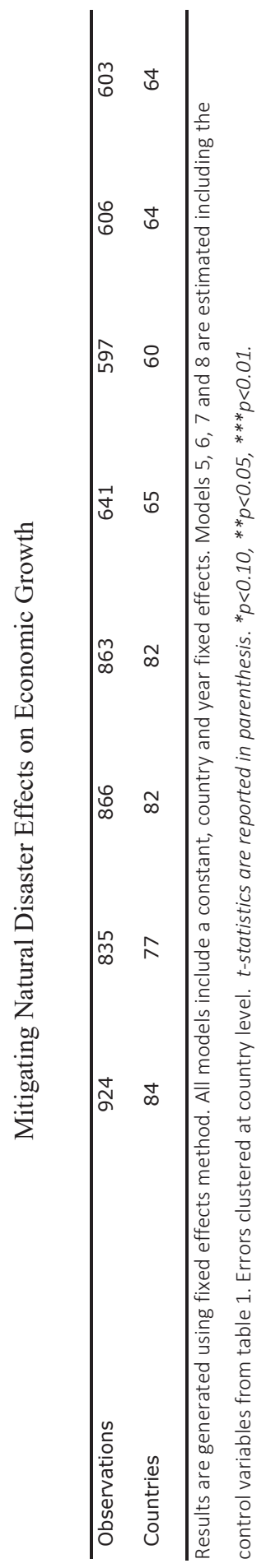


Incentives and Financial Institutions in the Development Process

Next, we explore whether it matters when an MFI is regarded as a non-profit or for profit intermediary. This examination is grounded on the argument that for profit intermediaries may not offer soft loans and are even more risk averse pertaining loan default. On the other hand, nonprofit intermediaries can easily provide soft loans or even alter their repayment procedures since their driving motive is not profit making. The results in Table 3 generally indicate that if we disregard of disasters, MFIs support for the growth of specific sectors. Surprisingly, we find no effect on the aggregate GDP growth possibly because of combining of all sectors in one variable. The reason why for profit MFIs are better in creating economic development is that they have the potential of selecting only the high return investment opportunities that might enhance economic development. Also they have a larger incentive in monitoring the activities of their clients. Due to their business model, these MFIs are usually also more subject to regulation. However, after a disaster, non-profit organizations are better able to stimulate recovery than for profit MFIs possibly because for profit MFIs can restrain from providing loans to victims due to the likely high risk of default, while non-profit MFIs may decide to extend assistance to victims with an aim of expanding their clientele. Secondly, for profit MFIs may stick to hard loan terms as compared to non-profit MFIs (which can offer soft loans) which instead affects their clients during the rehabilitation process. 


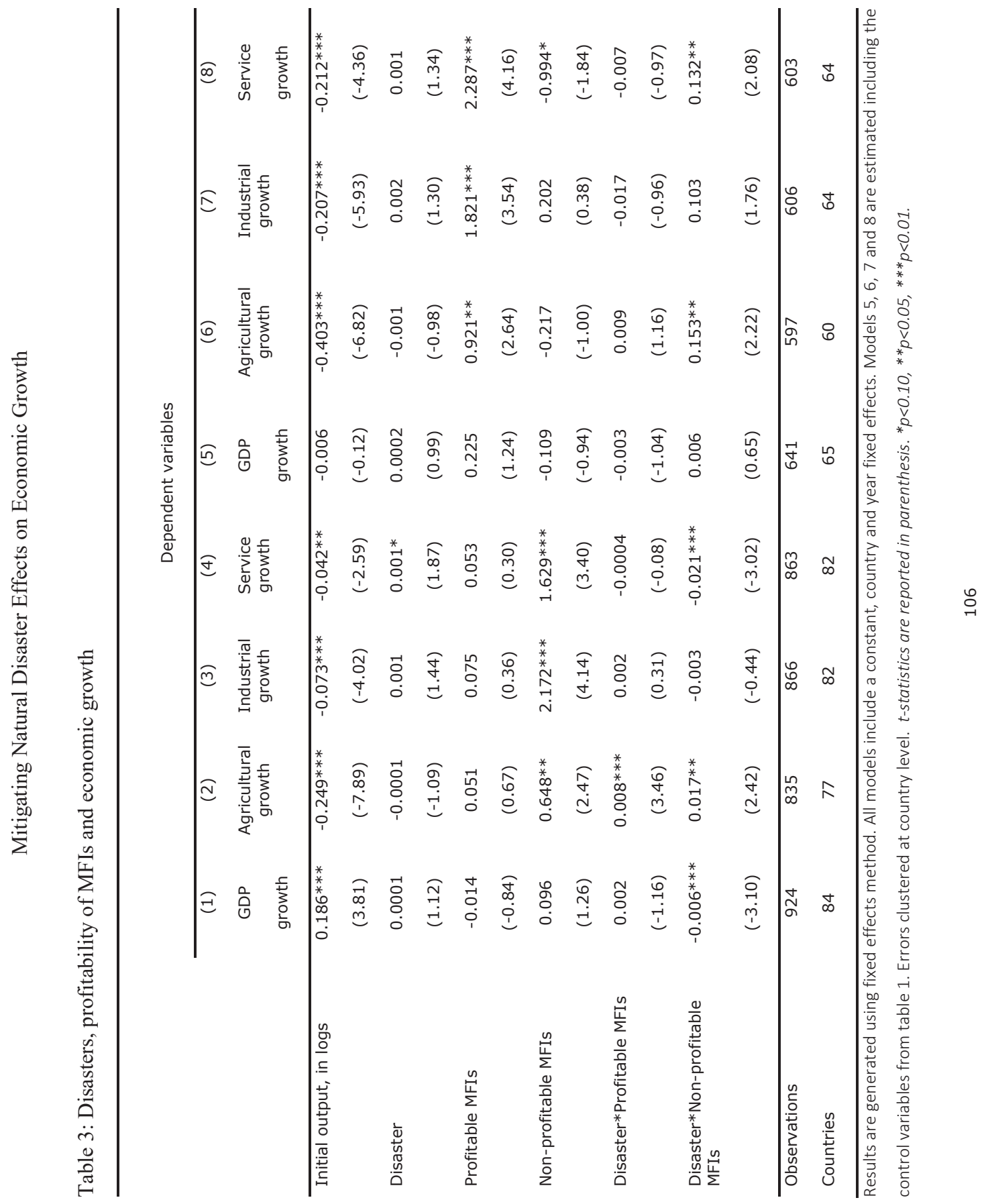


Incentives and Financial Institutions in the Development Process

We now turn to the legal status of MFIs. The legal status of any institution ascertains its legitimacy to operate in a given country. Secondly, it provides it with the legality of accessing funds from the government and other supporting institutions. For example, in Uganda fully registered MFIs can access funds from the microfinance support centre which is owned by the government to increase their liquidity. Upon this background, it becomes necessary to examine the behaviours of formal and informal MFIs when it comes to addressing disaster effects. It is documented Anand Kumar and Newport, (2005) and Shoji, (2006) that informal financial institutions play a fundamental role in dealing with disaster effects. These informal financial institutions provide not only informal credit especially to the poor but also provide informal insurance strategies that help the masses to guard against the disaster effects. Thus, we test the hypothesis that in developing countries informal financial insitutions are more supportive in helping disaster victims than formal institutions. To test for this, we estimate models when our MFI indicator is split along lines of regulated and non-regulated MFIs to proxy for formal and informal MFIs respectively. The results in table 4 suggest that during normal times, regulated MFIs are better able to stimulate economic development, while in times of hardship the story changes. This finding supports Anand Kumar and Newport, (2005) and Shoji, (2006) who observe that informal financial institutions play a fundamental role in dealing with disaster effects. The possible explanation for this finding could be in line with the binding conditions that regulated MFIs acquire after registration. For example, defining their area of operation, not giving out loans exceeding a certain amount, regulating of their capital base, defining of the beneficiaries' age groups etc.. Such restrictions may not apply to the non-regulated MFIs which puts them in a better position for helping the victims. 


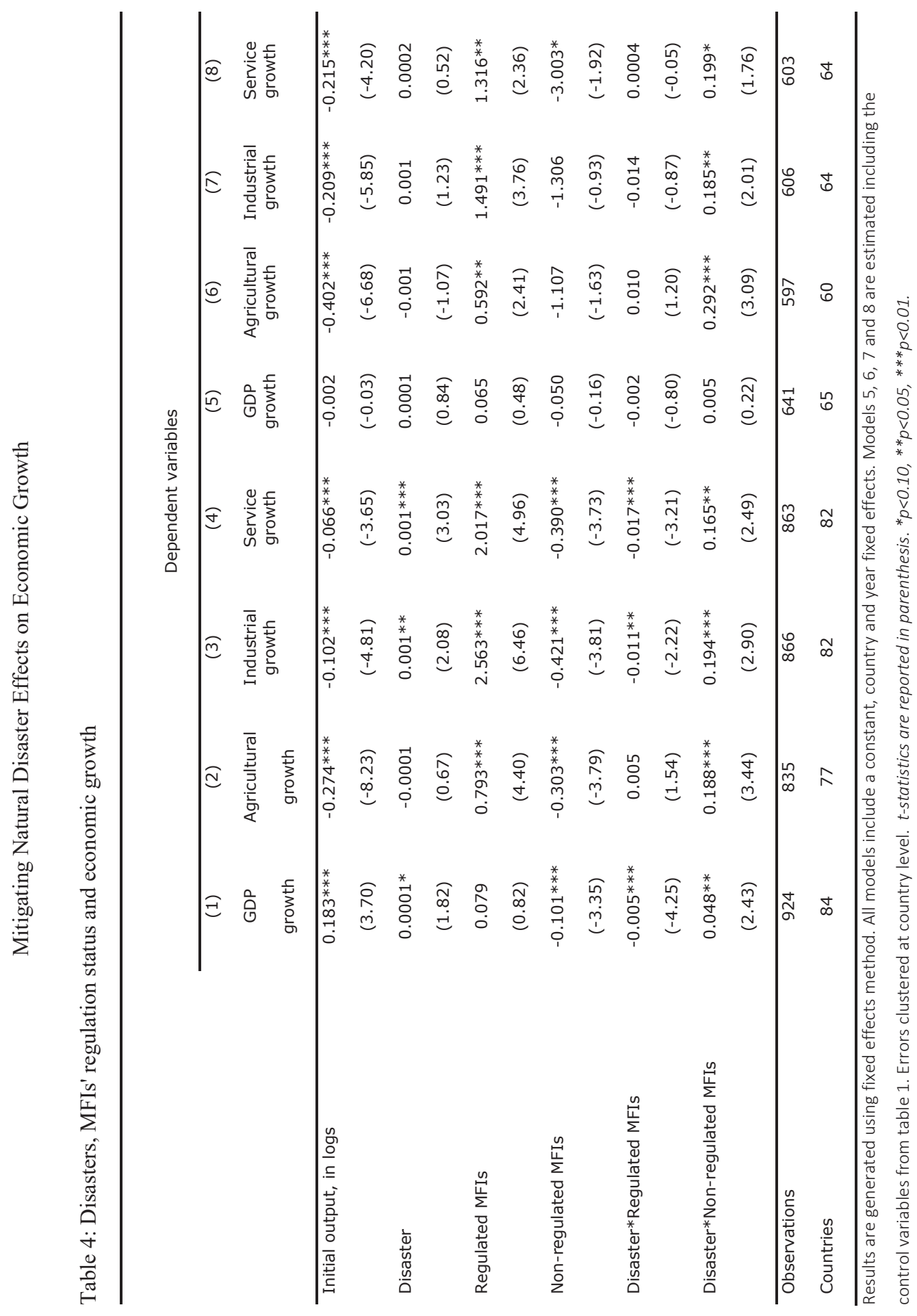


Incentives and Financial Institutions in the Development Process

Moreover, following Hermes et al., (2011) we also investigate whether the age of MFIs (measured as survival time since establishment) influences the extent of their intervention when dealing with disaster effects. Hermes et al., (2011) find old MFIs to be less efficient than new MFIs. They attribute this to knowledge acquisition by the new MFIs that is already accumulated by the old MFIs. We try to test for this with our data by introducing the MFI indicator in the analysis when it is split along lines of age (young and mature). In our analysis, young MFIs are constructed as a sum of new and young MFIs as classified by MIX market. The results in table 5 suggest that during normal times young MFIs are better in stimulating economic growth compared to mature MFIs. However, when disasters occur, mature MFIs seem to contribute more than young MFIs toward recovery. This argument is supported by the growth in the agricultural sector. One reason for this is that mature MFIs might have accumulated enough information about their clients making it easier to screen them for loans during hard times. This may not be possible for the young MFIs leaving them with limited options of restricting the loan amount and/or the number of loans. 


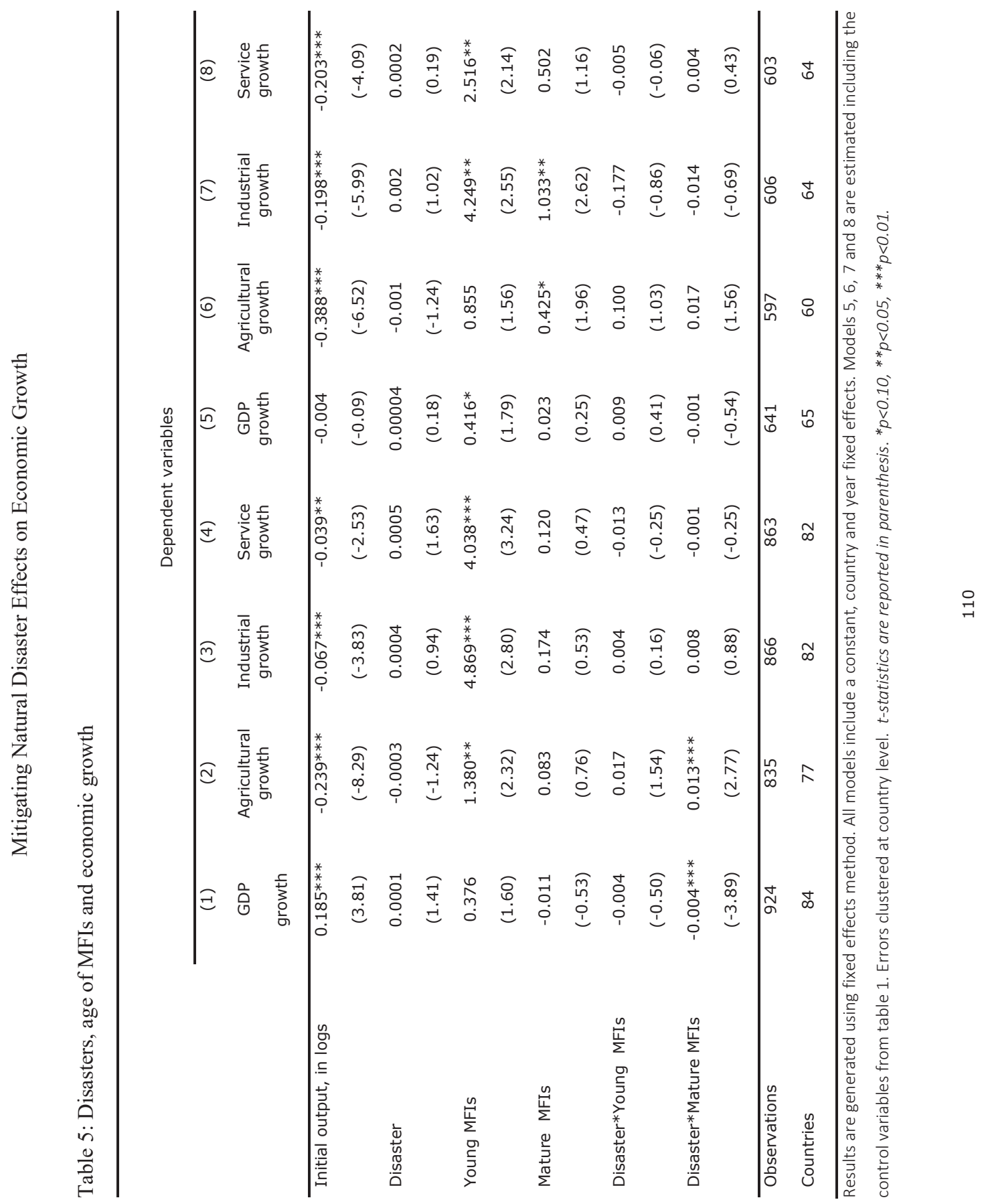


Lastly, besides age of MFIs, we further explore whether the number of clients served by MFIs can influence the extent of their intervention into the disaster mitigation process. As earlier discussed, during a disaster and soon after, many clients need capital to rehabilitate (Anand Kumar and Newport, 2007). As a result, many victims may apply for loans from the MFIs forcing them to be more selective in determining beneficiaries. Thus, their aggregate impact across regions or even among individuals may be significantly small. We test for this argument by splitting our MFI indicator along lines of outreach to proxy for the number of clients. The results in table 6 generally indicate that MFIs with large outreach potential boost economic growth during normal times and during times of a disaster. Their support is more evident in the agricultural sector. A similar result is revealed by the medium outreach MFIs (small outreach MFIs are only helpful in the restricted model 2). MFIs whose outreach capacity is relatively strong are likely to have a larger capital base compared to those with a smaller outreach capacity which enables them to support growth even during times of hardships. ${ }^{33}$

\footnotetext{
${ }^{33}$ We also test the argument that the extent to which MFIs can help disaster victims depends on their degree of transparency in distributing relief. We construct a dummy for diamond (see: www.mixmarket.org for the ranking of diamond). Our constructed dummy takes a value of 1 if the diamond score for the MFI is 4 and 5 and 0 otherwise. Our results suggest that when disasters occur, transparency of MFIs does not matter in aiding growth (detailed results are available upon request).
} 


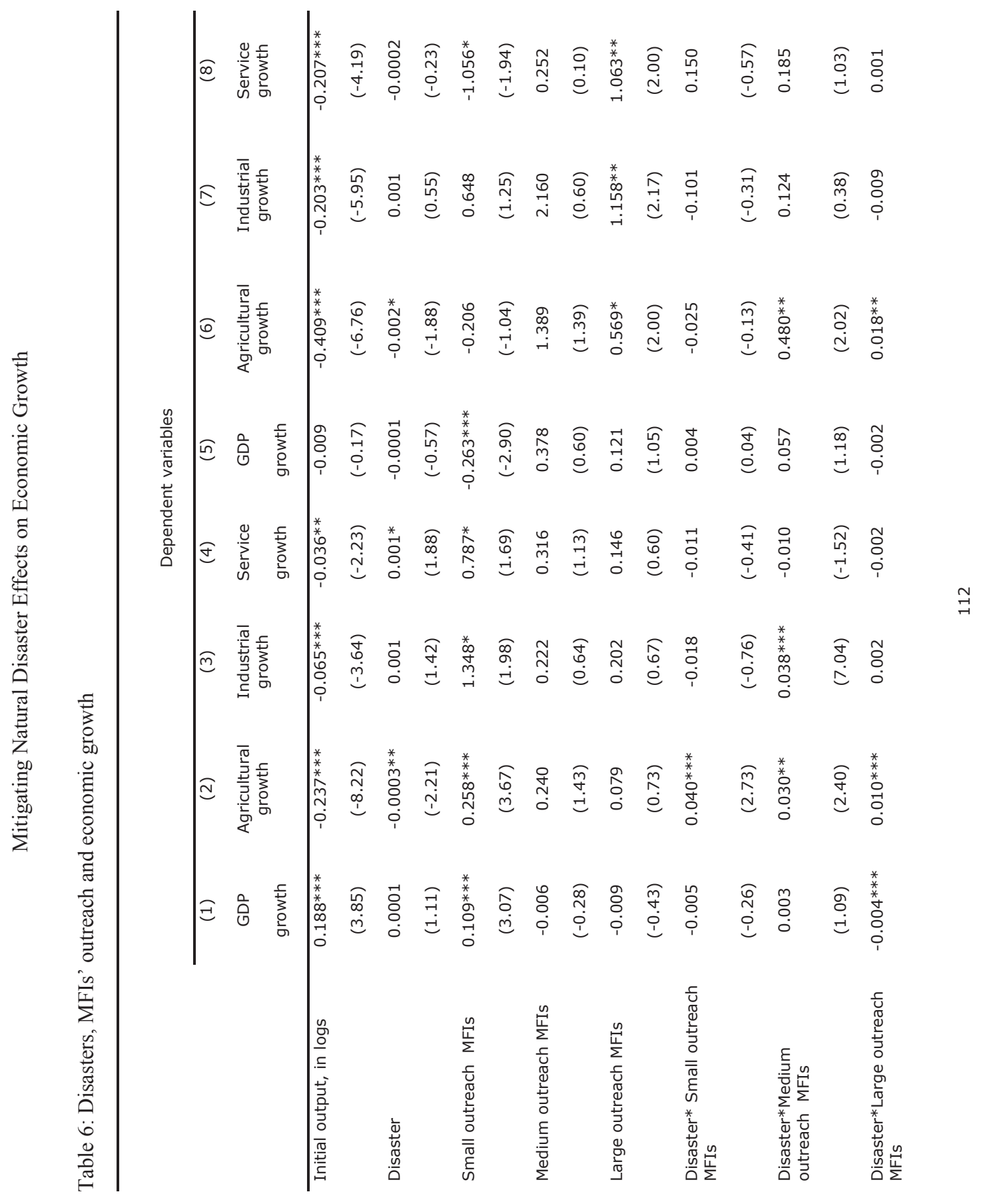




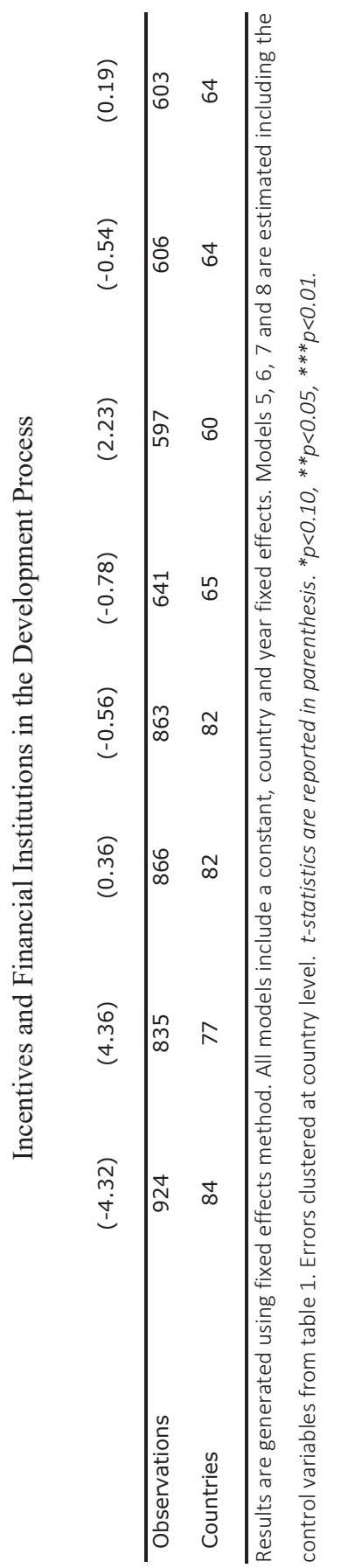




\section{Mitigating Natural Disaster Effects on Economic Growth}

\section{Robustness checks}

This section checks the robustness of our results to the effects of a lagged MFIs' indicator, specific disaster types, potential endogeneity and the dynamics of disasters to growth. First, the results presented in table 1 explain the contemporaneous effects of disasters to economic growth and the role of MFIs in mitigating these effects. However, one can argue that disasters also affect MFIs' activities say through destruction of their assets which in turn affects their degree of intervention. For this reason, entering our MFI accessibility indicator for a specific country-year may lender our results a doubt. To address this issue, we instead use the first lag of the MFI accessibility indicator and the corresponding interaction term in our regressions. The results in table 7 robustly support the findings in table 1 that in the aftermath, MFIs tend to remain more supportive to agriculture than to the other sectors. 


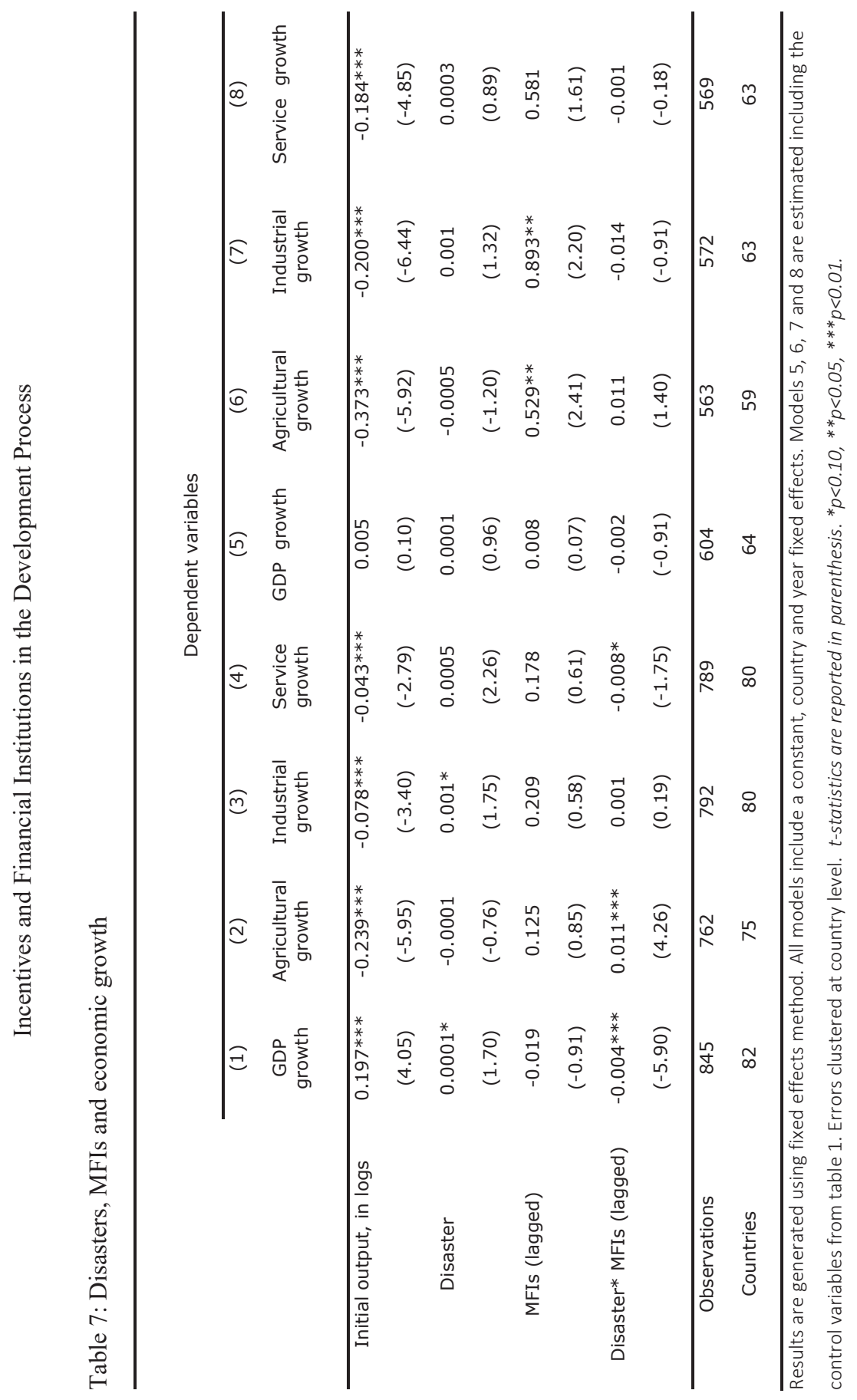




\section{Mitigating Natural Disaster Effects on Economic Growth}

Second, the growth models are re-estimated by including specific disaster types (droughts, floods, earthquakes and storms). Specific disasters have different impacts on aggregate growth and to specific sectors (Loayza et al., 2012). Moreover, we are also concerned about the heterogeneity of our sample in terms of MFIs. Put differently, the intervention of MFIs during a disaster event and in the aftermath may be significantly important in mitigating the effects of specific disasters and not to other disasters. As one would expect, results in table 8 indicate varying effects of specific disasters on economic growth. Floods impose a disastrous effect to the growth of the agricultural sector while earthquakes affect the industrial and service sectors. Some of these results seem not strange. For example, earthquakes are known of causing severe destruction to industrial infrastructure like buildings and machinery (Durukal et al., 2006) while floods majorly cause destructions on crops and other farm infrastructure (Devereux, 2007; Posthumus et al., 2009). On the interaction terms, results support our main finding that accessibility to MFIs in the aftermath reduces the impact of natural disasters in the agricultural sector. However, this impact is more evident with the occurrence of floods, storms and earthquakes. The probable explanation for these results is that, first, when disasters occur, farmers' output and farm infrastructure are normally severely destroyed which may not be the case for industry and service sectors. Second, because the majority of the MFIs' clients especially in developing countries are farmers, it becomes logical for these MFIs to support their clients to re-investment. The other results to note in table 8 point to the impact of MFIs to earthquake events. It is shown that accessibility to MFIs also reduces the adverse effects of earthquakes to aggregate growth. Not surprising because earthquakes can cause severe destructions within a short time period and thus, any intervention can easily be noticed. 


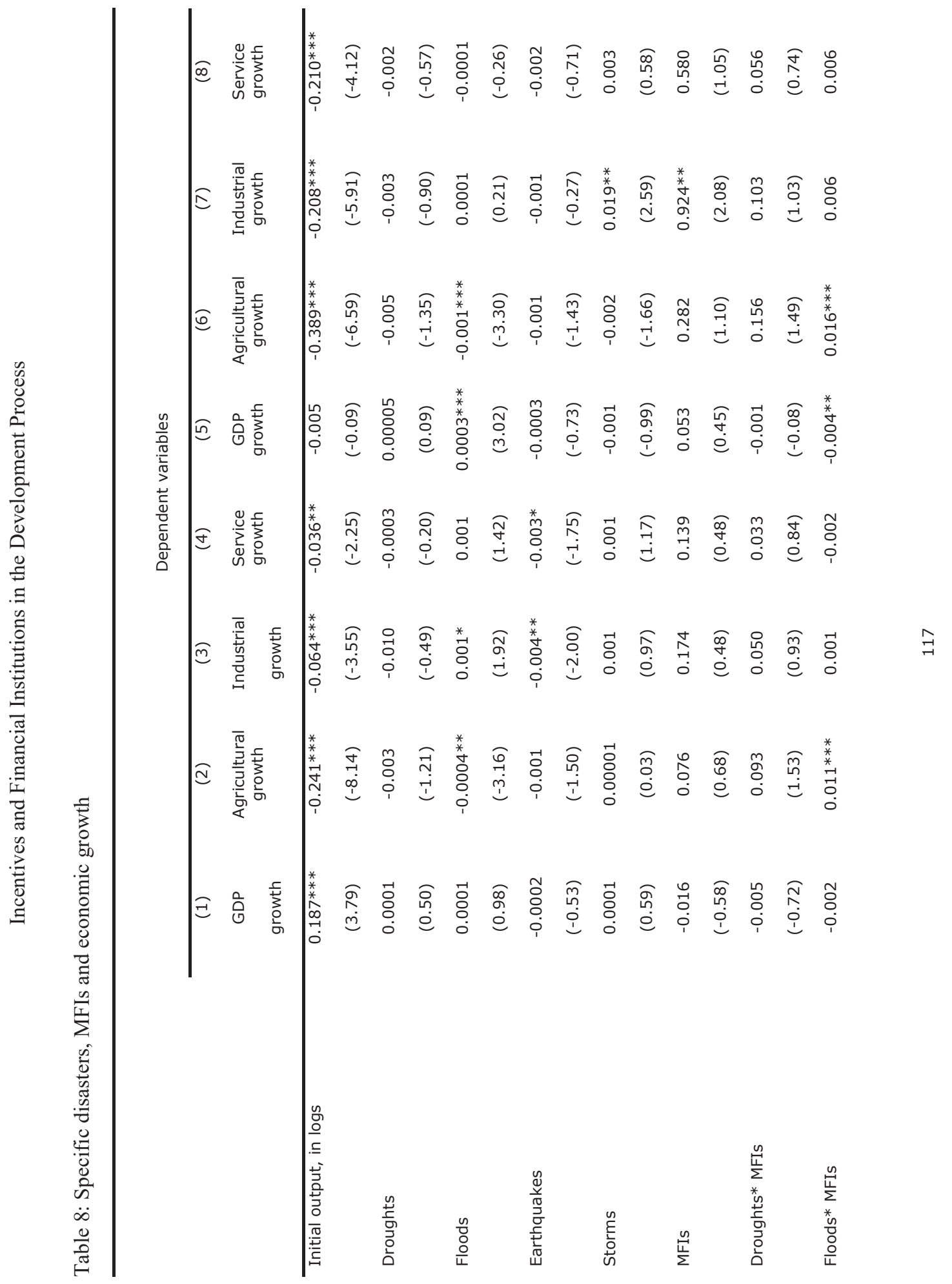




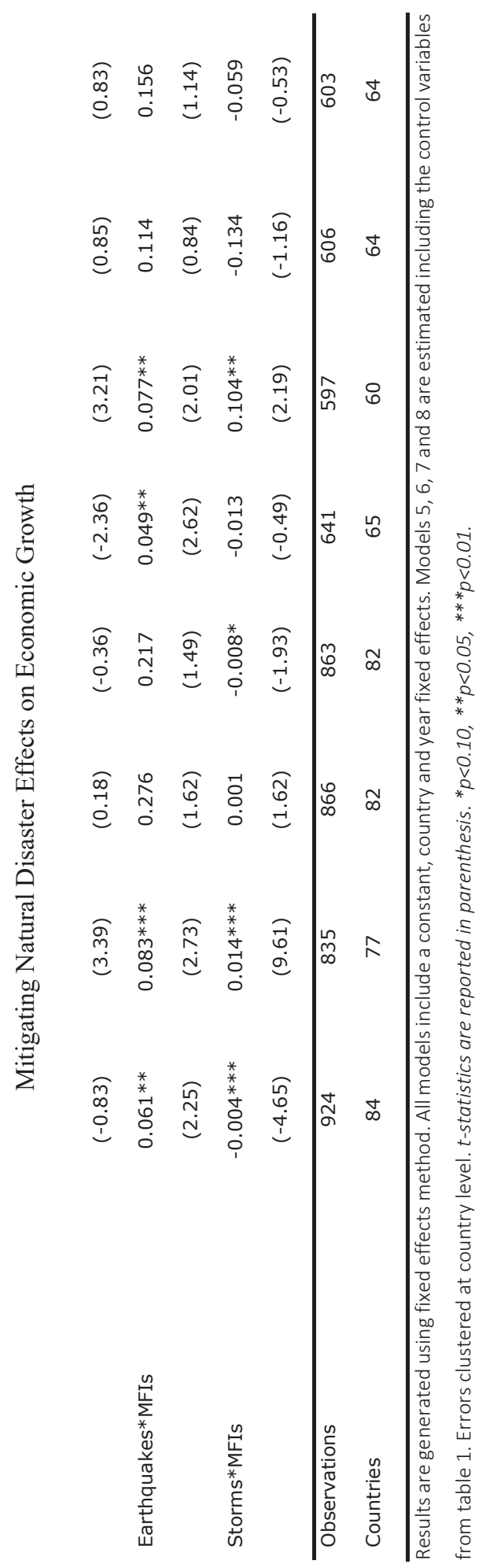


The other robustness check considers the potential endogeneity that could have resulted from the potential reverse causation. First, Even though we use GAME data for disasters which is based on the exogenous intensity, a disaster count variable which reduces the influence of potential selection bias and also include a set of control variables to account for the omitted variables bias, we may fail to fully solve the endogeneity problem because some explanatory variables may be correlated with the growth variables. Moreover, as argued earlier, during a disaster some MFIs can find themselves at a point of liquidity crisis because of the reduced individual savings and loan repayments coupled with increased savings withdraws. As a result, if many clients are severely affected by a disaster, the MFI is more likely to fail to meet their financial demands which causes their accessibility to be rather endogenous. So, instead of ignoring this potential endogeneity problem, we follow Loayza et al., (2012) and McDermott et al., (2014) and re-estimate the main model using a dynamic panel data estimator Arellano and Bover (1995)/Blundelland Bond (1998) designed to address this type of problem. ${ }^{34}$

\footnotetext{
${ }^{34}$ Of course one of the weaknesses of using GMM estimators is that their properties hold for large N. so, when N is small, they can be severely biased. For this reason, Bruno, (2005) suggests for the bias corrected Least Square Dummy Variable estimators (LSDVC) that uses stata command xtlsdvc to address the issue of small N. However, Bruno's approach fails to apply in our analysis because it automatically generates the coefficient of initial variable for the dependent variable of which we already include this variable in the model. So, we stick to system GMM estimator.
} 


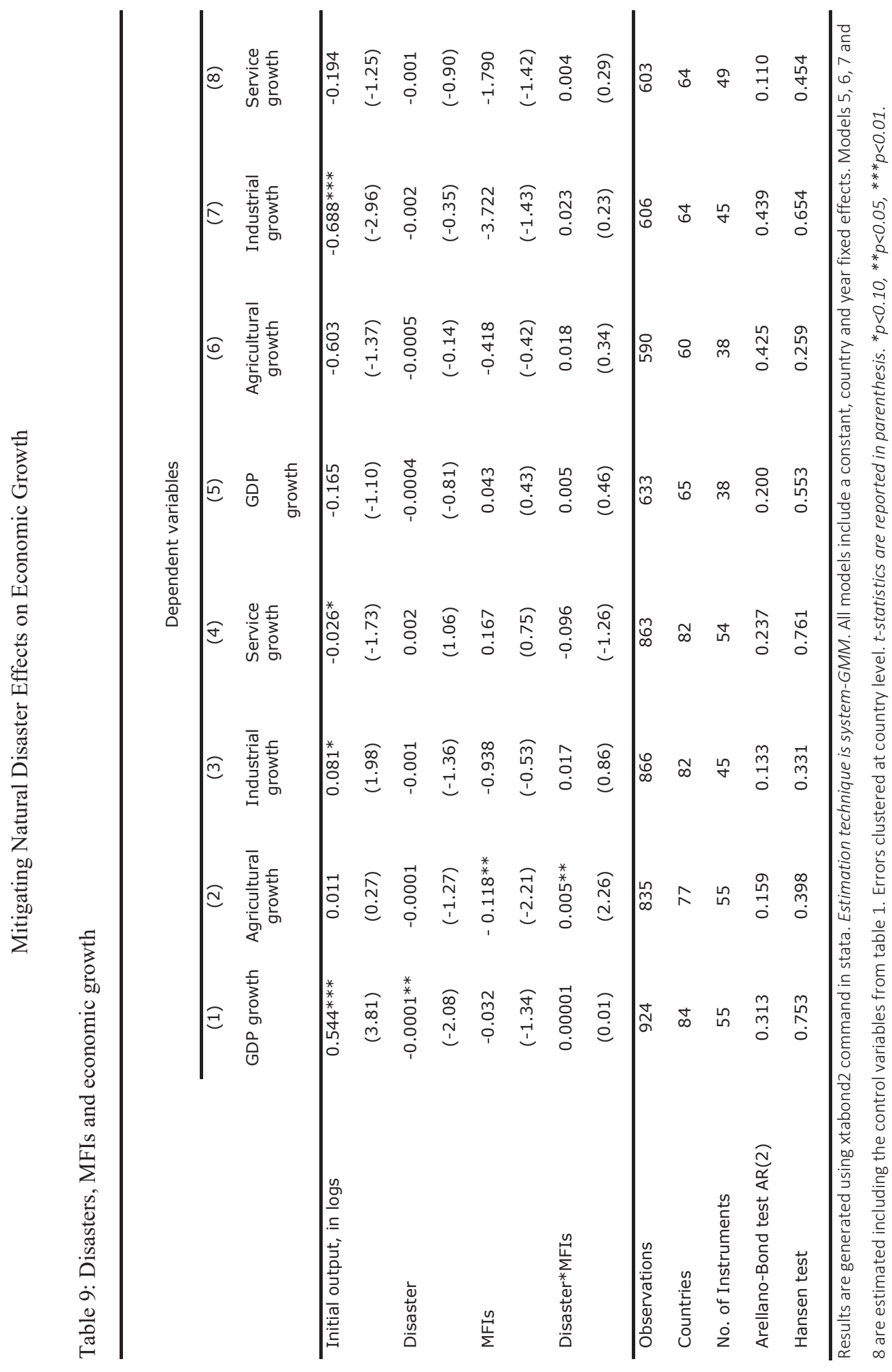


Focusing on the coefficients of the interaction term, the results in table 9 seem to robustly support our main finding which suggests that accessibility to MFIs reduces the impact of natural disasters in the agricultural sector.

Finally, the results presented so far demonstrate the impact of disasters to economic growth and the associated effect of the intervention of MFIs in the short-run. However, it is possible that the impact of the financial institutions' intervention in the aftermath may take long to be manifested. For example, even if MFIs intervene in addressing the disaster effects, their impact can still delay especially in the industrial and service sectors in which reconstruction may take quite long ${ }^{35}$. More still, countries with weak financial service development can experience a persistent negative effect beyond the short run (McDermott et al., 2014). For that reason, we follow McDermott et al. (2014) to test for persistence of the disaster effects and the delay in the mitigation process. Thus, we do a robustness check by re-estimating our main model including the disaster variable up to 4 lags (and the interaction term of these lagged disaster variables with the MFI indicator).

\footnotetext{
${ }^{35}$ Some equipment may have to be imported from other countries
} 


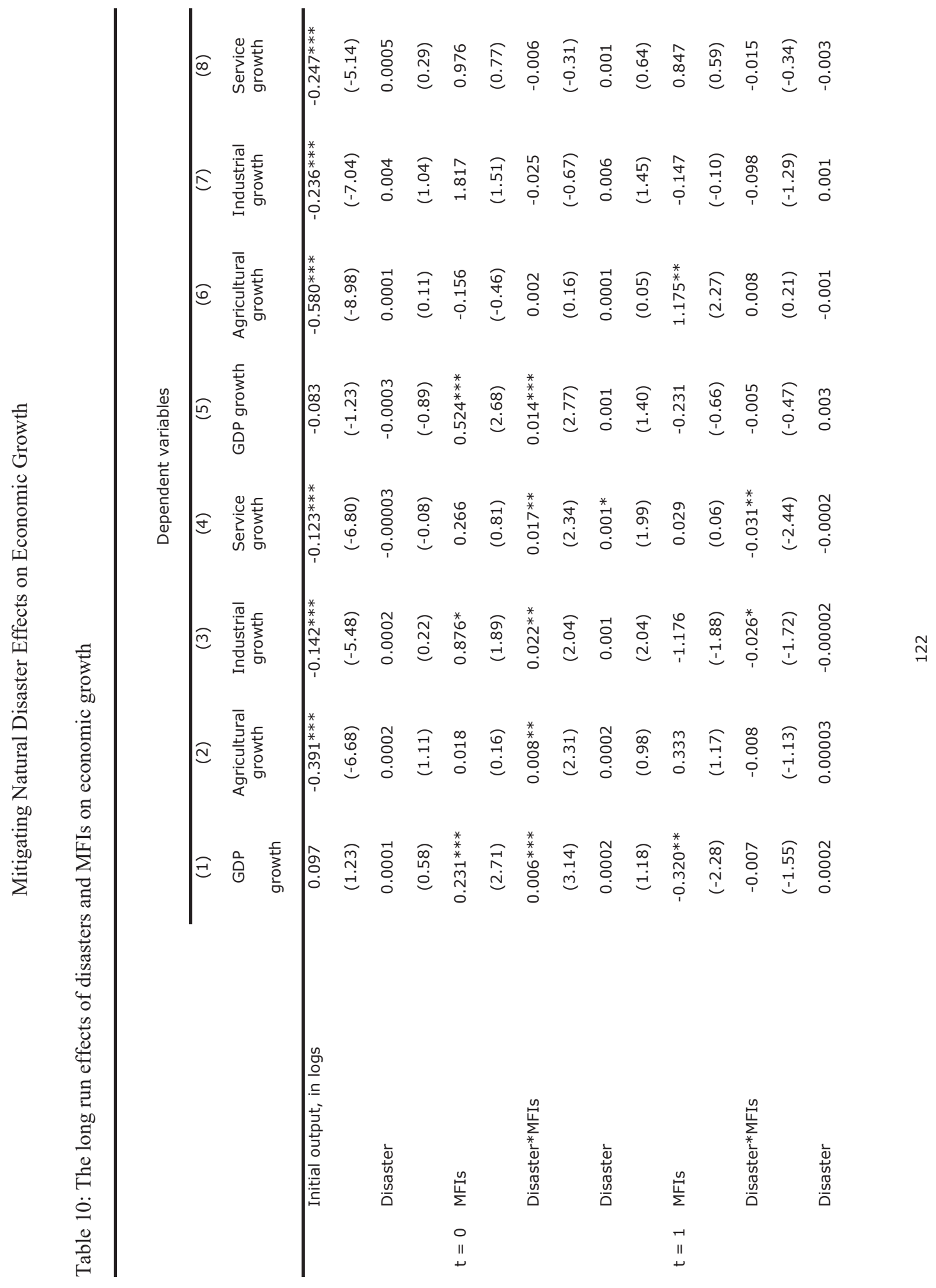




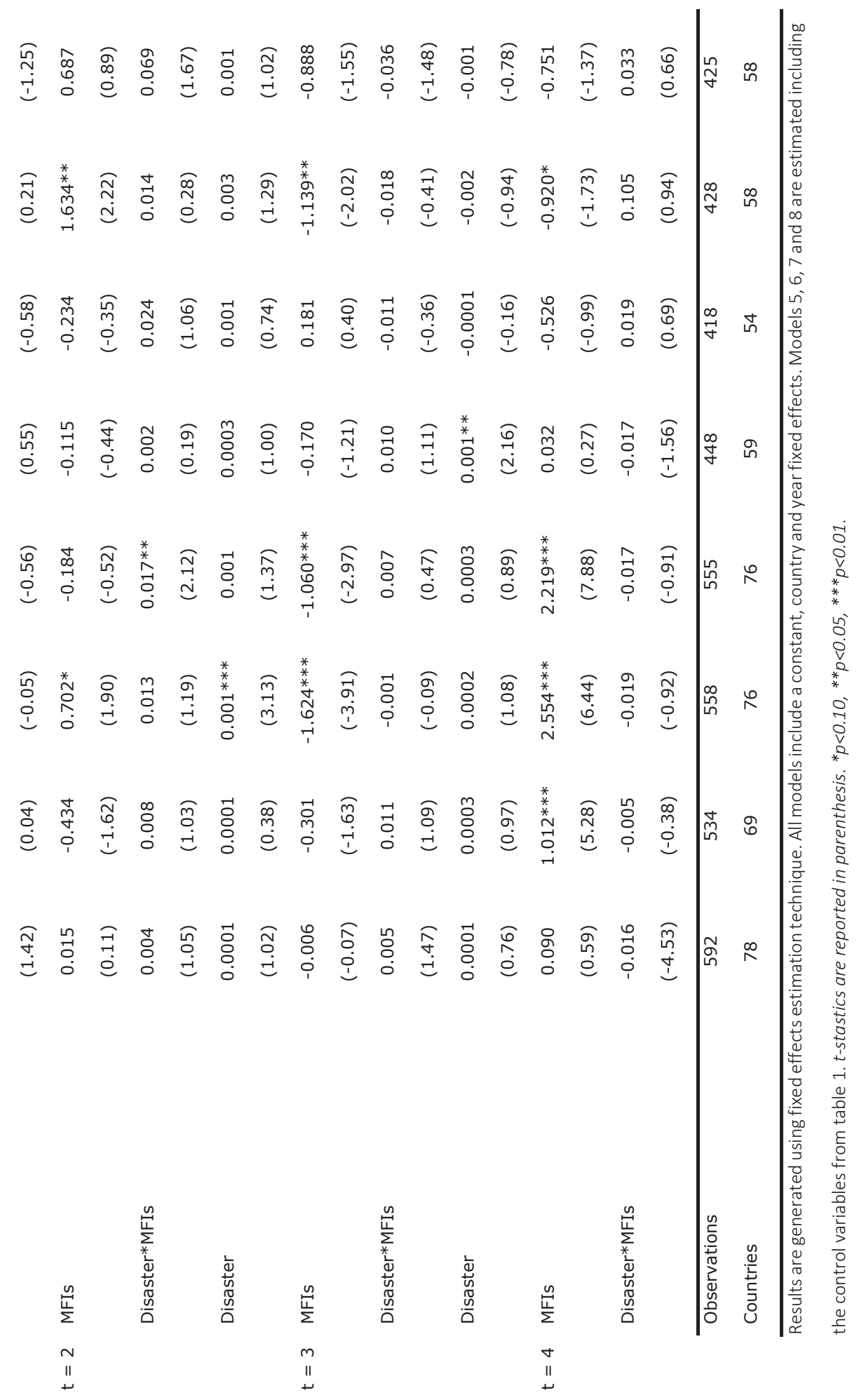




\section{Mitigating Natural Disaster Effects on Economic Growth}

The results in columns 1, 23, 4 and 5 indicate that the impact of the intenvention of MFIs in the aftermath only prevails in the short run. Actually, it disappears with the first lag even though it seems to appear again in the second lag of the service sector (column 4) but still disappears immediately. The possible explanations for this scenario could be that (1) if a disaster is persistent, MFIs may not have surfficient resources to withstand the persistent demand for credit and/or (2) the MFIs may develop a fear of possible default (if a disaster persists) given they can directly affect the clients' repayment capacities. As a word of caution, our reader needs not to confuse this finding with that in McDermott et al. (2014) especially on the sample of developing countries. Remember, we confine our analysis on MFIs while McDermott et al. (2014) confine their analysis on private credit which is normally bigger as compared to microcredit. In that case it becomes logically possible for the positive impact of the intervention of private credit to prevail up to the 8th lag as they demonstrate.

\subsection{Conclusions}

Literature is increasingly emerging pointing to the effects of natural disasters to economic development and specifically to agriculture, industry and service sectors. This literature has remained inconclusive with some studies finding positive effects and others negative. However, even with mixed conclusions, generally, disasters are more disastrous than beneficial to development. This explains why many strategies have been designed and implemented to try and mitigate such effects.

Our main contribution to the empirical literature is to examine how microfinance institutions help in mitigation the effects of natural disasters to economic growth. Our main findings suggest first that natural disasters only have an adverse effect on the performance of the agricultural sector. 
Incentives and Financial Institutions in the Development Process

However, access to lending facilities from MFIs mitigates about 35\% of this negative effect. Moreover, the extent to which MFIs are able to mitigate these effects depends to a large degree on their nature i.e. their organisational structure, profitability, legal status, age and the number of the clients they serve.

\section{Appendix 1: Summary statistics}

\begin{tabular}{|c|c|c|c|c|c|}
\hline Variables & Obs & Mean & Std.Dev & Min & Max \\
\hline \multicolumn{6}{|l|}{ Growth in } \\
\hline GDP & 1349 & 0.047 & 0.054 & -0.281 & 0.890 \\
\hline $\begin{array}{l}\text { Agricultural sector } \\
\text { (pc) }\end{array}$ & 1144 & 0.012 & 0.080 & -0.606 & 0.571 \\
\hline Industrial sector(pc) & 1191 & 0.074 & 0.193 & -1.686 & 1.822 \\
\hline Service sector(pc) & 1188 & 0.077 & 0.169 & -1.564 & 0.992 \\
\hline \multicolumn{6}{|l|}{ Control variables } \\
\hline $\begin{array}{l}\text { Education } \\
\text { attainment(in logs) }\end{array}$ & 1104 & 3.089 & 0.832 & 0.742 & 4.428 \\
\hline $\begin{array}{l}\text { Financial depth (in } \\
\text { logs) }\end{array}$ & 1315 & 2.939 & 0.925 & -0.382 & 5.110 \\
\hline $\begin{array}{l}\text { Government burden } \\
\text { (in logs) }\end{array}$ & 1286 & 25.175 & 2.718 & 16.213 & 34.061 \\
\hline Inflation (in logs) & 1254 & 0.125 & 0.246 & -0.142 & 3.748 \\
\hline $\begin{array}{l}\text { trade openness (in } \\
\text { logs) }\end{array}$ & 1329 & 4.134 & 0.591 & -1.171 & 5.395 \\
\hline $\begin{array}{l}\text { Growth rate of terms } \\
\text { of trade }\end{array}$ & 1142 & 0.007 & 0.109 & -0.975 & 0.518 \\
\hline $\begin{array}{l}\text { Number of active } \\
\text { borrowers }\end{array}$ & 932 & 925935.6 & 5403037 & 24.000 & $8.80 \mathrm{e}+07$ \\
\hline Population & 1376 & $5.58 \mathrm{e}+07$ & $1.79 \mathrm{e}+08$ & 465895 & $1.30 \mathrm{e}+09$ \\
\hline $\begin{array}{l}\text { Number of active } \\
\text { borrowers/population }\end{array}$ & 932 & 0.017 & 0.048 & $\begin{array}{c}5.70 \mathrm{e}- \\
07\end{array}$ & 0.733 \\
\hline
\end{tabular}


Mitigating Natural Disaster Effects on Economic Growth

\begin{tabular}{lccccc}
\hline Diamond dummy & 930 & 0.380 & 0.341 & 0.000 & 1.000 \\
Land size $(s q K M)$ & 1376 & 764587.6 & 1428676 & 1861 & 9400000 \\
Count measure for & & & & & \\
All disasters & 1360 & 1.511 & 2.416 & 0.000 & 14.667 \\
Droughts & 1360 & 0.743 & 2.088 & 0.000 & 12.000 \\
Floods & 1360 & 0.265 & 0.897 & 0.000 & 8.333 \\
Earthquakes & 1360 & 0.321 & 0.815 & 0.000 & 6.000 \\
Storms & 1360 & 0.182 & 0.372 & 0.000 & 2.000 \\
\hline
\end{tabular}

\section{Appendix 2: Control variables}

\begin{tabular}{lll}
\hline Variable & Description & Data source \\
\hline $\begin{array}{lll}\text { Education } \\
\text { attainment }\end{array}$ & Gross secondary school enrolment rate, in & World Devevelopment \\
Financial depth & Private credit/GDP, in logs & Indicators (2014) \\
& & World Devevelopment \\
Government & Government final consumption/GDP, in logs & World Devevelopment \\
burden & & Indicators (2014) \\
Inflation & $100+\%$ growth rate in CPI & World Devevelopment \\
& & Indicators (2014) \\
Trade openness & Exports + Imports/GDP, in logs & World Devevelopment \\
& & Indicators (2014) \\
Terms of trade & Log difference of the net barter terms of trade & World Devevelopment \\
& index. & Indicators (2014) \\
\hline
\end{tabular}


Incentives and Financial Institutions in the Development Process

Appendix 3: Sample of Countries

\begin{tabular}{lll}
\hline Afghanistan & Guinea & Paraguay \\
Albania & Guinea-Bissau & Peru \\
Angola & Guyana & Philippines \\
Argentina & Haiti & Poland \\
Armenia & Honduras & Romania \\
Azerbaijan & India & Rwanda \\
Bangladesh & Indonesia & Senegal \\
Benin & Jamaica & Serbia \\
Bolivia & Jordan & Sierra Leone \\
Bosnia and Herzegovina & Kazakhstan & South Africa \\
Brazil & Kenya & Sri Lanka \\
Burkina Faso & Laos & Sudan \\
Burundi & Macedonia & Swaziland \\
Cambodia & Madagascar & Syria \\
Chad & Malawi & Tajikistan \\
Chile & Malaysia & Tanzania \\
China & Mexico & Thailand \\
Colombia & Moldova & Togo \\
Comoros & Mongolia & Turkey \\
Democratic Republic of Congo & Morocco & Uganda \\
Costa Rica & Mozambique & Ukraine \\
Dominican Republic & Myanmar & Uruguay \\
Ecuador & Namibia & Uzbekistan \\
Egypt & Nepal & Venezuela \\
El Salvador & Nicaragua & Vietnam \\
Ethiopia & Niger & Yemen \\
Georgia & Nigeria & Zambia \\
Ghana & Pakistan & Zimbabwe \\
Guatemala & Papua New Guinea & \\
\hline
\end{tabular}


Mitigating Natural Disaster Effects on Economic Growth 


\author{
Chapter 5
}

\title{
Earthquakes and Economic Outcomes: Does Central Bank Independence Matter?
}

\begin{abstract}
This study explores whether the degree of central bank independence influences the economic performance in the period after an earthquake. Earthquakes create a classic monetary policy challenge: how to accommodate the real shock in the short-run with the objective of anchoring inflation. These two competing objectives demand opposite policy actions. This trade off will trigger a conflict of interest between policy makers since the government tries to stimulate economic recovery for electoral reasons by using expansionary policies, while, in turn, the central bank attempts to stabilize the economy again by following a more contractionary policy as the inflation pressure rises. The ultimate outcome of this dilemma depends for a large part on the degree of delegation of the monetary powers to an independent central bank and the inflation averseness of the central bank governors. Our main empirical findings indicate that the increase in the inflation rate after an earthquake is significantly smaller when monetary policy is conducted by a more independent central bank. At the same time, countries with an independent central bank are confronted with a wider output gap after an earthquake suggesting a slower economic recovery. Based on these findings we can conclude that central banks that are less politically constrained put
\end{abstract}


Central Bank Independence, Earthquakes and Economic Outcomes

more weight on lowering the inflation pressure after an earthquake at the expense of the short run output. However, it turns out that part of this effect can be explained by a number of monetary policy characteristics. For instance, central banks that follow a specific monetary policy rule (i.e., fixed exchange rate or inflation targeting) are more likely to pursue a contractionary policy than central banks that have more discrete powers.

Publication status: Sseruyange, J. and Klomp, J. (2018). Earthquakes and Economic Outcomes: Does Central Bank Independence Matter? Working paper. 
Incentives and Financial Institutions in the Development Process

\subsection{Introduction}

One of the main global challenges for sustainable economic development in the next decade is to limit the economic consequences of large-scale natural disasters. Since the 1970s the damagerelated costs of these events have risen dramatically. Record losses of some US\$380 billion were recorded in 2011, the year of the Tohoku earthquake in Japan, equivalent to 0.9 per cent of global GDP (EM-DAT, 2015). It is widely documented in the previous literature that these catastrophes put the macroeconomic performance of many countries under a considerable downward pressure since they will severely hit the countries' economic growth rates, their external performance, price level, financial system and fiscal sustainability (i.e., Felbermayr and Grösch, 2014; Skidmore and Toya, 2002; Raddatz, 2009; Noy 2009; Loayza et al., 2012; Lis and Nickel, 2010; Noy and Nualsri, 2011; Gassebner et al., 2010; Oh and Reuveny, 2010; Klomp, 2017).

Due to adverse economic consequences of natural disasters for the economic performance and in particular for the output produced and the inflation rate, it is expected that these events will influence the monetary policy decisions made by the central bank. The most important aim of the monetary authorities in the period after a natural disaster is to stabilize the economy again. However, there is only one concern since natural disasters create a classic monetary policy challenge: how to accommodate the real shock in the short-run with the objective of anchoring inflation. These two competing objectives demand opposite policy actions. On the one hand, natural disasters cause a shortfall in the output produced leading to a temporary negative deviation of the balanced growth path (Felbermayr and Grösch, 2014; Loayza et al., 2012; Klomp, 2016; Fomby et al., 2013). To spur economic recovery, the central bank might stimulate aggregate demand by using an expansionary monetary policy. However, loosening the monetary stance at a time when domestic output is temporarily reduced may risk fuelling inflation. On the other hand, 
natural disasters raise the marginal costs of domestic producers creating an upward pressure on the price level (Cavallo et al., 2014; Heinen et al., 2016; Parker, 2016). To stop the inflation rate from rising any further, central banks should stick to a more contractionary monetary policy. However, following this policy will depress the output even more. This dilemma demonstrates that central banks are not able to stimulate the economy and stabilize inflation at the same time after a disaster shock. The optimal policy in the period immediately following a disaster should therefore balance this trade-off.

Thus, whether monetary policy should be loosened or tightened in the wake of a natural disaster is contested and theoretically a priori not directly clear as it depends on many characteristics of the monetary policy followed. One key element in this debate is whether the monetary policy decisions are taken by a so-called independent central bank or contrariwise by a more politically constrained central bank. During the last two decades, many countries have implemented reforms designed to grant their monetary authorities greater independence from direct political influence. It is widely believed that central banks otherwise will give in to pressure from politicians who may be motivated by short-run electoral considerations (Kirchgässner, 1983; 1991) or may value shortrun economic expansions highly while discounting the longer-run inflationary consequences of expansionary policies (Walsh, 2005). If the ability of politicians to distort monetary policy results in excessive inflation, countries with an independent central bank should experience lower rates of inflation. Indeed, there is voluminous empirical evidence justifying this claim by suggesting that central bank independence $(\mathrm{CBI})$ may be instrumental in realizing low inflation (see Cukierman, 2008, Meade and Crowe, 2007 and Klomp and De Haan, 2010 for summaries ${ }^{36}$. In

\footnotetext{
${ }^{36}$ In a meta-regression analysis of 57 empirical studies Klomp and De Haan (2010) conclude first that legal CBI measures have a negative relationship with inflation in OECD countries, especially during the 1980s. Second, studies based on the turnover rate of the central bank governor suggest a positive relationship between this indicator of CBI and inflation in developing countries.
} 
Incentives and Financial Institutions in the Development Process

turn, as CBI causes a more contractionary monetary policy that should be reflected in lower output. However, little empirical evidence is found between measures of real economic activity and central bank independence (Alesina and Summers, 1993; Pollard, 1993). One can therefore argue that central bank independence appears to be a free $\operatorname{lunch}^{37}$.

Most empirical studies up so far are mainly concerned with the long run impact of central bank independence on the inflation rate or economic performance. However, in the long run the impact of economic shocks is assumed to be zero as they will be averaged out over time. In contrast, the contribution of our study is to explore whether central bank independence is also able to mitigate shocks immediately in the period when they happen. For this purpose, we use a quasi-experiment in which the frequency of earthquakes is taken as our measure of shocks hitting the economy. According to the large literature on retrospective voting, politicians are kept responsible by the electorate for the economic loss created by a natural catastrophe. However, at the same time voters reward government officials when they react quite promptly by taking decisive actions in the aftermath that will improve economic recovery (i.e., Healy and Malhotra, 2009; 2010; Reeves, 2011; Garrett and Sobel, 2003; Gasper and Reeves, 2011). So, this gives politicians a great incentive to stimulate the economy in the aftermath of a disaster by having more expansionary policies $^{38}$. To achieve this, governments might put some considerable political pressure on the central bank in the aftermath of a natural disaster to loosen its monetary policy. However, in countries with an independent central bank the monetary policy should be resistant to this political pressure motivated by electoral concerns. Consequently, a large part of the disaster impact is absorbed through the reduced output to stabilize the price level in the aftermath in countries with

\footnotetext{
${ }^{37}$ Alternatively, price stability is generally regarded as an essential condition for sustainable economic growth and that central bank independence should accordingly lead to a higher level of economic growth.

${ }^{38}$ This is also confirmed in the empirical literature. For instance, Garrett and Sobel (2003) find that nearly half of all disaster relief payments in the United States are motivated by political rent seeking as opposed to need.
} 
an independent central bank. In turn, in countries with a central bank that is more subject to political interference, it is expected that the output is more stimulated due to electoral considerations resulting in a higher price level in the short run.

Although the empirical evidence on the relationship between CBI and the economic performance after a natural disaster is lacking, there are some classical examples and anecdotes. For instance, the Reserve Bank of New Zealand loosened its monetary policy in the days after the Christchurch earthquake to stimulate the wider economy. The central bank of New Zealand is recognized as a rather politically dependent central bank since the government still has a relative large influence on central bank objectives. In contrast, the Federal Reserve (FED) decided to tighten monetary policy in the weeks after hurricane Katrina to limit the inflation pressure. The FED is regarded as much more independent from political interference in setting their policies.

The choice for earthquakes as our indicator for natural disasters is based on a number of reasons. First, these disasters occur rather exogenously as they cannot directly be influenced by human behaviour or are not related to the ongoing process of climate change. Second, though earthquakes happen only along the fault lines between two tectonic plates on land or the ocean floor, it is still hard to predict or forecast the timing of an event or develop an effective early warning system. Third, it is difficult to take precautionary measures that reduce the vulnerability of the population for geophysical disasters other than enforcing strict building and zoning codes. Fourth, earthquakes are more equally divided across LDCs and industrialized countries compared to other disasters such as floods or droughts. This reduces the possibility that our empirical results later on suffer from a sample selection bias. Finally, compared to other natural disasters, earthquakes have the largest real economic impact. Basing on the estimated damage figures reported by EM-DAT, the amount of damage per affected caused by a single earthquake is on average about 2.5 times larger 
Incentives and Financial Institutions in the Development Process

than, for instance, for a major flood. Even more, about half of the total reported damage costs related to natural disasters is attributed to earthquakes (EM-DAT, 2015).

We use a simultaneous equation model including about 400 major earthquakes in more than 90 countries between 1970 and 2013. We construct an exogenous measure on the frequency of geophysical disasters based on the information provided by the "Global Significant Earthquake Database" collected by the National Oceanic and Atmospheric Administration (NOAA). After extensive testing for the sensitivity of the results, our most important findings suggest that the increase in the inflation rate is smaller when monetary policy is conducted by a more independent central bank. At the same time, countries with an independent central bank have to deal with a wider output gap after an earthquake compared to countries where the monetary policy is influenced by the government. Based on these findings, we can conclude that central banks that are less politically constrained put more weight on lowering the inflation pressure after an earthquake at the expense of the short run output. However, it turns out that part of this effect can be explained by a number of monetary policy characteristics. For instance, central banks that follow a specific monetary policy rule (i.e., fixed exchange rate or inflation targeting) are more likely to pursue a contractionary policy than central banks that have more discrete powers.

The remainder of the paper is organized as follows. In the next section, we discuss our theoretical foundation underlying our hypothesis and review the literature on the economic impact of earthquakes. In section three, we describe our data and methodology used. In section four, we report our estimation results on the relationship between earthquakes, economic outcomes and central bank independence. Finally, we end in section five with our conclusion and discussion. 


\subsection{Theoretical considerations}

The term "central bank independence" (CBI) refers to the freedom of monetary policy makers from direct political influence or government interference in the conduct of policy. More independent central banks are able to set and control their own monetary objectives and are not constrained in the choice of policy instrument applied. However, when monetary policy is delegated to an independent central bank, it might lead to a conflict of interest between the monetary authorities and the central government as the economic objectives are not always aligned. This is in particular the case after an adverse supply shock. In this situation the government would prefer to use an expansionary monetary policy to stimulate economic recovery after the shock for electoral reasons, while the central bank prefers to use a more contractionary policy in an attempt to stabilize the economy again. The outcome of this trade-off ultimately depends on the degree of delegation of the monetary powers and inflation averseness of the central bank.

To illustrate the complex relationship between the economic consequences of natural disasters and central bank independence, we use a theoretical framework based on the time-inconsistency models suggested by Rogoff (1985), Kydland and Prescott (1977), Barro and Gordon (1983), McCallum (1995) and Eijffinger and De Haan (1996). In these models, dynamic inconsistency arises when the announced policy for some future period is no longer optimal when a supply shock happens in that particular period. Our model starts by considering the following expectationsaugmented aggregate supply curve.

$y_{t}=\bar{y}+\alpha\left(\pi_{t}-\pi_{t, t-1}^{e}\right)+s_{t} \quad \alpha>0$

where $y_{t}$ represents the output produced at time $t, \bar{y}$ is the natural output, $\pi_{t}$ is the current inflation rate, $\pi^{e}$ is expected inflation formed by the private sector, while $s_{t}$ is a temporarily supply shock 
Incentives and Financial Institutions in the Development Process

caused by a natural disaster. This shock $(s<0)$ raises the marginal costs of producers and creates production shortages in the short run. Consider further that the central government minimizes the following loss function

$$
\begin{array}{ll}
L_{G}=\left(y_{t}-y^{*}\right)^{2}+\kappa\left(\pi_{t}-\pi^{*}\right)^{2} & \kappa>0 \\
y^{*}=\bar{y}+\varpi \quad \varpi>0 &
\end{array}
$$

Politicians like to target an output $y^{*}$ that is above the natural rate for re-election considerations (the parameter $₫$ measures the magnitude of this distortion). Meanwhile, they assign a negative weight $\kappa$ to increases in the price level below or above the inflation target $\pi^{*}$ announced in advance by the central bank ${ }^{39}$. The quadratic form implies that large deviations cause disproportionately larger losses than small deviations. Suppose further that the government delegates part of the monetary policy power to a more inflation averse central bank. The main objective of the central bank is to stabilize the economy by minimizing a loss function of the following form

$L_{C B}=\left(y_{t}-\bar{y}\right)^{2}+(\kappa+\varepsilon)\left(\pi_{t}-\pi^{*}\right)^{2} \quad \varepsilon>0$

The central bank loses 'welfare' when output deviates from its long-run level and when inflation departs from its target level. The parameter $\varepsilon$ measures the degree to which the central bank is more conservative than the government in maintaining low inflation. Let $\beta$ indicate the degree to which the central bank is independent in managing monetary policy, then both the government and the central bank will be aiming at minimizing the following combined loss function

\footnotetext{
${ }^{39}$ It is for the national government beneficiary to allow for some little inflation to "grease the wheels" of the labour market.
} 
Central Bank Independence, Earthquakes and Economic Outcomes

$$
\begin{gathered}
\widetilde{L_{t}}=(1-\beta) L_{G}+\beta L_{C B}= \\
\left(y_{t}-\bar{y}\right)^{2}+(1-\beta)\left(\varpi^{2}-2 \varpi\left(y_{t}-\bar{y}\right)\right)+(\kappa+\beta \varepsilon)\left(\pi_{t}-\pi^{*}\right)^{2} \quad 0 \leq \beta \leq 1
\end{gathered}
$$

Intuitively, due to electoral considerations, the central government tries to accommodate a large part of the supply shock through a rise of the inflation rate to spur economic recovery by using an expansionary policy. In turn, a highly independent central bank will absorb the shock mainly through a drop in the output to keep prices stable by implementing a more contractionary policy. Thus, the actual outcome will depend on the degree of political independence of the central bank. More formally, the optimal inflation rate is derived by substituting the aggregate supply curve of equation (1) into the combined loss function of (4) and take the first-order condition with respect to the inflation rate. Solving this derivative for the inflation rate (taking the inflation expectations as given) yields.

$\pi_{t}=\frac{(\kappa+\beta \varepsilon) \pi^{*}+\alpha^{2} \pi_{t, t-1}^{e}-\alpha \mathrm{s}_{t}+\alpha(1-\beta) \varpi}{\alpha^{2}+\kappa+\beta \varepsilon}$

However, to solve the model any further for the output effects, we need to make some assumptions about how the private sector determines its inflation expectations. Actually, three possible situations exist. First, the central bank credibly sticks to an inflation target that is announced in advance and the public believes that the central bank will try to keep the inflation rate at this promised level. Applying this presumption delivers the following inflation rate and output gap

$\pi_{t}=\pi_{t, t-1}^{e}=\pi^{*} \quad y_{t}-\bar{y}=\mathrm{s}_{t}$

These results indicate that under strict inflation targeting the supply shock is completely passed on to the adjustment in the actual output and the inflation rate is unchanged. Thus, this outcome implies a fully contractionary monetary policy. However, one crucial condition is that the central 
Incentives and Financial Institutions in the Development Process

bank can credibly commit itself to this target even when this is not optimal from a central bank perspective as indicated in equation (5). It is more optimal for the central bank to allow an increase in the inflation rate after a negative shock. This issue is in particular of a concern for many developing countries which officially granted de jure an independent monetary policy. However, de facto the central bank is still under some considerable political control. So, in the second situation we describe, the central bank behaves in a more self-interested way, while the public is irrational and naïve and still believes that the central bank will stick to the announced inflation target $\left(\pi_{t, t-1}^{e}=\pi^{*}\right)$. This latter assumption is rather realistic for many LDCs since access to reliable information is quite limited in these countries. In this situation the inflation rate and output gap are respectively given by

$\pi_{t}=\pi^{*}+\frac{\alpha(1-\beta) \varpi-\alpha \mathrm{s}_{t}}{\alpha^{2}+\kappa+\beta \varepsilon} \quad y_{t}-\bar{y}=\frac{\alpha^{2}(1-\beta) \varpi}{\alpha^{2}+\kappa+\beta \varepsilon}+\left(\frac{\kappa+\beta \varepsilon}{\alpha^{2}+\kappa+\beta \varepsilon}\right) s_{t}$

When we compare the results in equation (7) with the outcomes under a scenario with a credible central bank that aims for the inflation target (see equation 6), we can conclude that the inflation rate is higher, while the fall in output is lower. This prediction suggests that the central bank implements a less contractionary policy (or even an expansionary policy) when the public is less informed. In the final situation, the public is rational and knows that the announced inflation target is not optimal for the central bank and that it will create some 'surprise' inflation by stimulating recovery. That is, the public takes into account that the central bank will probably deviate from the announced rule and has a lenient target $\left(\pi_{t, t-1}^{e}=\pi_{t}\right)$. Using this assumption yields the following outcomes

$\pi=\pi^{*}+\frac{\alpha(1-\beta) \varpi-\alpha \mathrm{s}_{t}}{\kappa+\beta \varepsilon} \quad y_{t}-\bar{y}=\mathrm{s}_{t}$ 
Comparing the three situations, we can draw two important empirical predictions. First, the inflation rate and the produced output after a natural disaster are lower in countries where monetary policy is to a great extent delegated $\beta$ to a more conservative central bank $\varepsilon$. Secondly, the output (inflation rate) after a natural disaster is lower (higher) in countries where large parts of the public are rational. That is, in these countries the population suffers the most in terms of price increase and output loss after a natural disaster. Thus, for countries that are regularly hit by supply shocks, it is more beneficial for the central bank to build a credible reputation by sticking to the announced inflation target.

In the remaining of this section, we briefly review the existing empirical evidence related to the impact of natural disasters, and in particular of earthquakes, on economic performance in terms of inflation and output. Most empirical studies on the macroeconomic impact of natural disasters confirm that in the short run there is a shortfall in production (i.e., Loayza et al., 2012; Klomp, 2016; Fomby, 2013; McDermott et al., 2014). This temporary deviation from the balanced growth path is mainly caused by a drop in the capital-labour ratio and the destruction of technology. For instance, the empirical results provided by Felbermayr and Gröschl (2014) suggest that a natural disaster in the top 1-percentile based on their created damage reduces the same-year GDP per capita by about 6.8 percent, while the top 5-percentile disasters cause per capita income to drop at least by 0.3 percent in the same year of a disaster ${ }^{40}$. Moreover, the key results of the empirical analysis reported by Fisker (2012) demonstrate that while there is no significant effect of an earthquake at the country level, earthquake exposure significantly decreases the economic growth

\footnotetext{
${ }^{40}$ In the long run the predictions are less clear. Traditional neo-classical growth models predict that the destruction of capital drives countries temporarily away from their balanced-growth path, while the endogenous growth models provide less clear-cut predictions. For example, models based on Schumpeter's creative destruction theory may even predict higher growth rates as disaster shocks can work as an accelerator for upgrading the capital stock (Loayza et al., 2012; Klomp, 2016; Klomp and Valckx, 2014).
} 
Incentives and Financial Institutions in the Development Process

rate at the local level. Regions at lower stages of economic development suffer harder in terms of economic growth than richer areas. Additionally, there are various event studies exploring the real macroeconomic impact of specific earthquakes (DuPont and Noy, 2015: 1995 Kobe; Doyle and Noy, 2015: 2010 Canterbury; Selcuk and Yeldan, 2001: 1999 Turkey; Barone and Mocetti, 2014: 1976 and 1980 Italy). The main conclusion that is shared among these case studies is that there is a negative effect of earthquakes on real GDP per capita at least in the short run.

Moreover, after a natural disaster the price level within a countries is under an upward pressure due to a number of reasons. First, the marginal costs of domestic producers increase since there is a shortage of inputs needed in production. Second, the general price level rises as the share of lesscompetitive imports increases to compensate for the shortage of domestic production. Three, the cost of transportation might rise as goods need to come from abroad or access to some remote areas is very restricted. Finally, a natural disaster may create a situation in which large amounts of aid flow into the country creating a small or local economic boom which in turn will lead to an increase in the price of goods needed in the recovery process.

Nevertheless, the empirical evidence on the inflationary impacts of natural disasters is rather inconclusive. For instance, using data from the Caribbean, Heinen et al. (2016) conclude that extreme weather events create a large upward pressure on the aggregate inflation mainly attributed to the price rises of food and housing. In contrast, Cavallo et al. (2014) examine the impacts of the 2010 Chile and the 2011 Japan earthquake on product availability and prices. The authors find that there are sharp falls in the availability of goods immediately ex-post. Surprisingly, these shortages did not translate into higher prices. Moreover, the results of Doyle and Noy (2015) suggest that the Canterbury earthquake in 2010 caused a drop in the inflation rate due to a fall in aggregate 
demand. Most evidence up so far is mainly based on case or regional studies. However, one exception is Parker (2016) who uses a large global panel to explore the inflationary effects of natural disasters. His results indicate that the inflation persistence of major natural events is for a large part conditional and relies on the level of development of a country, the type and strength of the disaster and the composition of the inflation measure.

\subsection{Data and methodology}

\subsubsection{Earthquake and CBI data}

One of the main challenges in the literature dealing with the macroeconomic impacts of natural disasters is the identification strategy of these events as they are the product of hazard, exposure and vulnerability (Felbermayr and Gröschl, 2014; Yonson et al., 2016). Most scholars agree that a large part of the hazard to a natural event is beyond government control or can be affected by the behaviour of a single person (exogenous). In contrast, the exposure and vulnerability part of a disaster event, in terms of the number of people affected or physical damage created, depend to some extent on the socio-economic situation or government choices made in the past (Kellenberg and Mobarak, 2008; Neumayer et al., 2014). For instance, the total damage created by a disaster is often positively related to the level of income, while the number of people affected is negatively affected by the level of income.

Therefore, to estimate the economic impact of earthquakes, it is important to separate the exposure and vulnerability element from the impact and focus exclusively on the hazard part. Hence, we should use detailed information about the physical strength of an event. However, for many disasters, especially slow onset events such as droughts, this intensity is rather difficult to observe 
or is based on a rather arbitrary definition. In turn, earthquakes are directly observable and data on the magnitude are readily available. To be specific, the data on the physical magnitude of earthquakes and their impact are documented in the "Global Significant Earthquake Database" collected by National Oceanic and Atmospheric Administration (NOAA). This NOAA database has worldwide coverage, and contains data for more than three centuries. The dataset includes information about magnitude, damage scale, location, geographical spread and whether a tsunami or volcano eruption has followed an earthquake. Each week more than one hundred earthquakes happen. However, to be included in the dataset an event should meet at least one the following two criteria: (1) creates damage (approximately $\$ 1$ million or more); or (2) causes fatalities. By imposing these criteria, it partially controls for the concern that two episodes may have completely different impacts because of their intensity and location. Thus, disasters that occur in the middle of the desert or far from the coastline are not considered as disasters under this measure. These low thresholds guarantee that most earthquakes are recorded which minimizes the under-reporting bias to a large extent. Nevertheless, many of the disasters recorded in this dataset still cause only a little physical damage. For example, based on the reported figures, only 10 percent of the earthquakes recorded worldwide involve damage that is over one-percent of GDP ${ }^{41}$. Given this distribution of the earthquake magnitude, it is conceivable that minor earthquakes will have only a negligible impact on monetary policy. For a disaster to have an empirical impact, it should be of a magnitude that can directly harm the macroeconomic performance of a country. For this reason we adopt an additional decision rule that filters out the major earthquakes included based on its intensity. To be specific, in our analysis later on we include only events that satisfy also one of the following restrictions (1) the earthquake is above magnitude 6.5 on the Richter scale or (2) the

\footnotetext{
${ }^{41}$ One needs to interpret these figures carefully as they might be plagued by a number of endogeneity concerns (Felbermayr and Gröschl, 2014).
} 
Central Bank Independence, Earthquakes and Economic Outcomes

Modified Mercalli Intensity scale is greater than X. Figure 1 shows that there is a close relationship between the magnitude of an earthquake measured by the scale of Richter and the monetary value of the damage reported. This filter leaves us with about 850 major earthquakes between 1960 and 2015. Figure 2 shows the distribution of the events across countries. In total there are about 120 countries that can potentially be affected by earthquakes as they occur only along the fault lines between two tectonic plates. Moreover, Figure 3 and 4 illustrates the average number and the mean magnitude of the included events over time. On average there are about 15 major events yearly and the average magnitude is around 7 on the Richter scale. In both, the frequency and magnitude of events, there is no significant time trend visible in our period of analysis. This proofs the exogeneity of the used disaster some further.

Figure 1: Correlation between monetary damage and earthquake strength

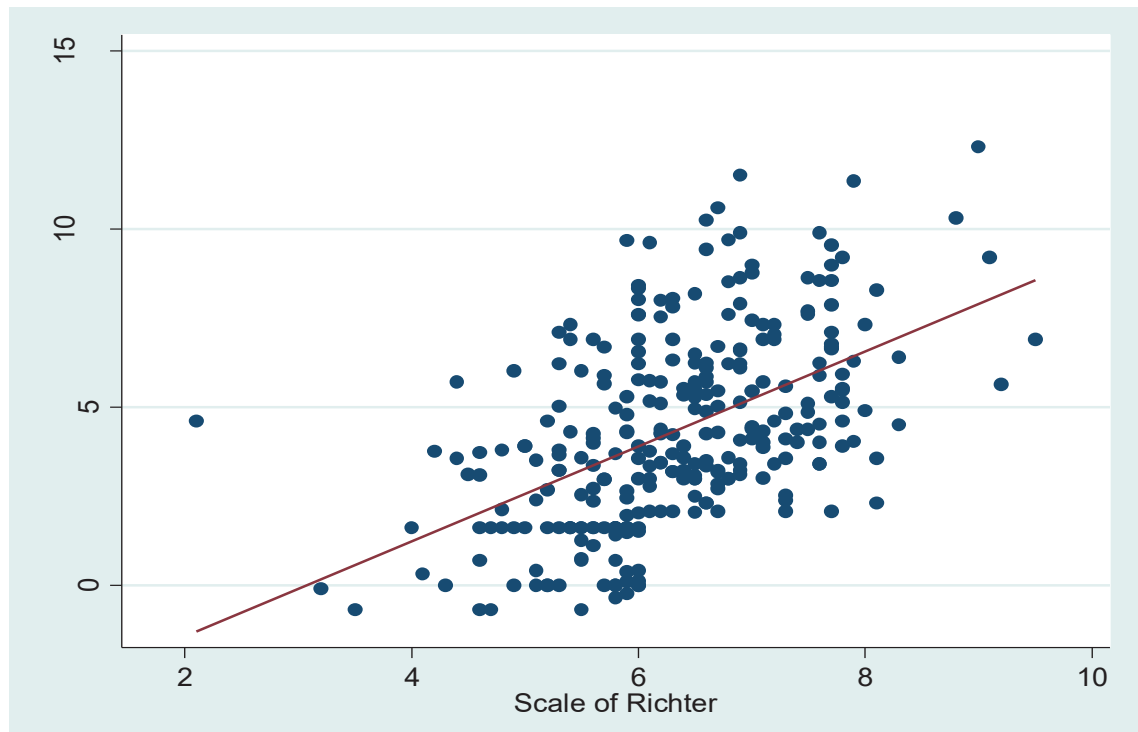

Based on data provided by NOAA. 
Figure 2: Earthquake map

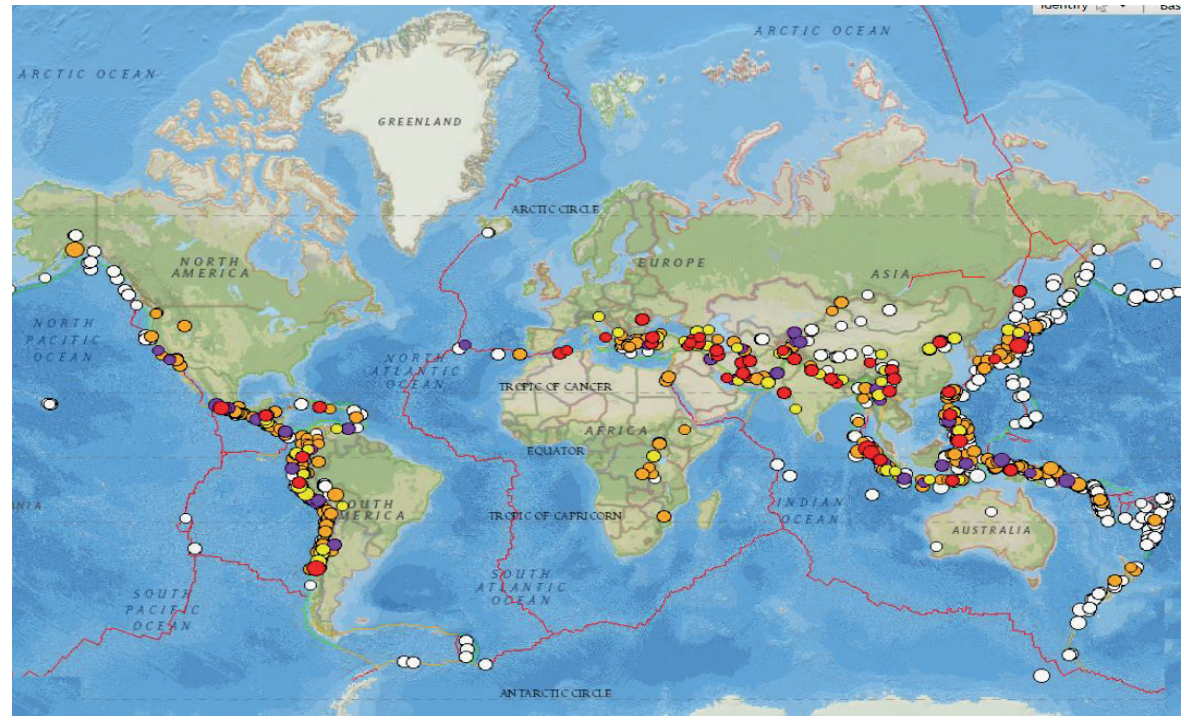

Note: the circles indicate a single earthquake included in our dataset. Source: NOAA.

Figure 3: Number of earthquakes

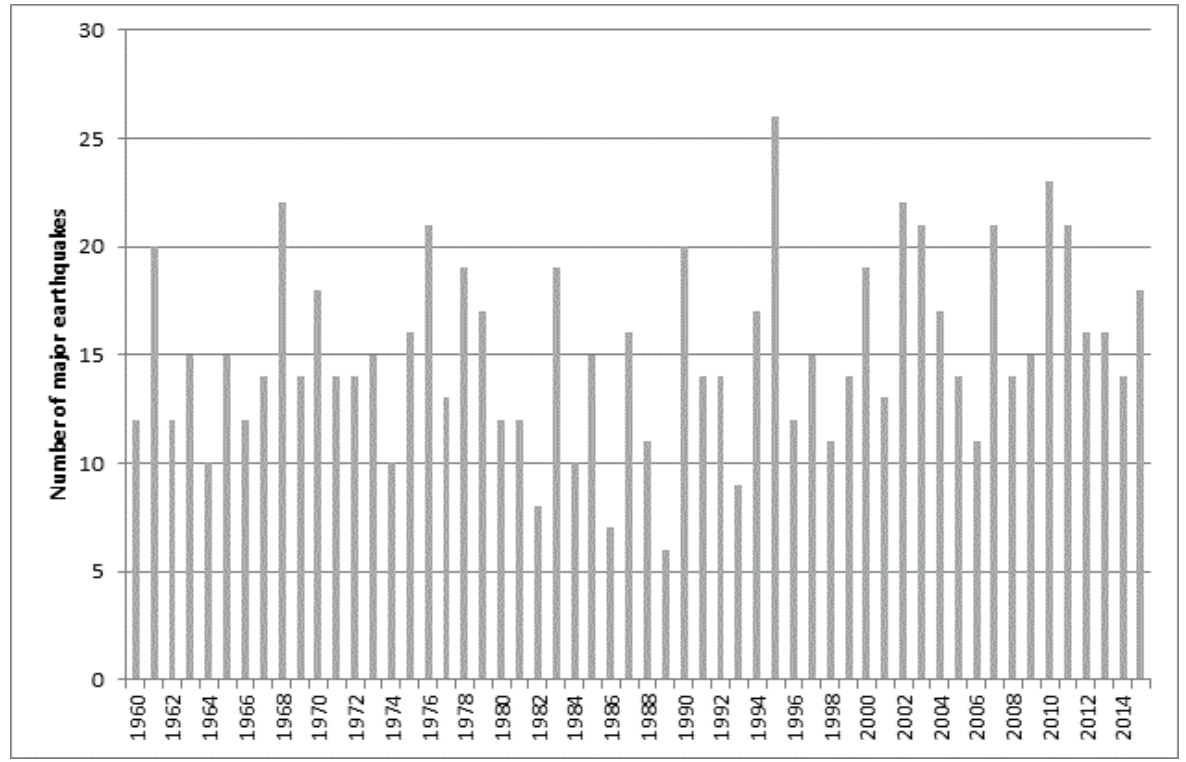

Based on data provided by NOAA. 
Figure 4: Average Scale of Richter

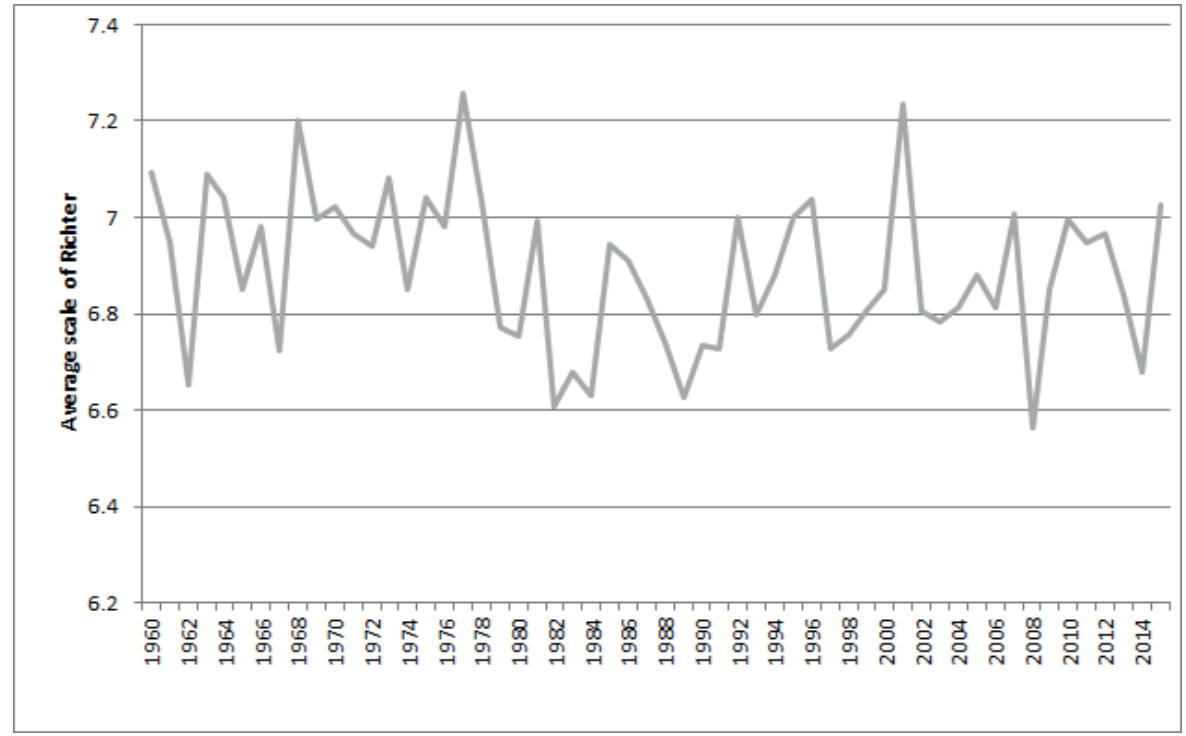

Based on data provided by NOAA.

To determine the impact of earthquakes on the economic performance, we construct for each country-year a disaster count variable that takes the timing of a quake in the course of a year into account. This allows events happening at the beginning of the year to have a different impact than those that happen near the end of the year.

$$
\text { earthquake }_{i t}= \begin{cases}\frac{\sum\left(\left(12-M_{k t}\right) / 12\right)+\sum\left(M_{n t-1} / 12\right)}{\rho_{i}} & (\text { post }) \text { disaster year } \\ 0 & \text { otherwise }\end{cases}
$$

Since the contemporaneous impact of an earthquake within one year is considered, our annual earthquake measure is calculated as the weighted sum of earthquakes $k$ that happened in the current year $t$ and the earthquakes $n$ that occurred in the previous year $t-1$. We weighted this sum by the 
Incentives and Financial Institutions in the Development Process

month $M$ when the respective earthquake happened. That is, we assign the value $(12-M) / 12$ to a disaster year and $M / 12$ to the post-disaster year. In all other years its value is set to zero. Using a count measure puts equal weight to the events. This has the advantage of reducing the influence of outlier events at the upper end of the distribution. Besides, a country that is hit more than once by a major earthquake in the same year will suffer a sharper economic downturns or increases in the inflation rate than a country which suffers only a single incident. We normalize the number of earthquakes by the land area of a country $i$ in $1,000 \mathrm{~km}^{2}$, represented by $\rho_{i}$. Obviously, larger countries have a higher probability of experiencing a geophysical event. When, for instance, the United States is hit by an earthquake the consequences for the economy as a whole are likely to be smaller than when Haiti, is hit by the same earthquake. Especially small island states are extremely vulnerable because of the higher frequency of earthquakes that have a disproportionately large impact on their economy (Skidmore and Toya, 2002; Gassebner et al., 2010; Pelling et al., 2002; Freeman et al., 2003; Rasmussen, 2004) ${ }^{42}$.

Many empirical studies employing the degree of $\mathrm{CBI}$ as their variable of interest base their measures of CBI on central banks statutes (i.e., Alesina, et al., 1989; Cukierman, 1992; Grilli, et al., 1991). Most de jure CBI indices are based on the methodological approach suggested by Cukierman (1992) and Cukierman et al. (1992) by coding the central bank legislation and institutional design on three different dimensions: personnel, financial, and policy independence. Personnel independence reflects limits to the government's influence on the central bank board's membership or tenure. Financial independence restricts the government's ability to use the central bank's loans to fund its expenditures, to avoid monetary policy subordination to fiscal policy.

\footnotetext{
${ }^{42}$ When not controlling for the land size, our earthquake measure may be correlated with the error term in our empirical estimation.
} 
Finally, policy independence reflects the central bank's powers to freely formulate and execute monetary policy and its ability to set the goals and/or choose the instruments of monetary policy. In our approach, we start by using the (weighted) de jure measure reported by Garriga $(2016)^{43}$. This measure takes into account the three dimensions of CBI and is available for more than 180 countries for the period 1970 to 2012. However, legal measures of CBI may not reflect the true relationship between the central bank and the government. Especially in countries where the rule of law is less strongly embedded in the political culture, there can be wide gaps between the formal, legal institutional arrangements and their practical impact (Walsh, 2005; Bodea and Higashijima, 2015). As argued by Hielscher and Markwardt (2012) granting a central bank more autonomy does not necessarily lead to better inflation performance. To lower inflation by increasing central bank independence, the quality of the political institutions must be sufficiently high. Therefore, in the next step, we multiply the measure of Garriga (2016) by the democracy measure (DEMOC) taken from the Polity IV dataset. This variable captures the rule of law of a country and is related to the accountability and transparency of the government. This product should therefore control for the difference between de jure and de facto $\mathrm{CBI}^{44}$. Finally, we scale the modified $\mathrm{CBI}$ measure in order to make the value of the $\mathrm{CBI}$ indicator run between 0 (fully political constrained) and 1 (completely independent). The mean level of CBI differs significantly between countries. For instance, the

\footnotetext{
${ }^{43}$ Using the following weighting scheme: appointment and dismissal of central bank governors $20 \%$; central bank objectives $15 \%$; policy formulation $15 \%$; and central bank lending $50 \%$.

${ }^{44}$ Alternatively one can include the interaction between the de jure CBI measure and the measure of rule of law into the empirical specification. However, this creates a large number of interactions as we also need to consider later on the interaction between CBI and our disaster measure (including some four way interactions). Due to the high correlation among the different interaction terms, it is hard to interpret these results. So we decided to compute a more direct measure on the de facto CBI. Moreover, there exist more direct measures on the rule of law for instance reported in the International Country Risk Guide from the PRS group or in the World Governance Indicators provided by the World Bank. However, due to country and time coverage concerns, these indicators result in a large drop in the number of observations that can be included in the regressions. Nevertheless, the main results presented in this study do not depend on the rule of law measure chosen. Detailed results are available upon request. Table A3 in the appendix shows the correlation matrix between different measures of rule of law, CBI and the used multiplicative term.
} 
Incentives and Financial Institutions in the Development Process

average CBI for a low-income country is about 0.18 , while for an average high-income country, the value of $\mathrm{CBI}$ is around 0.38 .

\subsubsection{Model}

To explore whether the impact of natural disasters on the output and inflation rate relies on the degree of central bank independence, we estimate the following system of two equations. We use a large unbalanced panel dataset, comprising about 90 countries for 1970 to 2013 . Table A1 in the appendix lists the countries included in this study.

$$
\begin{aligned}
\pi_{i t}= & \alpha_{i}+\beta_{1} \pi_{i t-1}+\beta_{2} \hat{y}_{i t}+\beta_{3} \text { earthquake }_{i t}+\beta_{4} C B I_{i t}+\beta_{5}\left(\text { earthquake }_{i t} \times C B I_{i t}\right)+ \\
& \mu_{n} \mathbf{z}_{t-j}^{n}+\varepsilon_{i t} \\
\hat{y}_{i t}= & \gamma_{i}+\theta_{1} \hat{y}_{i t-1}+\theta_{2} \pi_{i t}+\theta_{3} \text { earthquake }_{i t}+\theta_{4} C B I_{i t}+\theta_{5}\left(\text { earthquake }_{i t} \times C B I_{i t}\right)+ \\
& \varphi_{k} \mathbf{x}_{t-\boldsymbol{q}}^{k}+\vartheta_{i t}
\end{aligned}
$$

The variable $\pi$ is the modified inflation rate computed as $p /(1+p)$ where $p$ is the price change. With price increases, the transformed inflation rate takes a value from 0 to $1^{45}$. The transformation of the inflation rate reduces the heteroscedasticity of the error term. The variable $\hat{y}_{i t}$ is the output gap (as share of the actual GDP) in country $i$ in year $t$. To separate the cyclical component from the real GDP per capita series we apply the Hodrick-Prescott filter ${ }^{46}$.

Moreover, the variable earthquake is our constructed earthquake variable outlined above capturing the exogenous frequency and exposure of a country to geophysical hazard events. The parameters $\alpha_{i}$ and $\gamma_{i}$ are country-specific intercepts to control for time-invariant unobserved characteristics such as geographical factors. By using a country-specific intercept, we place the emphasis of our analysis on the identification of the within country variation over time. The variable $C B I$ measures

\footnotetext{
${ }^{45}$ Of course, in case of price decreases it ranges between -1 to 0 .

${ }^{46}$ We use a smoothing parameter $\lambda$ of 6.25 as suggested by Ravn and Uhlig (2002).
} 
the de facto independence of a central bank based on the indicator composed before. The final parameters $\varepsilon_{i t}$ and $v_{i t}$ are error terms.

Earthquakes affect the inflation rate (output gap) directly through $\beta_{3}\left(\theta_{3}\right)$ and $\beta_{5}\left(\theta_{5}\right)$, and indirectly through the impact on the output gap (inflation rate) through $\beta_{2}\left(\theta_{2}\right)$. Thus, to explore the mitigating impact of central bank independence on the economic outcomes, we need to consider the following complete first-order conditions

$$
\begin{aligned}
& \frac{\partial \pi}{\text { eearthquake }}=\frac{\partial \pi}{\text { dearthquake }}+\frac{\partial \pi}{\partial \hat{y}} \frac{\partial \hat{y}}{\partial \text { earthquake }}=\beta_{3}+\beta_{5} C B I+\beta_{2}\left(\theta_{3}+\theta_{5} C B I\right) \\
& \frac{\partial \hat{y}}{\text { eearthquake }}=\frac{\partial \hat{y}}{\partial \text { earthquake }}+\frac{\partial \hat{y}}{\partial \pi} \frac{\partial \pi}{\partial \text { earthquake }}=\theta_{3}+\theta_{5} C B I+\theta_{2}\left(\beta_{3}+\beta_{5} C B I\right)
\end{aligned}
$$

As the equations include the lagged endogenous variable, we estimate equations (10) and (11) using the Generalized Method of Moments (GMM) estimator to deal with endogeneity. This estimator does not require information on the exact distribution of the disturbances but is based upon the assumption that the disturbances in the equations are uncorrelated with a set of instrumental variables. In our estimations, the set of instrumental variables of each equation includes all exogenous right-hand side variables of both equations (including country and time dummies). The GMM estimator selects parameters in such a way that the correlations between the instruments and disturbances are as close to zero as possible, as defined by a criterion function. By choosing the weighting matrix in the criterion function appropriately, GMM can be made robust to heteroscedasticity and/or autocorrelation of unknown form. In more detail, we apply the twostep system GMM estimator developed in Arellano and Bover (1995) and Blundell and Bond (1998). In essence, it estimates in a system the regression equations in differences and levels, each 
Incentives and Financial Institutions in the Development Process

with its specific set of instruments. Relative to conventional instrumental variable methods, it improves substantially on the weak instruments problem through more formal checks of the validity of the instruments and provides for potentially improved efficiency.

In selecting control variables we draw on previous studies. The variables included in vector $\mathbf{z}^{\mathbf{n}}$ are based on studies that deal with income disparities across countries, while the controls included in $\mathbf{x}^{\mathbf{k}}$ are derived from the literature explaining inflation rate differences among countries. To be precise, in equation (10) we include imports as a share of GDP, a fixed exchange rate dummy, the external debt-to-GDP ratio, changes in the terms of trade as our control variables. In turn, in the vector $\mathbf{x}^{\mathbf{k}}$ of equation (11) we add government expenditure (as a share of GDP), trade openness (import plus export as a share of GDP), changes in terms of trade, domestic private credit (as a share of GDP), capital formation (as a share of GDP), secondary school enrolment rate and the degree of democracy as covariates ${ }^{47}$. All control variables are taken from the World Development Indicators or Polity IV and entered with a lag to control for the simultaneity concerns with our earthquake measure. We determine the optimal number of lags for each series using Schwarz's Bayesian Information Criterion (SBC). Table A2 in the Appendix offers a description of all variables used and provides their sources.

\subsection{Empirical results}

\subsubsection{Baseline results}

In columns (1)-6) of Table 1, we report the results of different econometric specifications and estimation techniques. In column (1) we start by estimating the system of equations using the system-GMM approach and without any control variables. The consistency of the GMM estimator

\footnotetext{
${ }^{47}$ The correlation between our de jure CBI indicator and the Polity IV score is rather low, less than 0.2. Leaving out the Polity IV score as control variable does not alter our main conclusions.
} 
depends on the validity of the instruments. To address this issue we consider the Sargan-Hansen statistic of over-identifying restrictions, which tests the overall validity of the instruments. The Sargan-Hansen test statistic provides no evidence of misspecification. We normalized the coefficients of the earthquake variable and interaction term by a median country size in our sample to make the interpretation easier ${ }^{48}$. To obtain robust standard errors we use the bootstrap procedure with 1,000 replicators and cluster them at the country level. This reduces, for instance, the possibility that our results are driven by small countries that have an extreme high frequency of earthquakes. We can draw a number of conclusions from these results. First, regardless of the degree of independence of a central bank, earthquakes raise significantly the price level within a country and widens the output gap. Second, countries that grant their central bank independence have lower inflation rates, while the output gap is not significantly affected by the degree of independence. One rational explanation for this latter finding is that on the one hand, according to our theoretical model, lower inflation rates caused by following a more contractionary policy should lead to lower levels of output. However, on the other hand, a low inflation rate is generally regarded as an essential condition for sustainable economic growth and that central bank independence should accordingly lead to a higher level of economic growth. These two effects apparently cancel each other out. This finding is in line with Alesina and Summers (1993) arguing that CBI in practice is a free lunch. Third, on the objective of our study, we find that the interaction term between earthquakes and CBI enters statistically significant with a negative sign in the inflation specification. This outcome indicates that when the central bank has a larger degree of independence it will try to limit the additional inflation pressure caused by the earthquake by implementing a more contractionary policy. When we interpret this finding for a country with a

\footnotetext{
${ }^{48}$ The median country size is about $200.000 \mathrm{~km}^{2}$.
} 
Incentives and Financial Institutions in the Development Process

median level CBI, we find that the additional inflation pressure explained by an earthquake is offset by about 30 percent $^{49}$. Consequently, the contractionary policy followed by more independent central banks in the aftermath hampers the economic recovery as the produced output is reduced further. In more detail, the degree of CBI will widen the output gap after a natural disaster by an additional 0.4 percentage-points or by 6 percent in a median country ${ }^{50}$.

In the bottom part of the table, we report the complete effect (based on equation (12) and (13)) by combining the first round inflation (output gap) effects with the second round output gap (inflation rate) effects. This overall mediating effect of $\mathrm{CBI}$ is statistically significant for both the inflation rate as well as for the output gap based on the joint F-test on the coefficients. About 90 percent of this mediating impact in both the inflation and output gap can be attributed to the first round effect.

However, one concern with the results presented so far is that it might suffer from an omitted variable bias since we included only a limited number of control variables. As already mentioned above, the inflation rate and output gap is determined by a number of economic factors. Therefore, in column (2) we estimate our model including the control variables suggested above. The findings indicate that adding covariates leaves the impact of earthquakes almost unaffected. However, one important note is that including the suggested control variables reduces our dataset by more than half as there is a trade-off between adding additional variables and country coverage due to missing data.

Additionally, we check whether our results are driven by the empirical technique applied. Therefore, we re-estimate our main models using Three-Stage Least Squares (3SLS) and Seemingly Unrelated Regressions (SUR) method. The results obtained when using these

\footnotetext{
${ }^{49}$ Calculated as follows $(0.25 *-0.06) / 0.05$

${ }^{50}$ Calculated as follows $(0.25 *-0.02) / 0.09$
} 
Central Bank Independence, Earthquakes and Economic Outcomes

alternative estimation methods are reported in columns (3)-(6) of Table 1. They are very similar to the GMM results. Thus, regardless of the estimation method or econometric specification chosen there is clear empirical support for our hypothesis that the inflation rate and output are lower after an earthquake when monetary policy is conducted by a more independent central bank.

Table 1: Earthquakes, CBI and economic outcomes

\begin{tabular}{|c|c|c|c|c|c|c|c|c|c|c|c|c|}
\hline & (1) & & (2) & & (3) & & (4) & & (5) & & (6) & \\
\hline \multicolumn{13}{|l|}{ Inflation regression } \\
\hline CBI & $\begin{array}{l}-0.114 \\
(0.011)\end{array}$ & $* *$ & $\begin{array}{l}-0.125 \\
(0.025)\end{array}$ & $* *$ & $\begin{array}{l}-0.121 \\
(0.013)\end{array}$ & $* *$ & $\begin{array}{l}-0.145 \\
(0.030)\end{array}$ & $* *$ & $\begin{array}{l}-0.132 \\
(0.016)\end{array}$ & $* *$ & $\begin{array}{l}-0.153 \\
(0.029)\end{array}$ & $* *$ \\
\hline Earthquakes & $\begin{array}{c}0.051 \\
(0.006)\end{array}$ & $* *$ & $\begin{array}{c}0.059 \\
(0.006)\end{array}$ & $* *$ & $\begin{array}{c}0.063 \\
(0.004)\end{array}$ & $* *$ & $\begin{array}{c}0.072 \\
(0.005)\end{array}$ & $* *$ & $\begin{array}{c}0.067 \\
(0.004)\end{array}$ & $* *$ & $\begin{array}{c}0.062 \\
(0.004)\end{array}$ & $* *$ \\
\hline $\mathrm{CBI} \times$ Earthquakes & $\begin{array}{l}-0.060 \\
(0.013)\end{array}$ & $* *$ & $\begin{array}{l}-0.082 \\
(0.017)\end{array}$ & $* *$ & $\begin{array}{l}-0.062 \\
(0.012)\end{array}$ & $* *$ & $\begin{array}{l}-0.088 \\
(0.018)\end{array}$ & $* *$ & $\begin{array}{l}-0.059 \\
(0.015)\end{array}$ & $* *$ & $\begin{array}{l}-0.094 \\
(0.018)\end{array}$ & $* *$ \\
\hline \multicolumn{13}{|l|}{ Output gap regression } \\
\hline CBI & $\begin{array}{l}-0.005 \\
(0.004)\end{array}$ & & $\begin{array}{l}-0.014 \\
(0.009)\end{array}$ & & $\begin{array}{l}-0.005 \\
(0.004)\end{array}$ & & $\begin{array}{l}-0.013 \\
(0.009)\end{array}$ & & $\begin{array}{l}-0.007 \\
(0.005)\end{array}$ & & $\begin{array}{c}-0.01 \\
(0.010)\end{array}$ & \\
\hline Earthquakes & $\begin{array}{l}-0.009 \\
(0.002)\end{array}$ & $* *$ & $\begin{array}{l}-0.015 \\
(0.003)\end{array}$ & $* *$ & $\begin{array}{l}-0.009 \\
(0.003)\end{array}$ & $* *$ & $\begin{array}{l}-0.012 \\
(0.003)\end{array}$ & $* *$ & $\begin{array}{l}-0.009 \\
(0.002)\end{array}$ & $* *$ & $\begin{array}{l}-0.009 \\
(0.003)\end{array}$ & $* *$ \\
\hline $\mathrm{CBI} \times$ Earthquakes & $\begin{array}{l}-0.018 \\
(0.005)\end{array}$ & $* *$ & $\begin{array}{l}-0.011 \\
(0.006)\end{array}$ & $*$ & $\begin{array}{l}-0.021 \\
(0.005)\end{array}$ & $* *$ & $\begin{array}{l}-0.011 \\
(0.005)\end{array}$ & $* *$ & $\begin{array}{l}-0.015 \\
(0.006)\end{array}$ & $* *$ & $\begin{array}{c}-0.01 \\
(0.005)\end{array}$ & * \\
\hline \multicolumn{13}{|l|}{ Complete CBI mediating effect } \\
\hline Inflation rate & $-6.5 \%$ & $* *$ & $-8.5 \%$ & $* *$ & $-6.8 \%$ & $* *$ & $-9.1 \%$ & $* *$ & $-6.3 \%$ & $* *$ & $-9.6 \%$ & ** \\
\hline Output gap & $-1.6 \%$ & $* *$ & $-0.9 \%$ & $*$ & $-1.9 \%$ & $* *$ & $-0.8 \%$ & $* *$ & $-1.4 \%$ & $* *$ & $-0.7 \%$ & $*$ \\
\hline Estimation methodoloy & GMM & & GMM & & 3 SLS & & 3SLS & & SUR & & SUR & \\
\hline Number of observations & 2890 & & 1194 & & 2929 & & 1201 & & 2987 & & 1217 & \\
\hline Number of countries & 98 & & 89 & & 100 & & 90 & & 101 & & 91 & \\
\hline Controls & NO & & YES & & NO & & YES & & NO & & YES & \\
\hline Sargan-Hansen test (p-value) & 0.812 & & 0.654 & & 0.823 & & 0.666 & & 0.835 & & 0.678 & \\
\hline
\end{tabular}

Note: **/* Indicating significance levels of respectively 5 and 10 percent. Bootstrapped standard errors are shown between brackets. 
Incentives and Financial Institutions in the Development Process

\subsubsection{Economic mechanisms}

The effect found so far shows that a more independent central bank tries to offset the inflation pressure caused by an earthquake at the cost of lower output. However, the magnitude of the CBI effect after an earthquake might rely to some extent on a number of characteristics related to the monetary strategy followed by the policy makers or the way the public sets its inflation expectations. In the remaining of this section we try to reveal these mechanisms underlying our previous results. In more detail, we estimate the following model.

$$
\begin{aligned}
\pi_{i t}=\alpha_{i}+\beta_{1} \pi_{i t-1}+\beta_{2} \hat{y}_{i t}+\beta_{3} \boldsymbol{m}_{\boldsymbol{t}}^{\boldsymbol{w}}+\beta_{4} \text { earthquake }_{i t}+\beta_{5}\left(\text { earthquake }_{i t} \times \boldsymbol{m}_{\boldsymbol{t}}^{\boldsymbol{w}}\right)+\beta_{6} C B I_{i t} \\
+\beta_{7}\left(C B I_{i t} \times \boldsymbol{m}_{\boldsymbol{t}}^{\boldsymbol{w}}\right)+\beta_{8}\left(\text { earthquake }_{i t} \times C B I_{i t}\right) \\
+\beta_{9}\left(\text { earthquake }_{i t} \times C B I_{i t} \times \boldsymbol{m}_{\boldsymbol{t}}^{\boldsymbol{w}}\right)+\mu_{n} \mathbf{z}_{\boldsymbol{t}-\boldsymbol{j}}^{\boldsymbol{n}}+\varepsilon_{i t} \\
\hat{y}_{i t}=\gamma_{i}+\theta_{1} \hat{y}_{i t-1}+\theta_{2} \pi_{i t}+\theta_{3} \boldsymbol{m}_{\boldsymbol{t}}^{\boldsymbol{w}}+\theta_{4} \text { earthquake }_{i t}+\theta_{5}\left(\text { earthquake }_{i t} \times \boldsymbol{m}_{\boldsymbol{t}}^{\boldsymbol{w}}\right)+\theta_{6} C B I_{i t} \\
+\theta_{7}\left(\text { CBI }_{i t} \times \boldsymbol{m}_{\boldsymbol{t}}^{\boldsymbol{w}}\right)+\theta_{8}\left(\text { earthquake }_{i t} \times C B I_{i t}\right) \\
+\theta_{9}\left(\text { earthquake }_{i t} \times C B I_{i t} \times \boldsymbol{m}_{\boldsymbol{t}}^{\boldsymbol{w}}\right)+\varphi_{k} \mathbf{x}_{\boldsymbol{t}-\boldsymbol{q}}^{\boldsymbol{k}}+\vartheta_{i t}
\end{aligned}
$$

Where $\mathbf{m}^{\mathbf{w}}$ is a vector containing the $w$ conditional factors represented by a series of dummies. The other variables have the same meaning as in equation (10) and (11). In Table 2, we report the regression results of this analysis using the linear combinations of estimators for the different samples to enhance the interpretation and comparison. We start by exploring whether there are differences between low- and high-income countries. Poor countries have often a history of high inflation rates, weaker checks and balances, more macroeconomic instability, less access to free information, less policy credibility and are more frequently affected by shocks. These particularities might for instance influence the way the public sets its inflation expectations. As 
already motivated above, people in developing countries might not act always rational as they lack information about the self-interest behaviour of the central bank. At the same time, the degree of de facto $\mathrm{CBI}$ is lower in these countries as they are more under a (undemocratic) political pressure. According to our theoretical model, both effects will result in a higher inflation rate. Based on the median real GDP per capita in our dataset, we create a dummy to separate our sample into lowand high-income countries. The results in columns (1) and (2) of Table 2 illustrate that in low income countries the mediating effect of $\mathrm{CBI}$ on disasters reduces the inflation rate, but leaves the output gap unaffected. In turn, in high-income countries the inflation is lower after an earthquake when the monetary policy is limited from political influence. However, this contractionary policy in these countries hampers the economic recovery. Thus, we provide some empirical evidence that the second situation outlined in our theoretical section above fits the case of an earthquake in LDCs the best, while the third situation described is more valid for industrialized countries.

Additionally, countries that base their monetary strategy on following a particular policy rule are less flexible when stabilizing supply shocks in the short run. For instance, countries can have only a fixed exchange rate when the domestic inflation rate is equal to the inflation rate in the foreign country. Likewise, to gain a credible reputation, central banks that have an explicit inflation target try to stick to the current inflation rate as close as possible to its target level. In columns (3)-(8) we include dummies in our $\boldsymbol{m}$ vector indicating whether a central bank followed a particular targeting strategy: inflation targeting, money growth targeting or fixed exchange rate. The results indicate that when the central bank has an explicit inflation target or a fixed exchange rate, central bank independence offsets the inflationary impact of earthquakes more compared to countries that do not follow these particular rules. In turn, the impact of earthquakes on the output gap is larger in 
Incentives and Financial Institutions in the Development Process

countries with a central bank that is more constrained in their monetary policy setting especially when governed by an independent central bank.

When the inflation rate rises after a supply shock there is a fear of a rapid outflow of foreign capital as the real interest rate drops. To withstand this pressure countries can either fight the increase in the inflation rate by raising the nominal interest rate or, alternatively, put capital controls in place that restrict the international mobility of capital. In the next regressions, we explore whether the economic outcomes after an earthquake are different when countries have severe capital controls in place or not. We base this measure on the average of the capital and interest rate controls indices taken from the Fraser Institute. The indices run from 0 to 10 where higher values indicate less controls. Based on the median value, we split our sample into high and low capital control countries. The results indicate that in countries that have taken more capital restrictive measures, independent central banks often put a higher weight on economic recovery. In turn, independent central banks in countries that do not limit capital outflows more often have policies that are primarily concerned with inflation rate stability. 


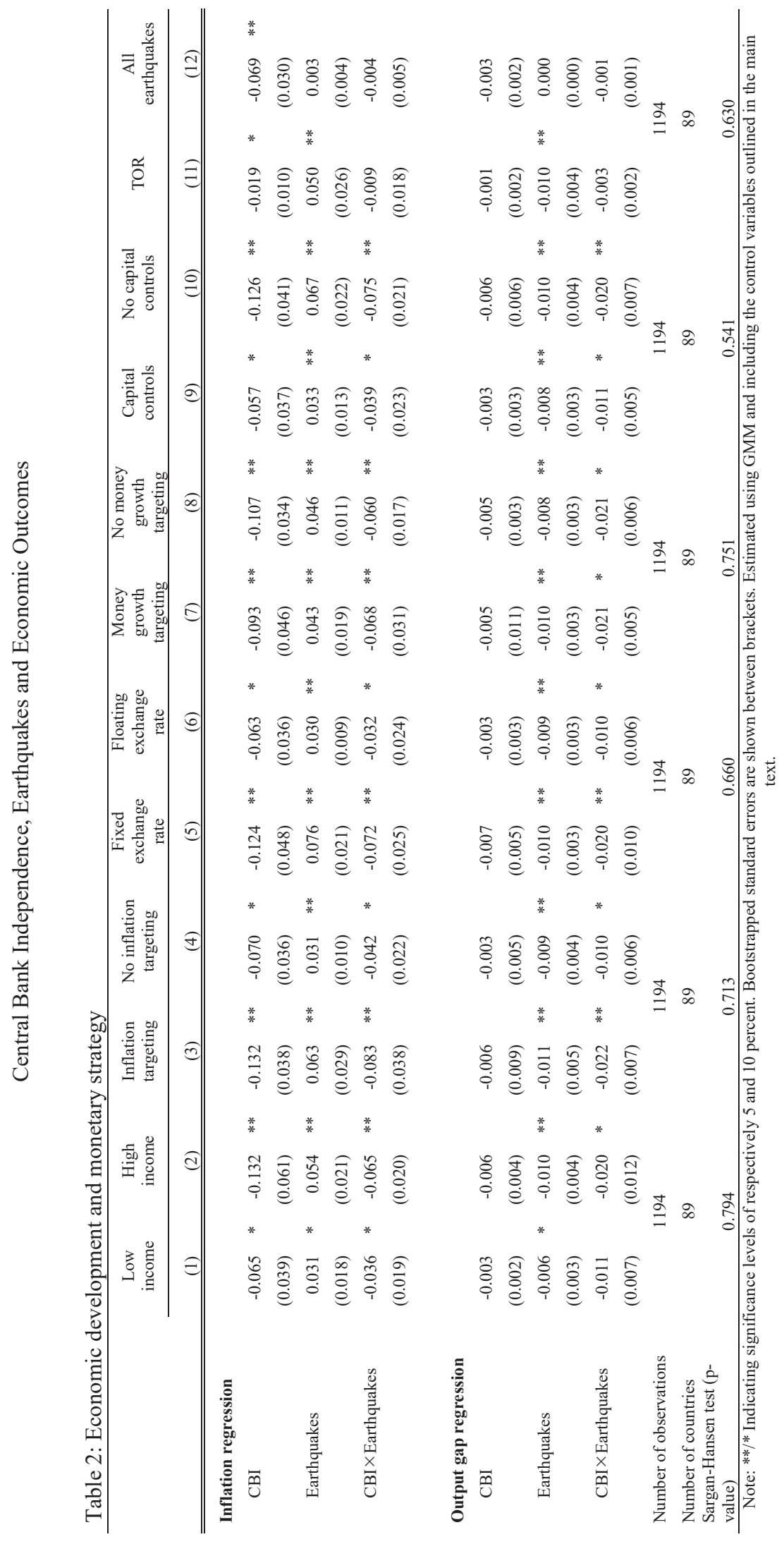


Incentives and Financial Institutions in the Development Process

\subsubsection{Robustness tests}

In this robustness section, we perform two tests using alternative measures on CBI and earthquakes. First, as already mentioned above, in countries where the rule of law is less strongly embedded in the political culture, there can be wide gaps between the formal, legal institutional arrangements and their practical impact (Walsh 2005). Cukierman et al. (1992) argues that the actual average term in office of the central bank governor may be a better proxy for CBI for these countries than measures based on central bank laws. The turnover rate (TOR) of central bank governors is based on the presumption that a higher turnover of central bank governors indicates a lower level of independence. We use data on the turnover of central bank governors reported by Dreher et al. (2010). We calculated the turnover rate using a rolling window of ten years ${ }^{51}$. The results in column (11) of Table 2 indicate that the price level rises less sharply after an earthquake when the turnover rate of the central bank governor is low. However, we do not find any evidence that the interaction between the TOR and our earthquake indicator affects the output gap. One possible explanation for this latter finding is that on the one hand, a lower turnover rate should reduce output due to a more contractionary monetary policy. However, on the other hand, a high turnover rate is related to a broader concept of political instability which normally harms growth. These effects appear to cancel each other out in the interaction term.

Second, up so far we include only major earthquakes in our dataset. However, this might lead to a selection bias as we include only about a quarter of the earthquakes reported by NOAA. In a next test we include all earthquakes that are reported in the NOAA dataset in our period of analysis. The findings indicate that CBI has no mitigating effect anymore of the impact of earthquakes on

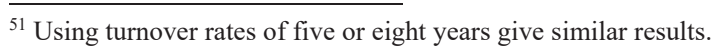


output and the inflation rate. One can therefore argue that monetary policy is only affected when the damage created is serious enough to be a threat for the economic performance of a country.

\subsection{Conclusion}

Due to the major adverse impact of natural disasters on the aggregate production and price level of a country, it is expected that these events will influence the monetary policy decisions made by the central bank. The main aim of the monetary authorities in the period following a disaster is to stabilize the economy again. However, there is one problematic concern since these events create a classic monetary policy challenge: how to accommodate the real shock in the short-run with the objective of anchoring inflation. These two competing objectives demand opposite policy actions. When monetary policy is delegated to an independent central bank, it might lead to a conflict of interest between the monetary authorities and the central government as the economic objectives are not always aligned. In this situation the government pushes the use of the monetary policy to stimulate economic recovery after the shock for electoral reasons, while the central bank prefers to use this policy in an attempt to stabilize the economy again. Thus, whether monetary policy should be loosened or tightened in the wake of a natural disaster is contested and theoretically a priori not directly clear as it depends on many characteristics of the monetary policy followed. One important element in this debate is whether the monetary policy decisions are made by a so-called independent central bank or contrariwise by a more politically constrained central bank.

Our contribution to the literature is to explore empirically whether, and if so to what extent, the degree of central bank independence determines the economic outcomes - in terms of inflation and output - after an earthquake. After extensive testing for the sensitivity of the results, our most important findings suggest that the inflation rate is lower and the output gap is larger after an 
Incentives and Financial Institutions in the Development Process

earthquake when monetary policy is conducted by a more independent central bank. That is, countries with less politically constrained central banks put more weight on lowering the inflation pressure after an earthquake at the expense of the short run output. However, it turns out that this impact is partly explained by a conditional effect. Central banks that base their monetary policy decisions on following a certain policy rule more often follow a contractionary monetary policy to fight the inflation pressure. This effect is in particular visible when the central bank is liberated from political influence. However, it turns out that part of this effect can be explained by a number of other monetary policy characteristics. Central banks that follow a specific monetary policy rule are more inclined to follow a more contraction policy than central banks that have no explicit target. 
Central Bank Independence, Earthquakes and Economic Outcomes

\section{Online appendix}

Table A1: Countries included

\begin{tabular}{|c|c|c|}
\hline Albania & Guatemala & Pakistan \\
\hline Algeria & Guinea & Papua New Guinea \\
\hline Antigua and Barbuda & Honduras & Peru \\
\hline Armenia & Hungary & Philippines \\
\hline Australia & Iceland & Poland \\
\hline Austria & India & Portugal \\
\hline Azerbaijan & Indonesia & Romania \\
\hline Bangladesh & Iran, Islamic Rep. & Russian Federation \\
\hline Bolivia & Iraq & Rwanda \\
\hline Brazil & Italy & Saudi Arabia \\
\hline Bulgaria & Japan & Serbia \\
\hline Burundi & Jordan & Slovak Republic \\
\hline Canada & Kazakhstan & Slovenia \\
\hline Chile & Kenya & South Africa \\
\hline China & Kyrgyz Republic & Spain \\
\hline Colombia & Lao PDR & Switzerland \\
\hline Congo, Rep. & Lebanon & Tajikistan \\
\hline Costa Rica & Libya & Tanzania \\
\hline Croatia & Macedonia, FYR & Thailand \\
\hline Cyprus & Malawi & Trinidad and Tobago \\
\hline Czech Republic & Malaysia & Tunisia \\
\hline Dominican Republic & Mexico & Turkey \\
\hline Ecuador & Mongolia & Uganda \\
\hline Egypt, Arab Rep. & Morocco & United Kingdom \\
\hline Ethiopia & Mozambique & United States \\
\hline Fiji & Myanmar & Vanuatu \\
\hline Gabon & Nepal & Venezuela, RB \\
\hline Georgia & Netherlands & Vietnam \\
\hline Germany & New Zealand & Yemen, Rep. \\
\hline Greece & Nicaragua & \\
\hline
\end{tabular}


Incentives and Financial Institutions in the Development Process

Table A2: Data used

\begin{tabular}{|c|c|c|}
\hline Variable & Definition & Source \\
\hline Imports & $\begin{array}{l}\text { Imports of goods and services as a share } \\
\text { of GDP }\end{array}$ & $\begin{array}{l}\text { World Development } \\
\text { Indicators (2015) }\end{array}$ \\
\hline Change in terms of trade & $\begin{array}{l}\text { Annual change in the net barter terms of } \\
\text { change }\end{array}$ & $\begin{array}{l}\text { World Development } \\
\text { Indicators (2015) }\end{array}$ \\
\hline Fixed exchange rate & $\begin{array}{l}\text { Dummy variable taking the value one } \\
\text { when a country has a fixed exchange } \\
\text { rate }\end{array}$ & IMF (2015) \\
\hline Government expenditure & $\begin{array}{l}\text { General government final consumption } \\
\text { expenditure as a share of GDP }\end{array}$ & $\begin{array}{l}\text { World Development } \\
\text { Indicators (2015) }\end{array}$ \\
\hline Trade openness & $\begin{array}{l}\text { Sum of exports and imports of goods } \\
\text { and services as a share of GDP }\end{array}$ & $\begin{array}{l}\text { World Development } \\
\text { Indicators (2015) }\end{array}$ \\
\hline Private credit & $\begin{array}{l}\text { Domestic credit to private sector as a } \\
\text { share of GDP }\end{array}$ & $\begin{array}{l}\text { World Development } \\
\text { Indicators (2015) }\end{array}$ \\
\hline $\begin{array}{l}\text { Secondary school } \\
\text { enrolment }\end{array}$ & Gross secondary school enrolment & Barro and Lee (2010) \\
\hline Capital formation & $\begin{array}{l}\text { Gross capital formation as a share of } \\
\text { GDP }\end{array}$ & $\begin{array}{l}\text { World Development } \\
\text { Indicators (2015) }\end{array}$ \\
\hline Democracy & The Polity IV score & Jaggers et al. (2015) \\
\hline
\end{tabular}

Table A3: Correlation matrix rule of law and CBI

\begin{tabular}{ll||ccccc}
\multicolumn{1}{l||}{} & & $(1)$ & (2) & (3) & (4) & (5) \\
\hline Rule of Law & & & & & & \\
(ICRG) & $(1)$ & 1.00 & & & & \\
Rule of Law (WGI) & $(2)$ & 0.44 & 1.00 & & & \\
Democracy (Polity) & $(3)$ & 0.33 & 0.57 & 1.00 & & \\
de jure CBI & $(4)$ & -0.08 & 0.10 & 0.18 & 1.00 & \\
de facto CBI & $(5)$ & 0.20 & 0.48 & 0.44 & 0.70 & 1.00
\end{tabular}


Central Bank Independence, Earthquakes and Economic Outcomes 
Incentives and Financial Institutions in the Development Process

Chapter 6

\section{Synthesis}

\subsection{Introduction}

The desire to better understand the drivers of development has taken considerable attention among economists and various scholars. The main aim of their effort is to guide policy for faster growth. Earlier scholars like the Classical economists and the Neo-classical economists focused on labour, resource endowments, capital and technology to account for income disparities among countries. However, in the recent past, other factors have emerged in explaining such variations in development levels either — within organisations/countries or between organisations/countries. Such factors include but are not limited to incentives and financial institutions. A voluminous body of literature exists that points to the role of incentives in the development process. For instance, incentives have great implications to production (Ferrall and Shearer, 1994; Grossman and Helpman, 2004; Repetto, 1987; Salam, 2009; Ward, et al., 2008) - yet, little is known about the role of such incentives in aiding the process of knowledge transfer and how these incentives can affect workers in terms of their effort allocations. A contribution that this thesis makes in chapters 2 and 3.

In the same interest for understanding development inequalities, economists have also demonstrated a relationship between a country's level of financial development and economic development (Al-Yousif, 2002; Arestis and Demetriades, 1997; Christopoulos and Tsionas, 2004; De Gregorio and Guidotti, 1995; Levine, 2005; Von Peter et al. 2012; McDermott, et al., 2014). Countries with developed financial markets tend to have a variety of financial options like formal 


\section{Synthesis}

credit and insurance markets which serve a crucial role in economic development. To be more specific, the degree of financial development is an important factor in restraining the macroeconomic consequences of various shocks (e.g. natural disasters) through lifting financial constraints faced by the private sector in the aftermath (see, Melecky and Raddatz 2015; Von Peter et al. 2012; McDermott et al. 2014). However, much of the existing literature defines financial development based on access to private credit which is more of a formal financial service, yet, informal financial markets also play a fundermental role in boosting development as well as dealing with shocks. According to Pantoja, (2002) poor households mainly rely on informal financial services to define their livelihoods. He further points out that when a shock like a disaster occurs, affected areas tend to experience a significant reduction in service provisions, an increase in unemployment and a shortage in food supply for which the informal financial services like those provided by MFIs try to address. Chapter 4 of this thesis contributes to literature relating financial sector development and disaster mitigation but emphasis is placed on the role of microfinance institutions.

Moreover, when disasters occur, commercial banks and microfinance institutions can raise their capacity for helping the victims to rehabilitate when central banks loosen their monetary policies. Even if the fundamental function of the central banks is to stabilise prices, they may be forced by the central government to perform extra functions in cases where disasters hit their countries. For example, the government may instruct the central bank to implement expansionary policies (especially if they are not fully independent) to stimulate the economy in the aftermath. However, such policies may instead cause prices to increase. If they behave contrary (through implementing contractionary monetary policies), price increments will be controlled but output may even reduce further. This implies that when disasters occur, central banks may face a trade-off resulting from 
Incentives and Financial Institutions in the Development Process

choosing either to expand or contract their policies given that both policies yield opposing effects. The fundamental question that needs to be answered is: Does the degree of central bank independence matter in mitigating the impact of natural disasters on output and inflation rate? Chapter 5 of this thesis tries to provide answers this question.

Taken to its overall contribution, this thesis provides a deeper understanding of some key factors that influence the development process. In other words, this thesis has attempted to provide analyses and discussions pertaining some key factors that influence development i.e. incentives, knowledge diffusion, wage differences, workers' effort, disasters and financial institutions. To do so, I exploited a combination of two rich datasets (data from field experiments and secondary data). The field experiment dataset was collected through a combination of field experiments and survey approaches while the panel dataset was collected from different sources as defined in individual chapters (see chapters 4 and 5 for data sources). In the context of a randomized intervention, I aimed to analyse the impact of a performance based incentive to knowledge sharing between the initially trained subjects and their peers within tightly-knit social groups (chapter 2). In chapter 3, I analysed the impact of wage differences framed as monetary incentives to workers' effort. This was done through a combination of a lab-in-the-field experiment and a survey. In chapters 4 and 5, I used panel dynamic models to analyse the role of microfinance institutions in the disaster mitigation process (chapter 4) and also to assess whether the degree of central bank independence matters in mitigating the impact of natural disasters on output and inflation rate (chapter 5). The main message that comes from the different chapters of this thesis is that incentives and financial institutions play a fundamental role in influencing the development process. The next sections present an overview of the key lessons from the various analyses in this thesis and also present the 


\section{Synthesis}

discussions of the resulting policy recommendations, and in the conclusion, I provide various areas that need future research.

\subsection{Incentives and economic outcomes.}

Incentives have a great implication to development (Banerjee and Newman, 1994; d'Aspremont, et al., 1998; Gordon, 2009; Holub and Williams, 1996; Ostrom, et al., 1993; Ward et al., 2008). For instance, they influence the rate of infrastructural development (Ostrom et al., 1993), diffusion of agricultural innovations (BenYishay and Mobarak 2016) and effort allocation by workers (Delfgaauw and Dur, 2008; Goerg and Kube, 2012; Jensen and Murphy, 1990). Yet, although the unfair allocation of incentives may not lead to better performance (Jenkins Jr, et al., 1998) as the underpaid members may feel discriminated and consequently reduce on their potential effort.

The analyses in chapters 2 and 3 of this thesis, demonstrate how incentives influence various economic outcomes. Specifically, in chapter 2, I looked at the impact of providing a performance based incentive to knowledge diffusion and in chapter 3, I framed monetary incentives in terms of differences in piece rate payments and investigated the impact of wage differences to workers' effort on both paid (contract) and voluntary work. First, we learned that incentives do not only increase knowledge sharing between the initially trained subjects and their peers within self-selected groups but also increase the motivation of the initially trained subjects to master the training content. We also learned that in absence of social comparison (i.e. when information about wage differences is restricted), effort supply is not responsive to wage differences, and also that social comparisons have a great influence on voluntary tasks relative to paid tasks. The results also suggest that if any development intervention is to reach out to a large population as it is normally the intention of the trainers/suppliers, then it is a better idea that suppliers provide incentives to the initially trained subjects instead of investing more into extra (and similar) conventional training. These findings fit 
Incentives and Financial Institutions in the Development Process

in a small empirical micro literature on diffusion and adaptation. Based on this literature, we already knew that adoption decisions of technologies especially for agricultural innovations like improved seeds and fertilizers, or bundles of agricultural activities is dichotomous in nature (adoption or non-adoption) (Feder et al. 1985). We also knew that diffusion of technologies that are supposed to improve human welfare is imperfect, which may be explained by a range of factors including imperfect capital markets (credit and insurance), incomplete tenure arrangements and by behavioural factors (Duflo et al. 2011). Moreover, literature also tells us that providing incentives to communicators increases the flow of agricultural innovations and fosters knowledge levels and adoption by co-villagers/peers (BenYishay and Mobarak 2016). The analysis in chapter 3 in which incentives are framed as piece rate payments suits the idea raised by Fehr et al., (1993), Cohn et al., (2014), Clark et al., (2010), Bracha et al., (2015) and Hennig-Schmidt et al., (2010) that the fairness in wages affects the supply of effort by workers. In other words, if workers are able to compare own earnings to those of fellow workers, it helps them to define a reference value upon which they can base to commit effort. In most cases, own earnings are likely to be evaluated as fair when they exceed this reference level and workers with wages above this reference level are likely to supply more effort. Putting that aside, we also knew that social comparisons affect effort supply (Karnes 2009; Clark et al. 2010; Gachter and Thöni 2010; Bracha et al., 2015). The empirics pertaining social comparisons and effort supply suggest for negative comparisons i.e. being paid less for the same task than your peer, without a clear justification reduces effort supply while positive comparisons do not increase effort on average (Breza et al. 2015; Cohn et al. 2015).

From a policy point of view, the fundamental insights that come from our results and discussions are that the process of knowledge transfer should be viewed as an economic process that involves costs in terms of time and effort not only experienced by the communicators but also by the 
Synthesis

recipients. In that respect, failure to adequately compensate the training participants for the incurred costs may result into disappointing outcomes (Chami et al. 2016). Moreover, it is also important to note that many development interventions are a target for a larger population than the initially trained. Thus, financing of the initial/first training without proper arrangements pertaining how information will flow to a wider population may not yield the intended outcomes or may lender the intervention a failure. Additionally, employers need to provide a proper justification for the differences in incentives allocated to workers as this will protect them from experiencing a downward effort allocation from their employees.

In light of our discussion, future research should focus on the idea raised by Banerjee et al. (2013), Cai et al., (2015) and Beaman et al. (2015) that diffusion of knowledge varies with the structure of social networks and the position of the innovators/communicators. The ability to identify the initial seed node/initially trained who is trusted and respected within the social network can serve a crucial role in increasing the uptake and adoption of knowledge — thus, future research needs to coin around the attributes of the communicator and at what position within the social network a communicator should be in order to yield better diffusion results. Secondly, in our study, the incentives were framed as performance based incentives which were provided basing on the test scores of the untrained. However, some development interventions which require adoption especially in agriculture are provided at the start of the program. This creates a gap for understanding the stage at which incentives can yield better outcomes. In other words, at what point/stage can incentives better motivate the seed nodes/initially trained to diffuse. Moreover, understanding the outcome (application) of the learned material is also equally important. Future research needs to focus on how the initially trained subjects translated the training content into practice and compare the outcome to that of the untrained (peers). This can help to inform policy 
Incentives and Financial Institutions in the Development Process

whether people learn more from the conventional (first) trainers or from their peers. Lastly, there is a need to better understand the most appropriate incentive structure that can make all workers feel a positive comparison with co-workers as this will safeguard the employers from experiencing a negative reciprocity from their employees.

\subsection{Financial institutions in the disaster mitigation process}

Natural disasters have great implications for the development of world economies. They cause voluminous deaths and physical damages on agricultural and industrial infrastructure leading to reduced production, income shocks and losses in economic welfare. Consequently, many governments and development agencies have pursued efforts aimed at disaster management. For example, through improving the political governance systems (e.g. defining of property rights say on land), increased awareness through sensitisation and preparedness campaigns, construction of better infrastructure in the risk prone areas and through improved functioning of financial markets (e.g. insurance markets, increased access to formal credit and micro-credit etc.).

The analyses in chapters 4 and 5 fit within this context. I looked at the role of microfinance institutions in mitigating the effects of natural disasters on economic growth (chapter 4), and I also explored whether the degree of central bank independence influences the economic performance in terms of inflation and output in the aftermath of a disaster (chapter 5). We learned that natural disasters adversely affect the performance of the agricultural sector compared to other sectors but agriculturalists can be helped to recover if they can access lending facilities from MFIs. We also learned that central banks that are less politically constrained put more weight on lowering the inflation pressure after a natural disaster than on stimulating short run output, possibly because stimulating output would require expansionally policies which may instead drive prices upwards. The other notable observation that comes from the analysis is that, it is not only on how accessible 
Synthesis

MFIs are to their clients, or not even the degree to which central banks are independent that matter in dealing with disaster effects but also the organisational structure for MFIs and the specific monetary policy rules that are followed by the central banks.

These findings represent the missing literature relating financial markets to disaster mitigation. We already knew that countries with developed financial markets tend to have a variety of financial options like formal credit, insurance markets, remittances and microfinance credit which serve a crucial role in economic development and consumption smoothing (Skees, 2000). We also knew that formal financial institutions lift the financial constraints faced by the private sector in the aftermath through providing of credit for reinvestment (Melecky and Raddatz 2015, Von Peter et al. 2012; McDermott et al. 2014). Moreover, we knew that independent central banks play a fundamental role in maintaining low inflation (Cukierman, 2008; Meade and Crowe, 2007; Klomp and De Haan, 2010). This is normally done through the use of more contractionary monetary policies. Literature also suggests that some of the real economic performance indicators like growth, unemployment and the real interest rates cannot be significantly influenced by independent central banks (Alesina and Summers, 1993). It is however to the best of our knowledge that there exists no study that has tried to unveil the relevance of microfinance institutions in the disaster mitigation process and also how the degree of central bank independence can influence economic outcomes in the aftermath.

These results have important implications for policy. First, in many developing countries, poor people are normally excluded and/or lack access to conventional credit systems and thus MFIs form an important financial strategy through which the marginalised sections of the private sector can access microcredit so as to safeguard against idiosyncratic income shocks (Armendariz and Morduch, 2005; Collier et al., 2013), enhance consumption and fight poverty in such countries. 
Incentives and Financial Institutions in the Development Process

Second, even if scholars tend to recognise microfinance as an enhancing factor for economic recovery after a natural disaster (Shoji, 2010; Berg and Schrader, 2012; Anand Kumar and Newport, 2005), timely involvement of these institutions in disaster management can yield better results. For example, they can be involved in risk mapping, sensitizing of their clients about disaster preparedness, organising of suitable insurance schemes and also in providing early warnings especially in the disaster prone areas. Third, at times disasters also affect MFIs especially those stationed in the affected areas. In other words, the achievements of an MFI can be erased by a single disaster or undermined by repeated disasters whereby causing them to be vulnerable (Pantoja, 2002). As a result, the operational and financial sustainability of such MFIs can be compromised especially if the frequency of the disasters is high. The policy implication for this is that MFIs are sometimes overwhelmed by some disaster events. So, they may need external funding say from the government to regain their operating capacity and be able to help the victims or less they may end up imposing heavy conditions on the borrowers (victims) who are desperate to receive loans for rehabilitation. Fourth, central bankers need to strike a balance between maintaining low inflation but at the same time stimulate the economy to avoid further reductions in output after a disaster. In respect of those two conflicting objectives which require opposing interventions, the central banker can exercise expansionary policy targeting increasing only output in the short run e.g. through subsidising imports as these can help to keep inflation low.

Basing on our results and discussions, future research needs to focus, first, on tracing the conditional impact of the financial institutions' interventions (formal or informal) to disaster victims. Put differently, while studies like ours use the interaction term to analyse the relevance of these financial institutions in the disaster mitigation process, they fail to fully capture the fact that 


\section{Synthesis}

even these financial institutions sometimes fall victims of disaster events ${ }^{52}$. In other words, there is a need to first examine how disasters affect the operations of financial institutions and then trace how the affected financial institutions behave in the aftermath. Precisely, there is a need to compare the extent of pre-disaster interventions of MFIs to their post-disaster interventions especially if they are also victims of the event. The second fertile ground for future research lies in understanding the nature of the intervention that can yield the best outcomes. MFIs are found of providing both financial and non-financial packages to disaster victims. However, these different packages may have different results in the recovery process. What works better? This can be assessed in a randomised control trail setting under which one treatment arm can be given financial packages and the other, non-financial packages though of equal value and then compare the outcomes. Lastly, to better understand the behaviours of the central banks in the presence of natural disasters, there is a need to extend the analysis and also focus on all (aggregated) disasters and disaster effects which occur more endogenously. For instance, using aggregated physical damages to indicate for disasters or even looking at others disaster types like floods and droughts since they have greater implications especially in the developing world.

\subsection{Concluding Remarks}

The thesis started with a motivation of understanding the factors that influence the development process. Throughout its chapters, special attention was placed on incentives and financial institutions. It has been shown that incentives affect knowledge sharing and workers' decisions to commit effort and also that mitigating of disaster effects requires the intervention of financial institutions. Yet, still, more needs to be done to uncover the mechanisms through which faster

\footnotetext{
52 Also see McDermott et al. (2014)
} 
Incentives and Financial Institutions in the Development Process

development can be realised. Particularly, there is a need to understand the attributes of the right person to receive the incentive and what incentive structure should be implemented. Additionally, because disasters have been found to be one of the impediments for development and that financial institutions can play a fundamental role in mitigating their effects, there is still a need to better understand which rehabilitation packages work better for the victims - financial or non-financial packages?

On the methodological note, even if using field experiments may not represent the real-life situation because of being organised in a controlled environment, they contribute to a better understanding of the behaviours of the participants. For instance, by conducting field experiments, I contributed to more understanding about how workers respond to the differences in wage allocations and also to how knowledge can spread to a larger population i.e. beyond the initially trained subjects. In addition, by using the dynamic panel models, I believe to have contributed to the missing literature that relates financial institutions and economic development. 


\section{References}

Akerlof, G. (1982). Gift exchange and efficiency wage theory: 4 views. American Economic Review 74, 470-492

Akerlof, G. and J. Yellen (1990). The fair wage efort hypothesis and unemployment. Quarterly Journal of Economics 105, 79-83

Alavi, M., and Leidner, D. (2001). Review: Knowledge management and knowledge management systems: Conceptual foundations and research issues. MIS quarterly, 107-136.

Albala-Bertrand, J. M. (1993). Natural disaster situations and growth: A macroeconomic model for sudden disaster impacts. World Development, 21(9), 1417-1434. doi:http://dx.doi.org/10.1016/0305-750X(93)90122-P

Alcántara-Ayala, I. (2002). Geomorphology, natural hazards, vulnerability and prevention of natural disasters in developing countries. Geomorphology, 47(2-4), 107-124. doi:http://dx.doi.org/10.1016/S0169-555X(02)00083-1

Alesina, A., \& Summers, L. H. (1993). Central bank independence and macroeconomic performance: some comparative evidence. journal of Money, Credit and Banking, 25(2), 151-162.

Alesina, A.; Mirrlees, J. and Neumann, M. J. M. (1989). Polit ics and Business Cycles in Industrial Democracies. Economic Policy, 4(8), 57-98.

Altonji, J. G., \& Blank, R. M. (1999). Race and gender in the labor market. Handbook of labor economics, 3, 3143-3259.

Altay, N., \& Ramirez, A. (2010). Impact of disasters on firms in different sectors: implications for supply chains. Journal of Supply Chain Management, 46(4), 59-80. 
Al-Yousif, Y. K. (2002). Financial development and economic growth: another look at the evidence from developing countries. Review of Financial Economics, 11(2), 131-150.

Anand Kumar, T., \& Newport, J. K. (2005). Role of microfinance in disaster mitigation. Disaster Prevention and Management: An International Journal, 14(2), 176-182.

Anand Kumar, T., \& Newport, J. K. (2007). Institutional preparedness and sustainability of micro finance institutions during post disaster scenario. Disaster Prevention and Management: An International Journal, 16(1), 21-32.

Anderson, J. R., \& Feder, G. (2004). Agricultural Extension: Good Intentions and Hard Realities. The World Bank Research Observer, 19(1), 41-60. doi:10.1093/wbro/lkh013

Anderson, R. V., \& Gallman, R. E. (1977). Slaves as Fixed Capital: Slave Labor and Southern Economic Development. The Journal of American History, 64(1), 24-46.

Arellano, M., \& Bover, O. (1995). Another look at the instrumental variable estimation of errorcomponents models. Journal of econometrics, 68(1), 29-51.

Arestis, P., \& Demetriades, P. (1997). Financial development and economic growth: assessing the evidence. The Economic Journal, 107(442), 783-799.

Ariely, D., Bracha, A., and Meier, S. (2009). Doing good or doing well? Image motivation and monetary incentives in behaving prosocially. American economic review, 99(1), 544-555.

Armendáriz, B., \& Morduch, J. (2005). The economics of microfinance: Cambridge, MA: MIt press.

Bandiera O, Rasul I. (2006). Social networks and technology adoption in Northern Mozambique. Economic Journal 116:869-902 
Banerjee, A. V., \& Newman, A. F. (1994). Poverty, incentives, and development. The American economic review, 84(2), 211-215.

Banerjee, A., Chandrasekhar, A. G., Duflo, E., \& Jackson, M. O. (2013). The diffusion of microfinance. Science, 341(6144), 1236498.

Barone, G., \& Mocetti, S. (2014). Natural disasters, growth and institutions: a tale of two earthquakes. Journal of Urban Economics, 84, 52-66.

Barnett, B. J., \& Mahul, O. (2007). Weather index insurance for agriculture and rural areas in lower-income countries. American Journal of Agricultural Economics, 89(5), 1241-1247.

Barro, R. J., \& Gordon, D. B. (1983). Rules, discretion and reputation in a model of monetary policy. Journal of monetary economics, 12(1), 101-121.

Bartling, B., Von Siemens, F. (2011). Wage inequality and team production: An experimental analysis. Journal of Economic Psychology 32, 1-16

Baum, C. L., \& Ford, W. F. (2004). The wage effects of obesity: a longitudinal study. Health Economics, 13(9), 885-899. doi:10.1002/hec.881

Battisti, G., \& Stoneman, P. (2005). The intra-firm diffusion of new process technologies. International Journal of Industrial Organization, 23(1), 1-22. doi:https://doi.org/10.1016/j.ijindorg.2004.12.002

Beaman, L., BenYishay, A. Magruder, J. and Mobarak, A. (2015). Can network theory based targeting increase technology adoption?” Northwestern University: Working Paper.

Beekman, G., Bulte, E., \& Nillesen, E. (2014). Corruption, investments and contributions to public goods: Experimental evidence from rural Liberia. Journal of public economics, 115, 3747. 
Beekman, G., Gatto, M., \& Nillesen, E. (2015). Family networks and income hiding: evidence from lab-in-the-field experiments in rural Liberia. Journal of African Economies, 24(3), 453-469.

Belenzon, S., \& Schankerman, M. (2009). University knowledge transfer: private ownership, incentives, and local development objectives. The Journal of Law and Economics, 52(1), 111-144.

Bellemare, C., and Shearer, B. (2009). Gift giving and worker productivity: Evidence from a firmlevel experiment. Games and Economic Behavior, 67(1), 233-244.

Beisland, L. A., \& Mersland, R. (2012). An analysis of the drivers of microfinance rating assessments. Nonprofit and Voluntary Sector Quarterly, 41(2), 213-231.

Bénabou, R., and Tirole, J. (2006). Incentives and prosocial behavior. The American Economic Review, 1652-1678.

Benabou, R., and Tirole, J. (2011). Identity, morals, and taboos: Beliefs as assets. The Quarterly Journal of Economics, 126, 805-855

Benabou, R. and Tirole, J, (2016). Mindful economics: The production, consumption and value of beliefs. Journal of Economic Perspectives 30(3), 141-164

BenYishay, A., and Mobarak, A. M. (2016). Social learning and communication: National Bureau of Economic Research.

Berg, G., \& Schrader, J. (2012). Access to credit, natural disasters, and relationship lending. Journal of Financial Intermediation, 21(4), 549-568. doi:http://dx.doi.org/10.1016/j.jfi.2012.05.003

Berge, L. I. O., Bjorvatn, K. and Tungodden, B. (2014). Human and financial capital for microenterprise development: Evidence from a field and lab experiment. Management Science, In Press.

Bjorvatn, K. and Tungodden, B. (2010). Teaching business in Tanzania: Evaluating participation and performance. Journal of the European Economic Association, 8(2/3), 561-570. 
Blinder, A. S. (1973). Wage discrimination: reduced form and structural estimates. Journal of Human resources, 436-455.

Blundell, R., \& Bond, S. (1998). Initial conditions and moment restrictions in dynamic panel data models. Journal of econometrics, 87(1), 115-143.

Bodea, C., \& Higashijima, M. (2015). Central Bank Independence and Fiscal Policy: Incentives to Spend and Constraints on the Executive. Forthcoming in the British Journal of Political Science.

Bracha, A., Gneezy, U. and G. Loewenstein (2015). Relative pay and labor supply. Journal of Labor Economics 33(2), 297-315

Breza, E. (2015). Field Experiments, Social Networks, and Development. Columbia Business School. Discussion Paper

Breza, E., Kaur, S. and Shamdasani, Y. (2015). The morale effects of pay inequality. Columbia Business School. Discussion Paper

Brown, S., Palliyaguru, R., \& Amaratunga, D. (2008). Managing disaster risks through quality infrastructure and vice versa: Post-disaster infrastructure reconstruction practices. Structural Survey, 26(5), 426-434.

Bruhn, M., G. Lara Ibarra and D. McKenzie (2013) Why is voluntary financial education so unpopular? Experimental evidence from Mexico, The World Bank, Development Research Group.

Bruno, G. (2005). Estimation and inference in dynamic unbalanced panel data models with a small number of individuals: Università commerciale Luigi Bocconi.

Bruno, M., \& Easterly, W. (1998). Inflation crises and long-run growth. Journal of Monetary Economics, 41(1), 3-26.

Bowles, S. and S. Polonia-Reyes (2012). Economic Incentives and Social Preferences: Substitutes or Complements? Journal of Economic Literature 50(2): 368-425 
Cai, J., De Janvry, A. and Sadoulet, E. (2015). Social networks and the decision to insure. American Economic Journal: Applied Economics, 7, 81-108

Canetti, E. (1991). Monetary growth and exchange rate depreciation as causes of inflation in African countries: An empirical analysis.

Carlsson, M., \& Rooth, D.-O. (2007). Evidence of ethnic discrimination in the Swedish labor market using experimental data. Labour Economics, 14(4), 716-729.

Cain, G. G. (1986). The economic analysis of labor market discrimination: A survey. Handbook of labor economics, 1, 693-785.

Cameron, A.C., J. Gelbach and D. Miller (2008). Bootstrap-Based Improvements for Inference with Clustered Errors. Review of Economics and Statistics 90(3): 414-427

Card, D., Mas, A., Moretti, E., and Saez, E. (2012). Inequality at work: The effect of peer salaries on job satisfaction, American Economic Review 102(6), 2981-3003

Cavallo, A., Cavallo, E., \& Rigobon, R. (2014). Prices and supply disruptions during natural disasters. Review of Income and Wealth, 60(S2), S449-S471.

Cavallo, E., Galiani, S., Noy, I., \& Pantano, J. (2013). Catastrophic natural disasters and economic growth. Review of Economics and Statistics, 95(5), 1549-1561.

Chaia, A., Dalal, A., Goland, T., Gonzalez, M. J., Morduch, J., \& Schiff, R. (2013). 2 Half the World Is Unbanked. Banking the world: empirical foundations of financial inclusion, 19.

Chami, G., D. Dunne, A. Fenwick, E. Bulte, M. Clements, F. Fleming, E. Muheki, A. Kontoleon (2016). Profiling Non-Recipients of Mass Drug Administration for Schistosomiasis and Hookworm Infections: A Comprehensive Analysis of Praziquantel and Albendazole Coverage in Community-Directed Treatment in Uganda. Clinical Infectious Diseases, 62(2): 200-207 
Charness, G. and Kuhn, P. (2007). Does pay inequality affect worker effort? Experimental evidence. Journal of Labor Economics 25(4), 693-723

Christopoulos, D. K., \& Tsionas, E. G. (2004). Financial development and economic growth: evidence from panel unit root and cointegration tests. Journal of development Economics, 73(1), 55-74.

Cecchi, F., Leuveld, K., \& Voors, M. (2016). Conflict exposure and competitiveness: Experimental evidence from the football field in Sierra Leone. Economic Development and Cultural Change, 64(3), 405-435.

Cecchi, F., \& Melesse, M. B. (2016). Formal law and customary change: A lab-in-field experiment in Ethiopia. Journal of Economic Behavior \& Organization, 125, 67-85.

Clark, L. C., Combs, G. F., Turnbull, B. W., Slate, E. H., Chalker, D. K., Chow, J., . . Gross, E. G. (1996). Effects of selenium supplementation for cancer prevention in patients with carcinoma of the skin: a randomized controlled trial. Jama, 276(24), 1957-1963.

Clark, A., Masclet, D., and Villeval, N.C. (2010). Effort and comparison income: Experimental and survey evidence. Industrial and Labor Relations Review 63(3), 407-426

Clark, A. and C. Senik (2010). Who compares to whom? The anatomy of income comparisons in Europe. Economic Journal 120, 573-594

Cohen, M. and Young, P. (2007). Using microinsurance and financial education to protect and accumulate Assets. In: Reducing Global Poverty: The Case for Asset Accumulation, 305. The Brookings Institution.

Cohn, A., Fehr, E., B. Herrmann, and Schneider, F. (2014). Social comparison and effort provision: Evidence from a field experiment. Journal of the European Economic Association 12(4), $877-898$ 
Cohn, A., E. Fehr and L. Goette (2015). Fair wages and effort provision: Combining evidence from a choice experiment and a field experiment. Management Science 61(8), 1777-1794

Cole, S., Sampson, T. and Zia, B. (2011). 'Prices or knowledge? What drives demand for financial services in emerging markets?', The Journal of Finance, vol. 66(6), pp. 1933-1967

Collier, P. (1999a). Doing well out of war. Paper presented at the conference on economic agendas in civil wars, London.

Collier, P. (1999b). On the economic consequences of civil war. Oxford Economic Papers, 51(1), $168-183$.

Conley, T. and Udry, C. (2010). Learning about a new technology: Pineapple in Ghana. The American Economic Review, 100, 35-69.

Cotton, J. (1988). On the decomposition of wage differentials. The review of economics and statistics, 236-243.

Cukierman, A. (1992). Central bank strategy, credibility, and independence: Theory and evidence (p. 393). Cambridge, MA: MIT press.

Cukierman, A., Kalaitzidakis, P., Summers, L. H., \& Webb, S. B. (1993). Central bank independence, growth, investment, and real rates. Paper presented at the CarnegieRochester Conference Series on Public Policy.

Cukierman, A., Web, S. B., \& Neyapti, B. (1992). Measuring the independence of central banks and its effect on policy outcomes. The world bank economic review, 6(3), 353-398.

Cukierman, A. (2008). Central bank independence and monetary policymaking institutionsPast, present and future. European Journal of Political Economy, 24(4), 722-736. 
Collier, B., Miranda, M. J., \& Skees, J. (2013). Natural disasters and credit supply shocks in developing and emerging economies. University of Kentucky Doctoral Dissertation.

Collier, B., \& Skees, J. (2012). Increasing the resilience of financial intermediaries through portfolio-level insurance against natural disasters. Natural hazards, 64(1), 55-72.

Copeland, J. D. (1993). Employer-employee relations. VETERINARY CLINICS OF NORTH AMERICA SMALL ANIMAL PRACTICE, 23, 957-957.

Crowe, C., \& Meade, E. E. (2007). The evolution of central bank governance around the world. The Journal of Economic Perspectives, 21(4), 69-90.

Cull, R., Demirgüç-Kunt, A., \& Morduch, J. (2009). Microfinance meets the market Moving Beyond Storytelling: Emerging Research in Microfinance (pp. 1-30): Emerald Group Publishing Limited.

De Gregorio, J., \& Guidotti, P. E. (1995). Financial development and economic growth. World development, 23(3), 433-448.

De Haan, J., \& Kooi, W. J. (2000). Does central bank independence really matter?: New evidence for developing countries using a new indicator. Journal of Banking \& Finance, 24(4), 643 664.

Delfgaauw, J., \& Dur, R. (2008). Incentives and workers' motivation in the public sector. The Economic Journal, 118(525), 171-191.

Devereux, S. (2007). The impact of droughts and floods on food security and policy options to alleviate negative effects. Agricultural economics, 37(s1), 47-58.

Dickens, W., \& Katz, L. F. (1986). Interindustry wage differences and industry characteristics: National Bureau of Economic Research Cambridge, Mass., USA. 
Ding, D. Z., Akhtar, S., \& Ge, G. L. (2009). Effects of inter- and intra-hierarchy wage dispersions on firm performance in Chinese enterprises. The International Journal of Human Resource Management, 20(11), 2370-2381. doi:10.1080/09585190903239716

Doyle, L., \& Noy, I. (2015). The short-run nationwide macroeconomic effects of the Canterbury earthquakes. New Zealand Economic Papers, 49(2), 134-156.

Dreher, A., Sturm, J. E., \& De Haan, J. (2010). When is a central bank governor replaced? Evidence based on a new data set. Journal of Macroeconomics, 32(3), 766-781.

Drexler, A., Fischer, G. and Schoar, A. (2014). Keeping it simple: Financial literacy training and rule of thumbs: Evidence from a field Experiment. American Economic Journal: Applied Economics, 6(2) 1-31

Drury, E. (1993). Age discrimination against older workers in the European Community.

Duessenberry, J. (1952). Income, saving and the theory of consumer behavior. Cambridge MA: Harvard University Press

Duflo E, Kremer, M, and Robinson J. (2009). Nudging farmers to use fertilizer: theory and experimental evidence from Kenya. American Economic Review 101(6): 2350-2390

Dufwenberg, M. and Kirchsteiner, G. (2004). A theory of sequential reciprocity. Games and Economic Behavior 47, 268-298

Dupas, P. (2014). Short-run subsidies and long-run adoption of new health products: Evidence from a field experiment. Econometrica 82(1): 197-228

duPont IV, W., \& Noy, I. (2015). What happened to Kobe? A reassessment of the impact of the 1995 earthquake in Japan. Economic Development and Cultural Change, 63(4), 777-812.

Durukal, E., Erdik, M., \& Sanli, B. (2006). Damage to and vulnerability of industry in earthquakes in Turkey. Paper presented at the Geophys Res Abstracts. 
d'Aspremont, C., Bhattacharya, S., \& Gérard-Varet, L.-A. (1998). Knowledge as a public good: efficient sharing and incentives for development effort. Journal of Mathematical Economics, 30(4), 389-404.

EM-DAT: The OFDA/CRED International Disaster Database, www.emdat.be/database, Université Catholique de Louvain, Brussels, Belgium.

Eijffinger, S., \& De Haan, J. (1996). The political economy of central-bank independence. Special Papers in International Economics, 19. Princeton University

Ernst, D., \& Kim, L. (2002). Global production networks, knowledge diffusion, and local capability formation. Research policy, 31(8), 1417-1429.

Fearon, J. (2008). Economic development, insurgency, and civil war. Institutions and economic performance, 292, 328.

Feder, G., Just, R., Zilberman, D. (1985). Adoption of agricultural innovations in developing countries: survey. Economic Development \& Cultural Change, 33: 255-98

Fehr, E., Kirchsteiner, G. and Rield, A. (1993). Does fairness prevent market clearing? An experimental investigation. The Quarterly Journal of Economics 108: 437-459

Fehr, E., and Falk, A. (2002). Psychological foundations of incentives. European Economic Review, 46(4), 687-724

Fehr, E. and L. Goette (2007). Do workers work more if wages are high? Experimental evidence from a randomized field experiment. American Economic Review 97(1), 298-317

Fehr, E., L. Goette and C. Zehnder (2009). A behavioral account of the labor market: The role of fairness concerns. Annual Review of Economics 1: 355-84

Felbermayr, G., \& Gröschl, J. (2014). Naturally negative: The growth effects of natural disasters. Journal of Development Economics, 111, 92-106. 
Ferrall, C., \& Shearer, B. S. (1994). Incentives, Team Production, Transaction Costs and the Optimal Contract: Estimates of an Agency Model Using Payroll Records.

Fisker, P. (2012). Earthquakes and economic growth, Development Research Working Paper Series No. 01/2012.

Fomby, T., Ikeda, Y., \& Loayza, N. (2009). The growth aftermath of natural disasters.

Fomby, T., Ikeda, Y., \& Loayza, N. V. (2013). The growth aftermath of natural disasters. Journal of Applied Econometrics, 28(3), 412-434.

Foster A. and Rosenzweig M. (1995). Learning by doing and learning from others: human capital and technical change in agriculture. Journal of Political Economy 103(6):1176-209

Foster, A.D. and M. Rosenzweig (2010). Microeconomics of technology adoption. Annual Review of Economics 2: 395-424

Frank, R. (1985). Choosing the right pond: Human behavior and the quest for status. New York: Oxford University Press

Freeman, P. K., Keen, M., \& Mani, M. (2003). Being Prepared. Finance \& Development, 40(3), $42-45$.

Freeman, R. B., \& Katz, L. F. (2007). Differences and changes in wage structures: University of Chicago Press.

Friedman, J., \& Silberman, J. (2003). University technology transfer: do incentives, management, and location matter? The Journal of Technology Transfer, 28(1), 17-30.

Gachter, S. and Thoni, C. (2010). Social comparison and performance: Experimental evidence on the fair wage-effort hypothesis. Journal of Economic Behavior and Organization 76, 531 543 
Galema, R., Lensink, R., \& Spierdijk, L. (2011). International diversification and microfinance. Journal of International Money and Finance, 30(3), 507-515.

Garrett, T. A., \& Sobel, R. S. (2003). The political economy of FEMA disaster payments. Economic Inquiry, 41(3), 496-509.

Garriga, A. C. (2016). Central Bank Independence in the World: A New Data Set. International Interactions, 42(5), 849-868.

Gasper, J. T., \& Reeves, A. (2011). Make it rain? Retrospection and the attentive electorate in the context of natural disasters. American Journal of Political Science, 55(2), 340-355.

Gassebner, M., Keck, A., \& Teh, R. (2010). Shaken, not stirred: the impact of disasters on international trade. Review of International Economics, 18(2), 351-368.

Giné, X., Karlan, D., and Ngatia, M. (2013). Social networks, financial literacy and index insurance. Working paper.

Giné, X. and Mansuri, G. (2014). Money or ideas? A field experiment on constraints to entrepreneurship in rural Pakistan. Policy Research Working Paper 6959. Washington DC: World Bank.

Gneezy, U., and List, J.A. (2006). Putting behavioral economics to work: Testing for gift exchange in labor markets using field experiments. Econometrica, 74(5), 1365-1384

Goerg, S. J., \& Kube, S. (2012). Goals (th) at Work-Goals, Monetary Incentives, and Workers' Performance.

Gordon, K. (2009). Investment guarantees and political risk insurance: institutions, incentives and development.

Gonzalez, A. (2007). Resilience of microfinance institutions to national macroeconomic events: An econometric analysis of MFI asset quality.

Graham, R. (1981). Slavery and economic development: Brazil and the United States South in the Nineteenth Century. Comparative Studies in Society and History, 23(04), 620-655. 
Grilli, V., Masciandaro, D., \& Tabellini, G. (1991). Political and monetary institutions and public financial policies in the industrial countries. Economic policy, 6(13), 341-392.

Grossman, G. M., \& Helpman, E. (2004). Managerial incentives and the international organization of production. Journal of International Economics, 63(2), 237-262.

Guimaraes, P., Hefner, F. L., \& Woodward, D. P. (1993). Wealth and income effects of natural disasters: An econometric analysis of Hurricane Hugo. The Review of Regional Studies, 23(2), 97.

Gutiérrez-Nieto, B., Serrano-Cinca, C., \& Molinero, C. M. (2009). Social efficiency in microfinance institutions. Journal of the operational research society, 60(1), 104-119.

Ha, J., Fan, K., \& Shu, C. (2003). The causes of inflation and deflation in Mainland China. Hong Kong Monetary Authority Quarterly Bulletin, 30.

Healy, A., \& Malhotra, N. (2009). Myopic voters and natural disaster policy. American Political Science Review, 387-406.

Heinen, A., Khadan, J., \& Strobl, E. (2016). The Inflationary Costs of Extreme Weather in Developing Countries. Mimeo.

Hielscher, K., Markwardt, G. (2012). The role of political institutions for the effectiveness of central bank independence. European Journal of Political Economy, 28, 286-301.

Hartarska, V. (2005). Governance and performance of microfinance institutions in Central and Eastern Europe and the newly independent states. World development, 33(10), 1627-1643. Hellerstein, J. K., Neumark, D., \& Troske, K. R. (1999). Wages, productivity, and worker characteristics: Evidence from plant-level production functions and wage equations. Journal of labor economics, 17(3), 409-446. 
Heltberg, R., Siegel, P. B., \& Jorgensen, S. L. (2009). Addressing human vulnerability to climate change: toward a 'no-regrets' approach. Global Environmental Change, 19(1), 89-99.

Hermes, N., Lensink, R., \& Meesters, A. (2011). Outreach and efficiency of microfinance institutions. World development, 39(6), 938-948.

Hennig-Schmidt, H., B. Rockenbach and A. Sadrieh (2010). In search of workers' real effort reciprocity -- A field and a laboratory experiment. Journal of the European Economic Association 8(4), 817-837

Holmlund, B., \& Zetterberg, J. (1991). Insider effects in wage determination: evidence from five countries. European Economic Review, 35(5), 1009-1034.

Holub, L., \& Williams, B. (1996). The general practice rural incentives program, development and implementation: progress to date. Australian Journal of Rural Health, 4(2), 117-127.

IPCC (2007), Climate Change 2007: The Scientific Basis. Contribution of Working Group I to the Fourth Assessment Report of the Intergovernmental Panel on Climate Change, edited by S. Solomon et al.Cambridge Univ. Press, New York.

Jenkins Jr, G. D., Mitra, A., Gupta, N., \& Shaw, J. D. (1998). Are financial incentives related to performance? A meta-analytic review of empirical research: American Psychological Association.

Jensen, M. C., \& Murphy, K. J. (1990). Performance pay and top-management incentives. Journal of Political Economy, 98(2), 225-264.

Jones, L. E., \& Manuelli, R. E. (1995). Growth and the effects of inflation. Journal of Economic Dynamics and Control, 19(8), 1405-1428.

Jirjahn, U., \& Kraft, K. (2007). Intra-firm Wage Dispersion and Firm Performance-Is There a Uniform Relationship? Kyklos, 60(2), 231-253. 
Kahn, M. E. (2005). The death toll from natural disasters: the role of income, geography, and institutions. Review of economics and statistics, 87(2), 271-284.

Kaindl, H., Brinkkemper, S., Bubenko Jr, J. A., Farbey, B., Greenspan, S. J., Heitmeyer, C. L., . . . Siddiqi, J. (2002). Requirements engineering and technology transfer: obstacles, incentives and improvement agenda. Requirements Engineering, 7(3), 113-123.

Karlan, D. and Valdivia, M. (2011). Teaching entrepreneurship: Impact of business training on microfinance clients and institutions. Review of Economics and Statistics, 93(2), 510-527.

Karnes, R. E. (2009). A change in business ethics: The impact on employer-employee relations. Journal of Business Ethics, 87(2), 189-197.

Keating, M., Loughlin, J., \& Deschouwer, K. (2003). Culture, institutions and economic development. Books.

Kellenberg, D., Mobarak, A. (2008). Does rising income increase or decrease damage risk from natural disasters?. Journal of Urban Economics, 63(3), 788-802.

Khan, A. A., Ahmed, Q. M., \& Hyder, K. (2007). Determinants of recent inflation in Pakistan.

Kirchgässner, G. (1983). The political business cycle if the government is not myopic: an integration of the long-run and short-run models of the political business cycle. Mathematical Social Sciences, 4, 243-260.

Kirchgässner, G. (1991). On the relation between voting intention and the perception of the general economic situation: an empirical analysis for the Federal Republic of Germany, 1972-1986. European Journal of Political Economy, 7, 497-526.

Klomp, J. (2014). Financial fragility and natural disasters: An empirical analysis. Journal of Financial Stability, 13(0), 180-192. doi:http://dx.doi.org/10.1016/j.jfs.2014.06.001

Klomp, J., \& Valckx, K. (2014). Natural disasters and economic growth: A meta-analysis. Global Environmental Change, 26, 183-195. 
Klomp, J., \& De Haan, J. (2010). Inflation and Central Bank Independence: A Meta-Regression Analysis. Journal of Economic Surveys, 24(4), 593-621.

Klomp, J. (2016). Economic development and natural disasters: A satellite data analysis. Global Environmental Change, 36, 67-88.

Klomp, J. (2017). Flooded with debt. Forthcoming Journal of International Money and Finance.

Knack, S., \& Keefer, P. (1995). Institutions and economic performance: cross-country tests using alternative institutional measures. Economics \& Politics, 7(3), 207-227.

Kube, S., Maréchal, M. A., and Puppe, C. (2012). The currency of reciprocity: Gift exchange in the workplace. The American Economic Review, 102(4), 1644-1662.

Knowler, D. and Bradshaw, B. (2007). Farmers' adoption of conservation agriculture: A review and synthesis of recent research. Food Policy 32(1): 25-48

Krauss, N., \& Walter, I. (2009). Can microfinance reduce portfolio volatility? Economic Development and Cultural Change, 58(1), 85-110.

Kumar, N. (2003). Intellectual property rights, technology and economic development: Experiences of Asian countries. Economic and Political Weekly, 209-226.

Kunreuther, H. (1996). Mitigating disaster losses through insurance. Journal of risk and Uncertainty, 12(2), 171-187

Kydland, F. E., \& Prescott, E. C. (1977). Rules rather than discretion: The inconsistency of optimal plans. Journal of political economy, 85(3), 473-491.

Laframboise, N., \& Loko, B. (2012). Natural disasters: mitigating impact, managing risks.

Lallemand, T., Plasman, R., \& Rycx, F. (2004). Intra-firm wage dispersion and firm performance: Evidence from linked employer-employee data. Kyklos, 57(4), 533-558.

Landerretche, O. M. and C. Martínez (2013). 'Voluntary savings, financial behavior, and pension finance literacy: evidence from Chile', Journal of Pension Economics and Finance, vol. 12(03), pp. 251-297. 
Lapan, H., \& Bardhan, P. (1973). Localized technical progress and transfer of technology and economic development. Journal of Economic Theory, 6(6), 585-595.

Laursen, K. (2000). Trade specialisation, technology and economic growth. Books.

Leibenstein, H. (1950). Bandwagon, snob, and Veblen effects in the theory of consumer demand. Quarterly Journal of Economics 64(2): 183-207

Levine, R. (2005). Finance and growth: theory and evidence. Handbook of economic growth, 1, 865-934.

Lin, J. Y., \& Nugent, J. B. (1995). Institutions and economic development. Handbook of development economics, 3, 2301-2370.

Lis, E. M., \& Nickel, C. (2010). The impact of extreme weather events on budget balances.

International Tax and Public Finance, 17(4), 378-399.

Loayza, N. V., Olaberria, E., Rigolini, J., \& Christiaensen, L. (2012). Natural disasters and growth: Going beyond the averages. World development, 40(7), 1317-1336.

Loungani, P., \& Sheets, N. (1997). Central bank independence, inflation, and growth in transition economies. Journal of Money, Credit, and Banking, 381-399.

Lucas, L. M., and Ogilvie, D. (2006). Things are not always what they seem: How reputations, culture, and incentives influence knowledge transfer. The Learning Organization, 13(1), 7-24.

Lundberg, S. J., \& Startz, R. (1983). Private discrimination and social intervention in competitive labor market. The American economic review, 73(3), 340-347.

Lusardi, A., and Mitchell, O. S. (2007). Baby boomer retirement security: The roles of planning, financial literacy, and housing wealth. Journal of monetary Economics, 54(1), 205-224.

Lusardi, A. and O. S. Mitchell (2008). 'Planning and financial literacy: How do women fare?', American Economic Review: Papers and Proceedings, vol. 98(2), pp. 413-417. 
Malecki, E. J. (1997). Technology and economic development: the dynamics of local, regional, and national change.

Manski, C. (1993). Identification of endogenous social effects: The reflection problem. The Review of Economic Studies, 60, 531-542.

Marinova, D. (2004). Actualizing innovation effort: the impact of market knowledge diffusion in a dynamic system of competition. Journal of Marketing, 68(3), 1-20.

McCallum, B. T. (1995). Two fallacies concerning central bank independence. NBER working paper w5075. National Bureau of Economic Research.

McDermott, T. K., Barry, F., \& Tol, R. S. (2014). Disasters and development: natural disasters, credit constraints, and economic growth. Oxford Economic Papers, 66(3), 750-773.

McKenzie, D. and Woodruff, C. (2014). What are we learning from business training and entrepreneurship evaluations around the developing world? The World Bank Research Observer, 29(1), 48-82

Mechler, R. (2003). Macroeconomic impacts of natural disasters. The World Bank.

Melecky, M., \& Raddatz, C. (2015). Fiscal responses after catastrophes and the enabling role of financial development. The World Bank Economic Review, 29(1), 129-149.

Mersland, R., \& Strøm, R. Ø. (2009). Performance and governance in microfinance institutions. Journal of Banking \& Finance, 33(4), 662-669.

Mersland, R., \& Strøm, R. Ø. (2010). Microfinance mission drift? World development, 38(1), 2836.

Miamidian, E., Arnold, M., Jacquand, M., \& Burritt, K. (2005). Surviving Disasters and Supporting Recovery: A Guidebook for Microfinance Institutions: The World Bank. 
Modi, S. B., \& Mabert, V. A. (2007). Supplier development: Improving supplier performance through knowledge transfer. Journal of Operations Management, 25(1), 42-64.

Montalvo, J. G., \& Reynal-Querol, M. (2005). Ethnic diversity and economic development. Journal of development Economics, 76(2), 293-323.

Munshi, K. (2004). Social Learning in a heterogeneous population: Technology diffusion in the Indian green revolution. Journal of Development Economics 73: 185-213

Narayan, P. K. (2003). Macroeconomic impact of natural disasters on a small island economy: evidence from a CGE model. Applied Economics Letters, 10(11), 721-723.

Nel, P., \& Righarts, M. (2008). Natural disasters and the risk of violent civil conflict. International Studies Quarterly, 52(1), 159-185.

Neumayer, E., Plümper, T., \& Barthel, F. (2014). The political economy of natural disaster damage. Global Environmental Change, 24, 8-19.

Nickerson, J. A., \& Zenger, T. R. (2008). Envy, comparison costs, and the economic theory of the firm. Strategic management journal, 29(13), 1429-1449.

Nissen, S. E., Tuzcu, E. M., Schoenhagen, P., Brown, B. G., Ganz, P., Vogel, R. A., . . Brodie, B. (2004). Effect of intensive compared with moderate lipid-lowering therapy on progression of coronary atherosclerosis: a randomized controlled trial. Jama, 291(9), 10711080 .

NOAA (2015). National Geophysical Data Center / World Data Service (NGDC/WDS):

Significant Earthquake Database. National Geophysical Data Center

Noy, I. (2009). The macroeconomic consequences of disasters. Journal of Development Economics, 88(2), 221-231. doi:http://dx.doi.org/10.1016/j.jdeveco.2008.02.005

Noy, I., \& Nualsri, A. (2011). Fiscal storms: public spending and revenues in the aftermath of 
natural disasters. Environment and Development Economics, 16(01), 113-128.

Nunn, N. (2008). Slavery, inequality, and economic development in the americas. Institutions and economic performance, 148-180.

Oaxaca, R. L., \& Ransom, M. R. (1994). On discrimination and the decomposition of wage differentials. Journal of Econometrics, 61(1), 5-21. doi:http://dx.doi.org/10.1016/03044076(94)90074-4

Ofori, G. (2002). Construction industry development for disaster prevention and response. Paper presented at the Proceedings of the i-Rec International Conference on Post-Disaster reconstruction: Planning for reconstruction.

Oh, C. H., \& Reuveny, R. (2010). Climatic natural disasters, political risk, and international trade. Global Environmental Change, 20(2), 243-254.

Oster, E., and Thornton, R. (2012). Determinants of technology adoption: Private value and peer effects in menstrual cup take-up. Journal of the European Economic Association 10(6): 12631293

Ostrom, E., Schroeder, L., \& Wynne, S. (1993). Institutional incentives and sustainable development: infrastructure policies in perspective: Westview Press.

Pantoja, E. (2002). Microfinance and disaster risk management: Experiences and lessons learned. The World Bank. Washington, DC.

Parker, M. (2016). The impact of disasters on inflation (No. DP2016/06). Reserve Bank of New Zealand.

Parker, W. N. (1970). Slavery and Southern Economic Development: An Hypothesis and Some Evidence. Agricultural History, 44(1), 115-125.

Pelling, M., Özerdem, A., \& Barakat, S. (2002). The macro-economic impact of disasters. Progress in Development Studies, 2(4), 283-305. 
Pfeffer, J., \& Ross, J. (1990). Gender-Based Wage Differences The Effects of Organizational Context. Work and Occupations, 17(1), 55-78

Pfeffer, J. and Langton, N. (1993). The effect of wage dispersion on satisfaction, productivity and working collaboratively: Evidence from college and university faculties. Administrative Science Quarterly 38(3), 382-407

Pollard, P. (1993). Central Bank Independence and Economic Performance. St. Louis FED

Review 75.

Posthumus, H., Morris, J., Hess, T., Neville, D., Phillips, E., \& Baylis, A. (2009). Impacts of the summer 2007 floods on agriculture in England. Journal of Flood Risk Management, 2(3), 182-189.

Raddatz, C. E. (2009). The wrath of God: macroeconomic costs of natural disasters. World Bank Policy Research Working Paper Series, Vol.

Rasmussen, T. N. (2004). Macroeconomic Implications of Natural Disasters in the Caribbean (EPub): International Monetary Fund.

Ravn, M. O., \& Uhlig, H. (2002). On adjusting the Hodrick-Prescott filter for the frequency of observations. Review of economics and statistics, 84(2), 371-376.

Reeves, A. (2011). Political Disaster: Unilateral Powers, Electoral Incentives, and Presidential Disaster Declarations. The Journal of Politics, 73(4), 1142-1151.

Repetto, R. (1987). Economic incentives for sustainable production. The Annals of Regional Science, 21(3), 44-59.

Rodrik, D., Subramanian, A., \& Trebbi, F. (2004). Institutions rule: the primacy of institutions over geography and integration in economic development. Journal of economic growth, $9(2), 131-165$.

Rogoff, K. (1985). The optimal degree of commitment to an intermediate monetary target. The 
quarterly journal of economics, 100(4), 1169-1189.

Saggi, K. (2002). Trade, foreign direct investment, and international technology transfer: A survey. The World Bank Research Observer, 17(2), 191-235.

Salam, A. (2009). Distortions in incentives to production of major crops in Pakistan: 1991-2008. Journal of International Agricultural Trade and Development, 5(2), 185-208.

Sarel, M. (1996). Nonlinear effects of inflation on economic growth. Staff Papers, 43(1), 199-215.

Sayinzoga, A., Bulte, E. and Lensink, B. (2016). Financial literacy and financial behavior: Experimental evidence from rural Rwanda. Economic Journal 126: 1571-1599

Selcuk, F., \& Yeldan, E. (2001). On the macroeconomic impact of the August 1999 earthquake in Turkey: a first assessment. Applied Economics Letters, 8(7), 483-488.

Shoji, M. (2006). Limitation of quasi-credit as mutual insurance: coping strategies for covariate shocks in Bangladesh.

Shoji, M. (2010). Does contingent repayment in microfinance help the poor during natural disasters? The Journal of Development Studies, 46(2), 191-210.

Skees, J. R. (2000). A role for capital markets in natural disasters: a piece of the food security puzzle. Food Policy, 25(3), 365-378.

Skidmore, M., \& Toya, H. (2002). Do natural disasters promote long-run growth? Economic Inquiry, 40(4), 664-687.

Smith, S. K., \& McCarty, C. (1996). Demographic effects of natural disasters: A case study of Hurricane Andrew. Demography, 33(2), 265-275.

Skoufias, E. (2003). Economic crises and natural disasters: Coping strategies and policy implications. World development, 31(7), 1087-1102. 
Sorenson, O., and Fleming, L. (2004). Science and the diffusion of knowledge. Research policy, 33(10), 1615-1634.

Steinhubl, S. R., Berger, P. B., Mann III, J. T., Fry, E. T., DeLago, A., Wilmer, C., . . . Investigators, C. (2002). Early and sustained dual oral antiplatelet therapy following percutaneous coronary intervention: a randomized controlled trial. Jama, 288(19), 24112420 .

Stole, L. A., \& Zwiebel, J. (1996). Intra-firm bargaining under non-binding contracts. The Review of Economic Studies, 63(3), 375-410.

Strömberg, D. (2007a). Natural Disasters, Economic Development, and Humanitarian Aid. The Journal of Economic Perspectives, 21(3), 199-222. doi:10.2307/30033741

Suri, T. (2011). Selection and comparative advantage in technology adoption. Econometrica, 79 (1), 159-209.

Szulanski, G. (2000). The process of knowledge transfer: A diachronic analysis of stickiness. Organizational behavior and human decision processes, 82(1), 9-27.

Tchakoute-Tchuigoua, H. (2010). Is there a difference in performance by the legal status of microfinance institutions? The quarterly review of economics and finance, 50(4), 436-442.

Toya, H., \& Skidmore, M. (2007). Economic development and the impacts of natural disasters. Economics Letters, 94(1), 20-25.

Tustin, D. H. (2010). An impact assessment of a prototype financial literacy flagship programme in a rural South African setting, African Journal of Business Management, vol. 4(9), pp. 1894-1902.

Van Gils, M., Vissers, G., \& De Wit, J. (2009). Selecting the right channel for knowledge transfer between industry and science: consider the R\&D-activity. European Journal of Innovation Management, 12(4), 492-511.

Von Peter, G., Von Dahlen, S., \& Saxena, S. C. (2012). Unmitigated disasters? New evidence on the macroeconomic cost of natural catastrophes. 
Walsh, C. (2005). Monetary theory and policy. MIT press.

Ward, C., Mansfield, D., Oldham, P., \& Byrd, W. (2008). Afghanistan: economic incentives and development initiatives to reduce opium production.

WHO (2013). A universal truth: No health without a workforce. Geneva: World Health Organization

Winter-Ebmer, R., \& Zweimüller, J. (1999). Intra-firm wage dispersion and firm performance. Kyklos, 52(4), 555-572.

Wolf, C. (1955). Institutions and economic development. The American economic review, 45(5), 867-883.

World Bank. (2015). World Development Indicators. Washington.

Yesuf, M., \& Köhlin, G. (2009). Market imperfections and farm technology adoption decisions-A case study from the highlands of Ethiopia.

Yonson, R., Gaillard, J., \& Noy, I. (2016). The measurement of disaster risk: An example from tropical cyclones in the Philippines. Mimeo. 


\section{Summary}

In this theis, I investigate the role of incentives and financial institutions in the development process. Although these concepts are fundamental in economic literature as drivers of economic development, there is still a lot to be understood about the mechanisms through which these incentives and financial insitututions can influence the process. I present evidence from a combination of field-experimental research conducted in Uganda and from panel data analysis (panel data is obtained from different sources as described in individual chapters) to demonstrate the influence of incentives and financial institutions to development.

In chapter 1, I present an overview about the different drivers of economic development, and the interaction between the key concepts in this thesis: incentives, knowledge diffusion, wage differences, workers' effort, disasters and financial institutions. This chapter also presents an overview of the methodologies and the research questions that guide the core chapters of this thesis. To be more specific, the main questions include: (1) Do monetary incentives matter in the process of knowledge diffusion? (Chapter 2); (2) do differences in monetary incentives affect workers' effort? (Chapter 3); (3) are microfinance institutions able to mitigate the adverse macroeconomic consequences of disasters to economic growth? (Chapter 4) and (4) does the degree of central bank independence matter in mitigating the impact of natural disasters on output and inflation rate? (Chapter 5)

In chapter 2, I assess the impact of a performance-based monetary incentive to knowledge diffusion within self-selected groups, using a field-experiment. The results show that incentives do not only increase knowledge sharing between the initially trained subjects and their peers within self-selected groups but also increase the motivation of the initially trained subjects to master the 
training content (they increase the effort to learn for the initially trained subjects), and provide a cost effective approach for boosting knowledge sharing. I urge that even within self-selected groups where members are tightly connected, knowledge and other innovations cannot flow freely between members but there needs to be a motivating factor to cause the communicators and the receivers of knowledge to invest time and effort in the knowledge sharing programs.

In chapter 3, I investigate the impact of wage differences to workers' effort allocation to both paid (contract) and voluntary work. I study the response of workers to wage differences using a lab-inthe-field experiment in Uganda. I test the participants under conditions of information absence and information availability. In order to allow for information about wage differences to spread during the experiment, participants were allowed time to interact at some stage of the experiment. I find weak evidence to support the hypothesis that positive social comparisons invite extra effort during paid work, but, they instead invite extra effort to the voluntary work. The study also suggests that the consequences of social comparisons extend beyond "contractible tasks" for which subjects receive payment, and that both positive and negative comparisons matter for productivity. Precisely, if workers compare themselves and feel privileged, they can be motivated and decide to reciprocate.

In chapter 4, I use a panel model to explore whether microfinance institutions are able to mitigate the adverse macroeconomic consequences of disasters on economic growth and also on specific economic sector growth. I find natural disasters to adversely affect the performance of the agricultural sector — but if agriculturalists can access lending facilities from MFIs, such effects can be mitigated. The analysis also suggest that the extent to which MFIs can mitigate disaster effects does not only depend on how accessible they are to the borrowers but also to their organisational structure and the size of their clientele. 
In chapter 5, I use a quasi-experiment to explore whether the degree of central independence influences the economic performance in the period following a disaster - earthquake. I find central banks that are less politically constrained putting more weight on lowering the inflation pressure after an earthquake than on stimulating short run output. In other words, an increase in the inflation rate after an earthquake is significantly smaller when monetary policy is conducted by a more independent central bank, and that countries with an independent central bank are confronted with a wider output gap following an earthquake. However, in the analysis, it turns out that, the extent to which independent central banks can impact on inflation and output following a disaster depends on specific monetary policy rules like fixed exchange rate systems and inflation targeting. Finally, chapter 6 provides the synthesis and discussions for broader policy implications and also provides areas that still call for future research. 


\section{Acknowledgements}

Even though, I have a number of people to whom my heart yearns to appreciate for their countless contributions towards my entire $\mathrm{PhD}$ study period, let me first extend my wealthy gratitude to Prof. Eria Hisali from the College of Business and Management Sciences, Makerere University for the effort you put in to find a suitable scholarship for me and for the continuous encouragement that you always provided to me during the entire period. This was not only assistance that helped me to realise my dreams but it was more of parenting.

Besides, my heartfelt thanks go to my supervisors Prof. Erwin Bulte and Dr. Jeroen Klomp for the immeasurable guidance and contributions towards my career development. Not only that, but also for your contributions towards the various chapters that make up this thesis. I have not only been able to put up the thesis with your help, but I have also learnt a lot from you that will help me build up my research carrier. Working with both of you has been great in the entire life of my $\mathrm{PhD}$. In a special way, deep thanks are extended to Prof. Erwin for allowing me to undertake my studies under the MFS 11 project which was directly under your supervision.

I also express my warm thanks to my colleagues at the Development Economics Group (DEC), Wageningen University and its entire secretariat for the memorable assistance you provided to me during my stay at the University and in the Netherlands. Things which are unforgettable include but are not limited to the shared coffee breaks, end of month drinks and the responses I got from whoever I would consult at whatever time. In a special way, a word of thanks goes to Mequanint Melesse with whom I have shared an office for almost my entire time at the University, Dr. Rein Haagsman for the encouraging talks that I shared with you, fellow PhDs with whom I had discussions from time to time. You really provided good moments to me even when I was weakened by the $\mathrm{PhD}$ hardships. For the DEC secretariat, I cannot show the degree to which I am really thankful for your help. You all stood by my side. My humble request is that you take it in your hearts that your support is highly appreciated.

As you have noticed in this thesis especially in chapters 2 and 3, it would not be possible to have all this work the way it looks minus CBS Pewosa staff, local leaders at various levels, research assistants and respondents from Wakiso and Kamuli districts. For that reason, it becomes understandable to dedicate this paragraph to those people. In a special way, I extend sincere thanks 
to the Managing Director, Central Broadcasting Services (CBS-Radio), Mr. Kawooya .M. Mwebe for granting me the opportunity to work with CBS Pewosa as a hosting institution during the field research. Thanks still go to Florence Luwedde (Project Manager-CBS Pewosa), Omumbejja Aisha Nakarema and other field officers at Pewosa for your assistance towards the success of the field projects. I also appreciate the commitment showed by Mr. Paul Wabiga and Mr. Jordan Semwanga for the supervisory roles you played during the field research.

At the time of writing this acknowledge, I felt that putting you in the middle of the text, would possibly not demonstrate the feelings I have while expressing my appreciation for your patience and encouragement during my studies. Even if, I have already dedicated this thesis to you, I feel it is not enough to show my thankfulness for the patience you showed whenever I was away from home or even when I was at home but failed to give you the time you deserved. I know and believe that you always missed your papa. My thanks also go to my wife for taking care of the family in my absence. Sincere thanks go to one and only one-my beloved mother, Nabbanja Matilda. I know, you do not enjoy having your children being far away from you but time came for me to depart for a long time. I am happy that you managed to cope-up with it and you instead encouraging me to the end. This is greatly appreciated maama.

Lastly, warm thanks go my brothers and sisters, friends like Robert Van Mannan and your wife Angelique, Kees Van Dalen, the Livingstone family in Amersfoort, the Esorf family in Amersfoort, Mr. Nana Kwabena Buruwaa in Wageningen, Alan Maddock in Dublin, Ireland, Victoria Clayton in England, the Queen of Peace community in Uganda, Prof. Ddumba Ssentamu, Mr. Godfrey Bazanye Nkangi and Mr. Lutalo Solomon. Mr. Solomon, you taught me at primary level when I was still a small boy but I hold it in my heart that you provided a strong foundation for my entire academic achievements. You will always be remembered for your effort in framing my future. 

John Sseruyange

Wageningen School of Social Sciences (WASS)

Completed Training and Supervision Plan

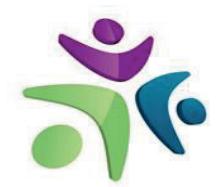

Wageningen School

of Social Sciences

\begin{tabular}{|c|c|c|c|}
\hline Name of the learning activity & Department/Institute & Year & ECTS* \\
\hline \multicolumn{4}{|l|}{ A) Project related competences } \\
\hline Advanced Macroeconomics (ENR 30806) & Wageningen University & 2014 & 6 \\
\hline $\begin{array}{l}\text { Advanced Environmental Economics and } \\
\text { Policy (ENP 32306) }\end{array}$ & Wageningen University & 2014 & 6 \\
\hline Advanced Econometrics (AEP 60306) & Wageningen University & 2014 & 6 \\
\hline \multicolumn{4}{|l|}{ B) General research related competences } \\
\hline Introduction to $\mathrm{PhD}$ & WASS & 2013 & 1 \\
\hline $\begin{array}{l}\text { Research Methodology: From Topic to } \\
\text { Proposal }\end{array}$ & WASS & 2013 & 4 \\
\hline Research Proposal & WASS & 2014 & 6 \\
\hline Project and Time Management & WGS & 2014 & 1.5 \\
\hline Information Literacy for $\mathrm{PhD}$ & WGS & 2014 & 0.6 \\
\hline $\begin{array}{l}\text { Techniques for Writing and Presenting a } \\
\text { Scientific Paper }\end{array}$ & WGS & 2014 & 1.2 \\
\hline $\begin{array}{l}\text { Experiments in developing countries. } \\
\text { Methods and applications. }\end{array}$ & $\begin{array}{l}\text { Summer School, } \\
\text { University of Groningen }\end{array}$ & 2015 & 2 \\
\hline Systematic Literature Review & WASS & 2016 & 4 \\
\hline \multicolumn{4}{|c|}{ C) Career related competences/personal development } \\
\hline $\begin{array}{l}\text { Do Incentives Matter for Diffusion of } \\
\text { Financial Knowledge? Experimental } \\
\text { Evidence from Uganda }\end{array}$ & CSAE (Oxford) & 2017 & 1 \\
\hline $\begin{array}{l}\text { Mitigating Natural Disaster Effects on } \\
\text { Economic Growth. The Role of } \\
\text { Microfinance Institutions }\end{array}$ & AAICBE (Addis Ababa) & 2017 & 1 \\
\hline $\begin{array}{l}\text { Wage Differentials and Workers' Effort: } \\
\text { Experimental Evidence from Uganda }\end{array}$ & CSAE (Oxford) & 2018 & 1 \\
\hline Total & & & 41.3 \\
\hline
\end{tabular}

*One credit according to ECTS is on average equivalent to 28 hours of study load 

The research described in this thesis was financially supported by the Dutch Organisation for Scientific Research (NWO), grant \# 2100888800 and the Development Economics Group of Wageningen University.

Financial support from the Development Economics Group for printing the thesis is greatly appreciated.

Printed by: Digiforce||Proefschriftmaken 


\section{Propositions}

1. Providing incentives for diffusing knowledge without a proper understanding of the attributes of the communicator may not lead to desired outcomes. (this thesis)

2. Social comparisons amongst workers affect workers' productivity. (this thesis)

3. The use of mosquito nets to reduce exposure to malaria is an economic loss to some rural households in Uganda.

4. Relying on Genetically Modified Organisms (GMOs) is not a solution to food insecurity in Uganda.

5. Fear rather than respect from the people determines the term of some countries' incumbent presidents.

6. To promote a smooth $\mathrm{PhD}$ trajectory, weekly $\mathrm{PhD}$ lunch meetings should be made a university policy.

Propositions belonging to the thesis entitled: Incentives and Financial Institutions in the Development Process. Evidence from Field Experiments and Panel Data Analysis.

John Sseruyange

Wageningen, 16 May 2018 